Old Dominion University

ODU Digital Commons

Summer 2019

\title{
Persistence of Depositional Features in a Strongly Seasonal, Tide- Dominated Delta
}

Kallie Flaxington Brown

Old Dominion University, kbrow141@odu.edu

Follow this and additional works at: https://digitalcommons.odu.edu/oeas_etds

Part of the Geology Commons

\section{Recommended Citation}

Brown, Kallie F.. "Persistence of Depositional Features in a Strongly Seasonal, Tide-Dominated Delta"

(2019). Master of Science (MS), Thesis, Ocean \& Earth Sciences, Old Dominion University, DOI: 10.25777/ khab-gp69

https://digitalcommons.odu.edu/oeas_etds/96

This Thesis is brought to you for free and open access by the Ocean \& Earth Sciences at ODU Digital Commons. It has been accepted for inclusion in OES Theses and Dissertations by an authorized administrator of ODU Digital Commons. For more information, please contact digitalcommons@odu.edu. 


\title{
PERSISTENCE OF DEPOSITIONAL FEATURES IN A STRONGLY SEASONAL, TIDE-DOMINATED DELTA \\ by \\ Kallie Flaxington Brown \\ B.S. May 2016, The College of William \& Mary
}

\author{
A Thesis Submitted to the Faculty of \\ Old Dominion University in Partial Fulfillment of the \\ Requirements for the Degree of \\ MASTER OF SCIENCE \\ OCEAN AND EARTH SCIENCE \\ OLD DOMINION UNIVERSITY \\ August 2019
}

Approved by:

Richard P. Hale (Director)

G. Richard Whittecar (Member)

Thomas R. Allen (Member) 


\begin{abstract}
PERSISTENCE OF DEPOSITIONAL FEATURES IN A STRONGLY SEASONAL, TIDEDOMINATED DELTA
\end{abstract}

Kallie Flaxington Brown

Old Dominion University, 2019

Director: Dr. Richard P. Hale

The Ganges-Brahmaputra-Meghna (GBM) Delta is one of the largest deltas in the world, covering more than $100,000 \mathrm{~km}^{2}$. The GBM River system transports over one billion tons of sediment annually and delivers $\sim 750$ million tons to the Bay of Bengal, $\sim 25 \%$ of which is advected by tides into the fluvially abandoned western delta plain. The Sundarbans National Forest (SNF) is located within the GBM Delta and, covering more than $10,000 \mathrm{~km}^{2}$, is the world's largest continuous mangrove stand. The present rate of sediment delivery allows the SNF platform elevation to keep pace with regional sea level rise, but India's National River Linking Project (NRLP) could decrease the suspended sediment loads of Ganges and Brahmaputra Rivers by $39-75 \%$ and $9-25 \%$ respectively, and thus may change future sedimentation. In this study, we examine the idea that sediment stored in the tidal channels throughout the year is being resuspended and delivered to the mangrove platform during the dry season when sediment input to the system is at a minimum. Over two field seasons 70 shallow $(<50$ $\mathrm{cm}$ ) sediment cores were collected from the channel banks, imaged using x-radiography to observe fine scale changes in depositional characteristics on tidal channel banks, and subsampled for subsequent textural analysis. In more than half of the cores examined there is no change in the style of the laminations, suggesting that the 
processes controlling deposition remain constant throughout the year, despite a change in the external sediment supply. Cores where the depth of laminations decreases from wet to dry season demonstrate that sediment is being eroded from the banks and advected elsewhere, with the mangrove platform a likely sink. Over $70 \%$ of cores showed surface $(0-2 \mathrm{~cm})$ grain sizes coarsening between the monsoon to the dry season, which could be the product of the winnowing of fine sediments as overall sediment supply decreases and material with lower bulk density is preferentially taken away. Total organic carbon (TOC) results indicate constant reworking of sediment on the banks throughout the year. These results demonstrate that sediment in this system is constantly being reworked, and a portion of the sediment delivered to the platform during the dry season can be sourced from the banks. 


\section{ACKNOWLEDGMENTS}

I thank my advisor, Rip Hale, for patience, guidance, and motivation during my time as a graduate student. My committee, Dr. G. Richard Whittecar and Dr. Thomas R. Allen, deserves thanks for their input and assistance editing this manuscript. Thank you to the crew of the M.L. Bawali and M.B. Mawali and my research assistant, Sourov Datta, who assisted in making this research possible. 
Chapter

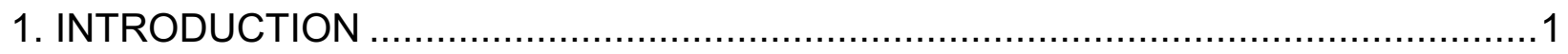

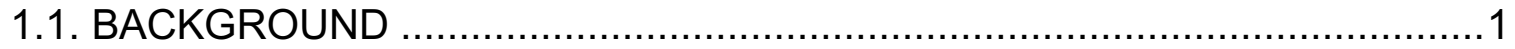

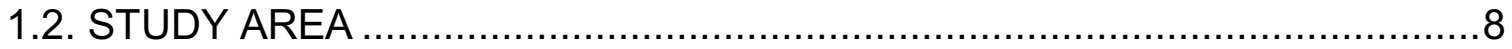

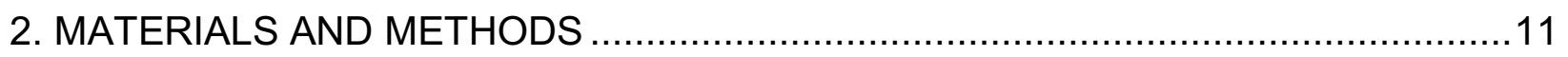

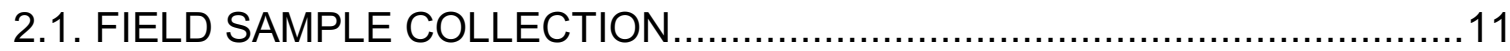

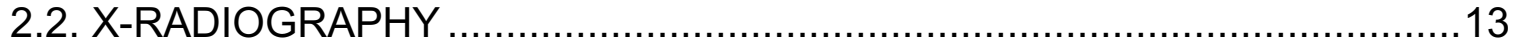

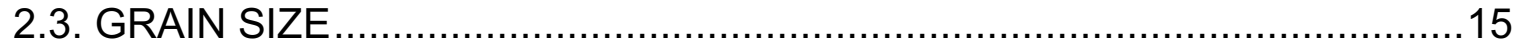

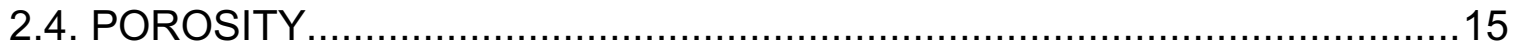

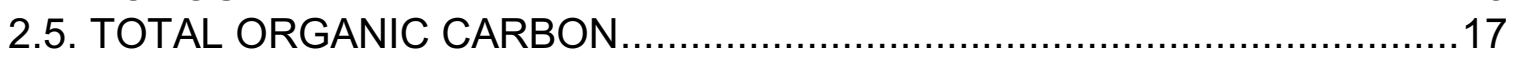

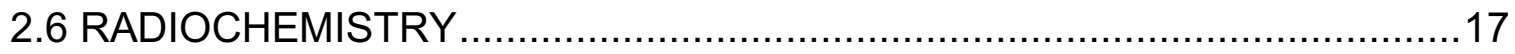

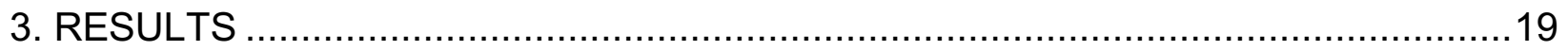

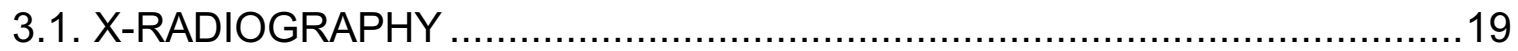



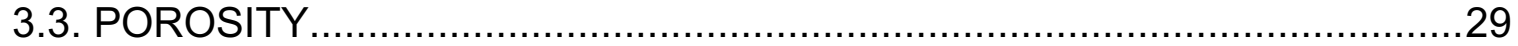



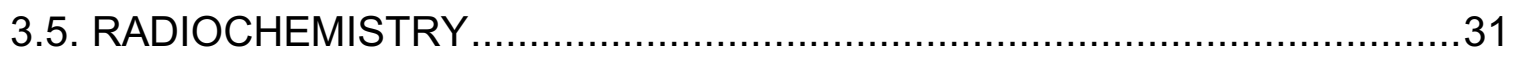

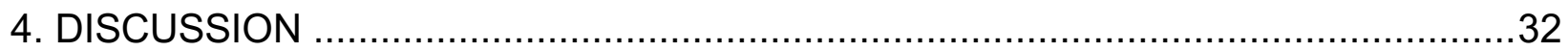

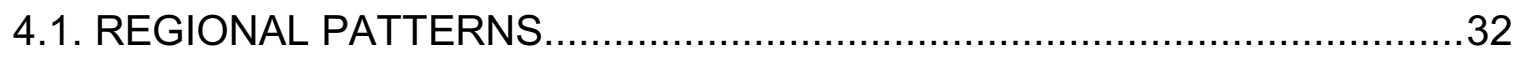

4.2. SEASONAL VARIABILITY, OBSERVED SEASONAL DEPOSTIONAL PATTERNS, AND IMPLICATIONS ……………...................................

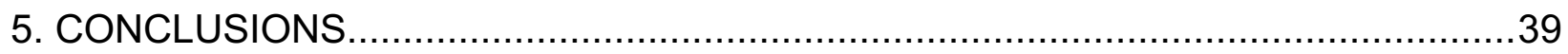

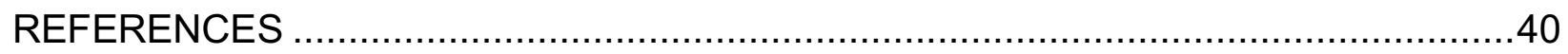

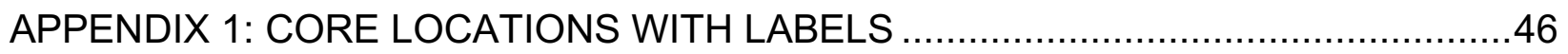

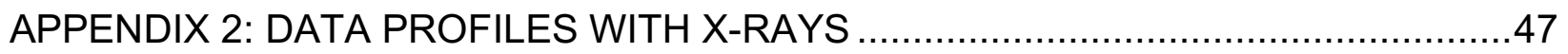

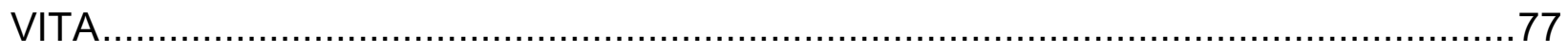




\section{LIST OF FIGURES}

Figure

Page

1. Map of the Ganges-Brahmaputra-Meghna Delta .................................................

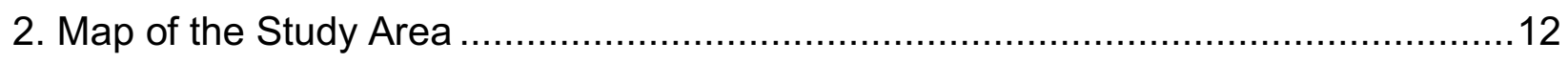

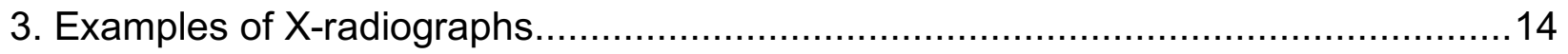

4. X-rays, Textural, and Geochemical Properties Down-Core ................................20

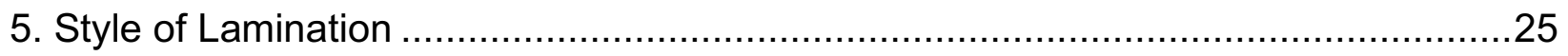

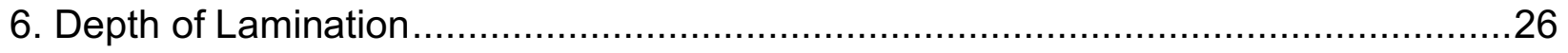

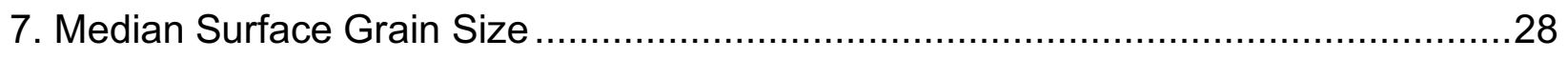

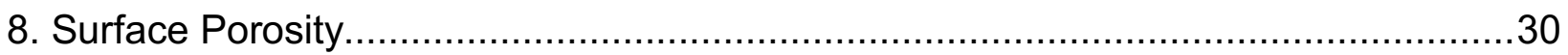




\section{CHAPTER 1 \\ INTRODUCTION}

\subsection{Background}

The Ganges-Brahmaputra-Meghna (GBM) river system is one of the muddiest river systems in the world (Allison, 1998), with a total combined sediment load of approximately $1.06 \times 10^{9}$ tons/yr (Milliman and Syvitski, 1992). This material is composed of over $70 \%$ silt (Coleman, 1969), and derived primarily from the Himalayan mountains (Allison, 1998). Of the more than one billion tons of sediment in the rivers, an estimated $25 \%$ is deposited in the channels and their adjacent floodplains, while the other $75 \%$ is delivered to the Bay of Bengal (Goodbred and Kuehl, 1999). In this region of the world, climate is controlled by the SW Asian monsoon in the form of wet and dry seasons. In the wet season, between May and November, $85-95 \%$ of annual rainfall occurs (150-300 cm; Brammer, 2014), resulting in water and sediment discharge maxima (Allison, 1998).

Throughout the Holocene, the GBM rivers migrated eastward, abandoning the former delta plain to the west, and resulting in virtually no direct input of fluvial sediment to this region (Allison et al., 2003, Flood et al., 2018). That said, the western delta plain is not completely starved of river sediment as a result of the indirect connection between these two physiographic provinces (Rogers et al., 2013). After sediment discharges from the GBM rivers, wind patterns, estuarine circulation, and especially tidal dynamics advect sediment into the region west of the river mouth, maintaining the "abandoned" delta plain (Barua et al., 1994; Allison and Kepple, 2001; Rogers et al., 2013; Wilson and Goodbred, 2015; Hale et al., 2019). 
The delta in southwest Bangladesh is strongly dominated by tidal forcing. Indeed, in the Galloway (1975) classification scheme, the GBM exists near the tide-dominated endmember. Effects of tidal processes can be seen in channels $>100 \mathrm{~km}$ from the deltafront, where the spring tide range can exceed $4 \mathrm{~m}$ (Barua et al., 1994; Allison and Kepple, 2001; Pethick and Orford, 2013; Rogers et al., 2013; Wilson and Goodbred, 2015; Hale et al., 2019). During the monsoon season, tidal waters across the delta remain fresh with salinity between 0 and 1 practical salinity units (PSU), due to the magnitude of the freshwater discharge (Barua et al., 1994; Wilson and Goodbred, 2015). Conversely, in the dry season when the river discharge is low, salinity can reach 20-30 PSU as far as $100 \mathrm{~km}$ inland in the western delta (Barua et al., 1994; Allison et al., 2003; Wilson and Goodbred, 2015, Shaha and Cho, 2016).

The southern GBM Delta contains the Sundarbans National Forest (SNF), the largest, continuous mangrove stand in the world, covering more than $10,000 \mathrm{~km}^{2}$ (Fig. 1). This region is home to many endangered species, including the Royal Bengal tiger and the Ganges and Irrawaddy dolphins. A conservation wildlife management plan by Seidensticker and Hai (1983) identified more than 334 plant species in the SNF of Bangladesh, revealing its ecological importance for human, animal, and other plant life in the GBM Delta. The SNF platform inundates during spring tides year-round, resulting in sufficiently rapid sedimentation rates $\left(\sim 1.1 \mathrm{~cm} \mathrm{yr}^{-1}\right)$ for the mangrove forest elevation to keep pace with the rate of local relative sea-level rise (RSLR), which is $\sim 1.0 \mathrm{~cm} \mathrm{yr}^{-1}$ (Rogers et al., 2013; Pethick and Orford, 2013). 


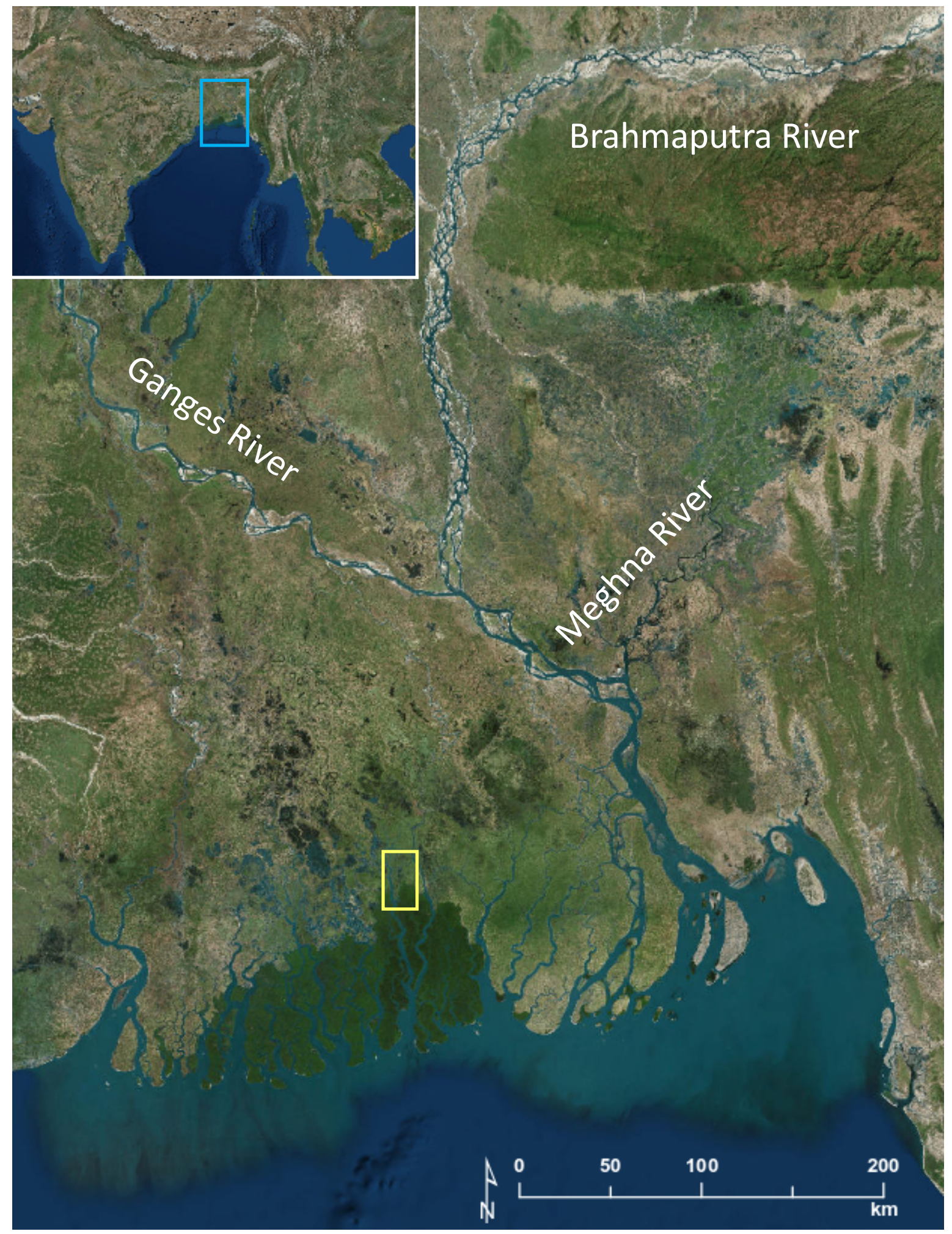

Fig. 1. Map of the Ganges-Brahmaputra-Meghna Delta. The SNF is represented in the bottom left and covered in dark green vegetation. The study area is noted by the yellow box on the main map. Basemap source: ESRI. 
To the north of the SNF is an array of human-populated islands protected by earthen embankments, known by the Dutch term "polder". The polders were built in the 1960s and 1970s as part of a government-sponsored program to expand land area for food production (Rahman and Salehin, 2013). Polders also defend the islands from high waters caused by storm surges and extreme high tides (Auerbach et al., 2015). Although successful in each of these ambitions, the polders have resulted in unintended negative consequences for the islands and communities of people living inside them. By protecting the island from flooding events that would otherwise occur during spring tides throughout the year, the polders have also stopped the delivery of sediment to the land inside the embankments (Rahman and Salehin, 2013; Auerbach et al., 2015; Rogers and Overeem, 2017). Sediment exclusion, along with compaction of the existing landscape and decomposition of the root material in this former mangrove forest, has resulted in an average elevation of these islands $\sim 1 \mathrm{~m}$ below mean high water (MHW) (Allison, 1998; Goodbred and Kuehl, 1998; Rogers et al., 2013; Auerbach et al., 2015). In the adjacent, unmodified SNF, a constant supply of sediment delivered during springtide flooding events as allowed for the platform elevation to increase at a pace consistent with RSLR, achieving a current elevation $100 \mathrm{~cm}$ higher than inside the polders (Auerbach et al., 2015; Bomer et al., submitted; Hale et al., in review).

The elevation disparity between tidal-channel water levels and the poldered landscape can be catastrophic if embankments fail. As an example, Cyclone Aila made landfall in southwest Bangladesh in May of 2009 , leading to five embankment failures on Polder 32 (Auerbach, 2015), located on the north-central border of the SNF. Because of the decades of land subsidence inside Polder 32, much of the polder was 
subject to deep flooding $(\sim 100 \mathrm{~cm})$ for almost $10 \mathrm{hr} \mathrm{d}^{-1}$, regardless of tidal range (Auerbach et al., 2015). This disaster was a horrifying ordeal for the residents of this area, and it took several years for the polders to be fully reconstructed. In this time period, $\leq 72 \mathrm{~cm}$ of mud was deposited in the polder interior, which corresponds to decades of sedimentation in even the highest-accumulating natural areas (Auerbach et al., 2015). This deposit of sediment suggests the possibility of using the sediment from the muddy tidal channels to rapidly elevate the old, compacted landscape.

Unfortunately, proposed future changes to the water and sediment delivery by the GBM Rivers could have disastrous implications for the Sundarbans mangrove stand and the $\sim 20$ million people inhabiting the coastal area.

India is moving forward with a nation-wide project known as the National River Linking Project (NRLP) that, if fully implemented, will divert water from the Ganges and Brahmaputra Rivers to expand cultivatable land in India by 34 million ha, and increase water resources in regions affected by water scarcity and drought (Joshi, 2013; Bagla, 2014). The project is designed to link 44 rivers through a network of dams and diversions approximately $15,000 \mathrm{~km}$ in length, with the hope of diverting 174 billion cubic meters of water from the two large rivers (Joshi, 2013; Bagla, 2014). Unfortunately, the NRLP will also negatively affect the entire nation of Bangladesh, which sits downstream of the Ganges and Brahmaputra Rivers in the GBM Delta.

If completed as proposed, the annual flow of the Ganges and Brahmaputra Rivers is expected to decrease by $24 \%$ and by $6 \%$, respectively (Higgins et al., 2018). From decreasing river discharge and trapping sediment behind dams, the suspended sediment load will be reduced by $39-75 \%$ in the Ganges and $9-25 \%$ in the Brahmaputra 
(Higgens et al., 2018). Across the delta, model results suggest that the ability for sediment to aggrade and maintain elevation will decrease by $30 \%$, from 3.6 to $2.5 \mathrm{~mm}$ $\mathrm{yr}^{-1}$, which could result in wide-scale delta drowning (Higgens et al., 2018). Many productive delta plains around the world have suffered a similar fate, losing invaluable resources such as farmland and protected natural areas by the drastic cutting of their usual sediment supply by anthropogenic factors (e.g. Britsch and Dunbar, 1993; Syvitski et al., 2009; Tessler et al., 2015). In the Mississippi River Delta, tens of thousands of square miles of wetlands have been lost, in part, from similar processes that will be used in the NRLP, such as connecting distributary channels and building dams for water storage (Britsch and Dunbar, 1993). The Mekong River Delta, located just over 2000 km from the GBM, experienced 2 kyr period of rapid growth in the late Holocene, which propagated the delta more than $200 \mathrm{~km}$ (Ta et al., 2002). Now, $50 \%$ of the once rapidly accreting delta's shoreline is suffering from erosion (Anthony et al., 2015). Anthony et al. (2015) assert that this erosion is mainly due to the decrease in sediment supply from anthropogenic factors such as damming, similar to what might be seen in the GBM. A later study done in the mangrove forests of the Mekong Delta found that decreases in suspended sediment were a key factor in reducing sediment accumulation rates in the mangroves (Fricke et al., 2017).

Although the outlook seems foreboding, recent studies have shown that deltas have the ability to sustain themselves even with a significant decrease in the sediment load. A study recently conducted by Nittrouer and Viparelli (2014) on the Mississippi River demonstrates that despite a dam-induced termination of the sand load upstream of the lowermost dam, the sand load downstream remains relatively unaffected. In fact, 
only when the numerical model is extended 600 years into the future is there a noticeable decrease in the sand load downstream of the lowermost dam (Nittrouer and Viparelli, 2014). This timeframe is similar to the reservoirs' projected lifetime, at the completion of which, pre-dam sediment-supply levels should resume. The authors explain that when the river is relieved of its sediment load through deposition in the reservoir, carrying capacity increases, which can scour the riverbed downstream of the dam, thereby continuing the supply of sediment to maintain the delta. Importantly, the authors are considering the sand load, as previous research (e.g. Roberts et al., 2003) has demonstrated that sand is the most important grain size for constructing stable deltas. It is important to note that the Mississippi River is a fluvial-dominated delta, whereas the GBM is dominated by tides. Because of this, the mechanism of sediment delivery to the topset is different-yearly floods in the Mississippi and daily and seasonal tides in the GBM.

It is apparent that although the monsoon season climate exists from about June to October, monsoon conditions [near-fresh water and increased suspended sediment concentration (SSC)] in the tidal channel persist into December (e.g. Hale et al., 2019). Sediment and water discharge of the GBM rivers are drastically reduced during the dry season, suggesting that local resuspension of sediment from the channel banks might be responsible for the observed elevated SSC. As the dry season progresses, SSC decreases, potentially because the most readily suspended material has been removed from the channel banks and delivered to the mangrove platform. 


\subsection{Study Area}

This study was conducted in the vicinity of Polder 32 , which suffered terrible consequences following polder failure during Cyclone Aila in 2009. Polder 32 is situated on the northern border of the SNF, providing the opportunity to examine how the expansive muddy riverbanks vary seasonally in both the natural and embanked settings. The three rivers surrounding Polder 32 vary in width (Shibsa River, $\sim 2 \mathrm{~km}$ wide; Dhaki River, $\sim 500 \mathrm{~m}$ wide; Bhadra/Sutarkhali River, $\sim 100 \mathrm{~m}$ wide), which allows us to examine the relative importance of seasonal versus tidal forces in channels of varying sizes. Previous research has identified that tidal range varies from 3 to $5 \mathrm{~m}$ depending on whether neap or spring conditions are being measured (e.g., Pethick and Orford, 2013; Auerbach et al., 2015; Hale et al., 2019). While they do vary depending on channel size, suspended sediment concentrations are greatest during the monsoon, with values routinely exceeding $500 \mathrm{mg} / \mathrm{l}$ in the Sutarkhali River (Hale et al., 2019). Dry season values are lower, though still frequently in excess of $100 \mathrm{mg} / \mathrm{l}$ (Hale et al., 2019). Around Polder 32 , salinity ranges from completely fresh during the monsoon to $\sim 25$ PSU in the dry season (Ayers et al., 2016; Shaha and Cho, 2016).

The Gorai River, which turns into the Pussur and passes just east of Polder 32, experiences a peak annual water discharge of $\sim 3500 \mathrm{~m}^{3} \mathrm{~s}^{-1}$ (Pethick and Orford, 2013; Bain et al., in press), which represents only $\sim 10 \%$ of the water discharge measured during spring tides on the adjacent Shibsa. As a result, most sediment delivered to this region is originally sourced from the GBM rivers (Rogers et al., 2013). Of the sediment deposited on the platform during the monsoon season, $\sim 60 \%$ is material recently ( $<6$ 
months) sourced from the GBM rivers, with the remainder composed of older, reworked material (Rogers et al., 2013).

As mentioned, the polders have been instrumental in excluding sediment from deposition inside the embanked islands. This sediment exclusion, in conjunction with a decrease in the tidal prism (Pethick and Orford, 2013), has led to reduced current velocities causing many tidal channels to infill with sediment (e.g. Wilson et al., 2017). An estimate of the thickness of new sediment in the channels by Wilson et al. (2017), and confirmed with optically stimulated luminescence (OSL) by Chamberlain et al. (2017), found vertical accretion rates of $19-31 \mathrm{~cm} \mathrm{yr}^{-1}$. These rates support the notion that under modern conditions with limited area over which material could be deposited, there exists an excess of sediment in the system. Furthermore, Hale et al. (2019) measured the mass of sediment in transport through these channels and deduced that there is currently more than enough sediment in the system to be deposited on the delta topset in order to keep pace with RSLR, even if polders are removed. Rogers et al. (2013) estimated $\sim 100 \mathrm{Mt} \mathrm{yr}^{-1}$ of sediment is deposited in the Sundarbans; hydrodynamic observations from Hale et al. (2019) suggest that an equivalent amount of sediment is transported in the main tidal channel of the Shibsa River year-round.

In this study, we investigate the idea that sediment delivered to the western delta plain during the monsoon is temporarily stored on the banks of tidal channels, and subsequently advected onto the mangrove forest platform throughout the dry season. We use a combination of textural, radiochemical, and geochemical properties of sediment cores to assess sedimentation processes and how they do or do not vary 
between seasons. Results from this study will be invaluable to future studies modeling the fate of the delta given impending changes in sea level and sediment supply. 


\section{CHAPTER 2}

\section{MATERIALS AND METHODS}

\subsection{Field Sample Collection}

I conducted field work during two, two-week field seasons in October 2017 and March 2018 in the vicinity of Polder 32 and the SNF. Sample locations visited during the monsoon field season (October 2017) were reoccupied during the dry season (March 2018) to examine seasonal variability. In total, we collected 70 shallow sediment cores between the two field seasons to examine sediment on the banks of the tidal channels (Fig. 2). Cores consist of a sediment slab of constant thickness retrieved using an acrylic tray ( $\sim 50 \mathrm{~cm}$ long $\times 11 \mathrm{~cm}$ wide $\times 2 \mathrm{~cm}$ thick). Cores were collected along the tidal channel shoreline at or near the spring-low-tide water level, in both the natural and embanked regions (Fig. 2). A variety of tools were used for textural, radiochemical, and geochemical analyses, as described below. 


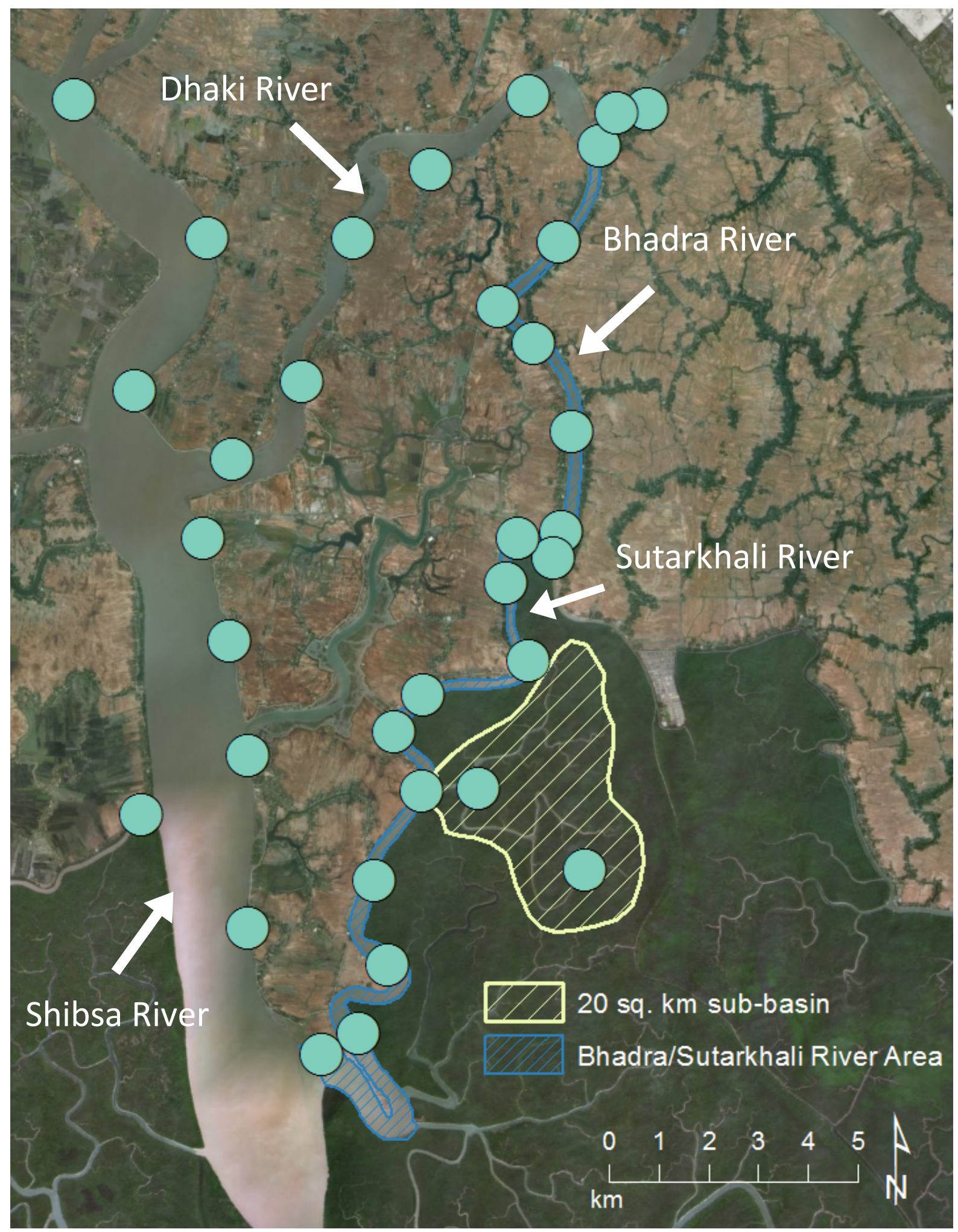

Fig. 2. Map of the study area. Core locations from October 2017 and March 2018. Poldered island are represented by light brown agricultural fields. SNF is represented by dark green, dense vegetation. Basemap source: ESRI. 


\subsection{X-radiography}

X-ray images of sediment cores provide a high-resolution proxy for sediment bulk density, illuminating sedimentary structures that are undetectable to the naked eye. These structures serve as indicators of the conditions under which sediment was deposited. In this study, lighter colors correspond to higher-bulk-density material (typically coarser-grained), while darker colors represent lower-bulk-density sediment (e.g., Boldt et al., 2013; Fig. 3). Changes in bulk density can be observed at the mmscale, providing details at a sampling interval that would be impossible to resolve using traditional grain size and porosity measurements. An important caveat is that $\mathrm{x}$ radiography is only a measure of relative bulk density, as a result of variability in the collection and processing of $x$-radiograph images. That is to say, a particular shade of gray across two cores may not refer to the same absolute bulk density.

As soon as possible following collection (typically < three hours), we imaged cores using an EPX-Series Diagnostic X-ray System at $50 \mathrm{kV}$ and $25 \mathrm{mAs}$ for 12 exposures, and developed the film using Photographers' Formulary developer for five minutes, stop bath for 10 minutes, and Kodak fixer for one minute.

The depths of laminations are measured from the surface downward and compared between core pairs collected in the wet and dry seasons. The style of laminations is qualitatively assessed in the cores based on the thickness of individual laminae or groups of laminations and divided into three categories: coarsely laminated ( cm scale; Fig. 3A), finely laminated ( mm scale; Fig. 3B,C), and not laminated (Fig. 3D). If the physically stratified layers in cores collected at the same location becomes finer and more distinct between the monsoon and dry season coring events, this is 
considered an increase in the style of lamination. If the layers become thicker and less defined or disappear entirely, this is considered a decrease in lamination style.
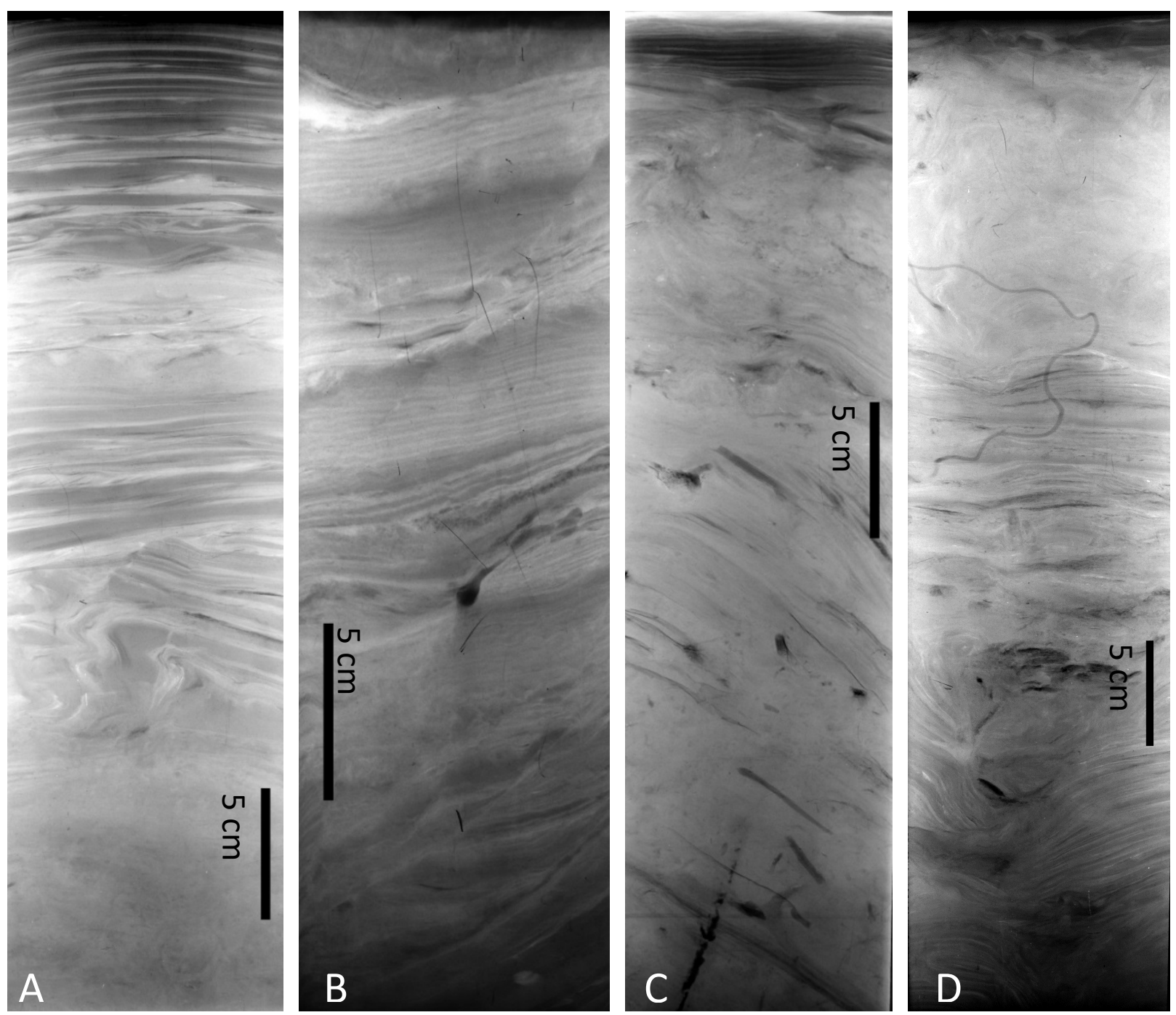

Fig. 3. Examples of $x$-radiographs. A) DR-5, physically stratified on top of homogenized layer; B) SB-20, physically stratified throughout; C) BR-16, almost completely homogenized; D) DR-4, visible evidence of bioturbation (e.g. worm burrows). 


\subsection{Grain Size}

Measuring sediment grain size distributions is an important tool to assess the energy and process responsible for generating a specific deposit. In this study, we can use grain size to quantify changes in sediment texture between the wet and dry season samples. Grain size also correlates with bulk density, where coarser grains tend to have a lower porosity and higher bulk density than finer grains (e.g. Boldt et al., 2013). From this, we can confirm whether or not the observed changes in bulk density (inferred from x-ray or porosity) are due to changes in grain size or something else (e.g., compaction/dewatering).

Approximately one gram of sediment from each core sample (698 in total) was set aside for grain size analysis. This subsample soaked for 24 hours in a weak solution of sodium hexametaphosphate to disaggregate particles. Samples were sonified for 2 minutes to break up remaining aggregates, then analyzed using a Malvern Mastersizer 2000. The Malvern uses laser diffraction to measure particle sizes in a sample. A laser beam is passed through the sample and particulate matter scatters the light at different angles and intensities with respect to grain size (i.e., large particles scatter at smaller angles than small particles; Malvern Panalytical, 2018).

\subsection{Porosity}

Porosity is a measurement of the pore space of a given sample. This useful tool scales linearly with bulk density and can be used to quantify the qualitative changes observed in $\mathrm{x}$-radiographs. Porosity tends to decrease as bulk density increases, owing to the increased grain-to-grain contact of coarse grains relative to fines. Porosity also 
tends to decrease with depth down core, as compaction results in the dewatering of fine-grained deposits.

To measure porosity, a subsample of $\sim 10 \mathrm{~g}$ wet sediment is weighed and then dried for $\sim 48$ hours at $45^{\circ} \mathrm{C}$. Once dry, the sample is weighed again, and the mass of water lost is calculated from the difference in mass between wet sediment and dry sediment. Dry season porosity was calculated in order to account for the saline environment. The density of sediment, $\rho_{\mathrm{s}}$, is $2.65 \mathrm{~g} \mathrm{~cm}^{-3}$, the density of saltwater, $\rho_{\mathrm{w}}$, with a salinity of $25 \mathrm{PSU}$ was $1.025 \mathrm{~g} \mathrm{~mL}^{-1}$, and the salt fraction, $F_{s}$, was 0.025 . After weighing, drying, and reweighing, the fraction of water, $W$, was calculated using the equation:

$$
W=\frac{\text { wet mass }- \text { dry mass }}{\text { wet mass }}
$$

Next, the fraction of sediment and salt, $S$, was calculated using:

$$
S=1-W
$$

The volume of water and salt, $V_{s w}$, was calculated using:

$$
V_{S w}=\frac{W}{1-F_{S}} * \frac{1}{\rho_{w}}
$$

The volume of sediment, excluding salt, $V_{s}$, is found using:

$$
V_{S}=\frac{S-\left(W\left(\frac{F_{S}}{1-F_{S}}\right)\right)}{\rho_{s}}
$$

Finally, the salt-corrected porosity, $P_{s c}$, is found using the following equation:

$$
P_{s c}=\frac{V s w}{V s w+V s}
$$

In the monsoon season, since the salinity is $0 \mathrm{PSU}$, we assume a water density, $\rho_{\mathrm{w}}$, of 1 $\mathrm{g} \mathrm{mL}^{-1}$ and a salt fraction, $F_{s,}$ of 0 . 


\subsection{Total Organic Carbon}

Total organic carbon (TOC) was measured in a representative group of subsamples. From the samples, we collected approximately one gram of dried sediment from the top two centimeters of 10 wet season cores and their co-located dry season cores. In addition, we collected approximately one gram of dried sediment from the same cores at depths where depositional features changed (i.e., where homogenized sediment begins under laminations or where lamination thickness changes). Old Dominion University's Chesapeake Bay Program's Water Quality Lab analyzed samples following the protocol of Schumacher (2002). Samples were measured for total inorganic carbon and then total carbon, and the resulting difference between the two was the reported TOC.

\subsection{Radiochemistry}

${ }^{7} \mathrm{Be}$ is a naturally occurring cosmogenic radionuclide with a half-life of 53.2 days, that falls from the atmosphere and accumulates on land surfaces. Following precipitation events and surface water runoff, ${ }^{7} \mathrm{Be}$-tagged sediment accumulates in rivers at relatively enhanced activity levels. If a sample is found with ${ }^{7} \mathrm{Be}$ activity higher than the background atmospheric-supply levels, this suggest that the sediment was recently deposited (< 6 months). Presumably, monsoon-deposited sediment would have a detectable ${ }^{7} \mathrm{Be}$ above background levels, indicating the sediment had been recently derived from a subaerial location. A total of 35 samples from the monsoon season were analyzed for their ${ }^{7} \mathrm{Be}$ activity, using the following method. 
Dry samples were ground with a mortar and pestle, packaged in Falcon $50 \times 9 \mathrm{~mm}$ (12 mL; 10 g) petri dishes, and sent to the Virginia Institute of Marine Science's Sediment Analysis Laboratory where they were exposed for 48 hours by gamma spectroscopy using Low Energy Germanium (LEGe) detectors. 


\section{CHAPTER 3}

\section{RESULTS}

Examples of how the various properties vary down core are shown in Fig. 4.

\subsection{X-Radiography}

X-radiographs in this study demonstrate a variety of laminated and homogenized layers throughout the cores. A representative suite of sedimentary facies can be observed in the example presented in Fig. 3. Core DR-5, collected on the Dhaki River, exhibits a physically stratified section from the surface to approximately 8-cm depth, overlying a higher bulk density homogenous layer below (Fig. 3A). Core SB-20, collected within the SNF, demonstrates physical stratification throughout, and relative bulk density changing in $3 \mathrm{~cm}$ intervals (Fig.3B). BR-16, from the Bhadra River, is almost completely homogenized throughout the entire core (Fig. 3C). Core DR-4, collected 3.3 river km from DR-5 on the Dhaki River, demonstrates visible evidence of bioturbation, and minimal evidence of physical stratification in the upper $10 \mathrm{~cm}$ (Fig. 3D). This bioturbation is shown in a lighter color than the physical laminations, with an example of a worm borrow near the bottom of the bioturbated section. Interlaminated high and low bulk density layers occur on the $\mathrm{mm}$ to $\mathrm{cm}$ scale. These layers exist in packages, which are approximately 3 to $10 \mathrm{~cm}$ thick, and alternate throughout the core. 

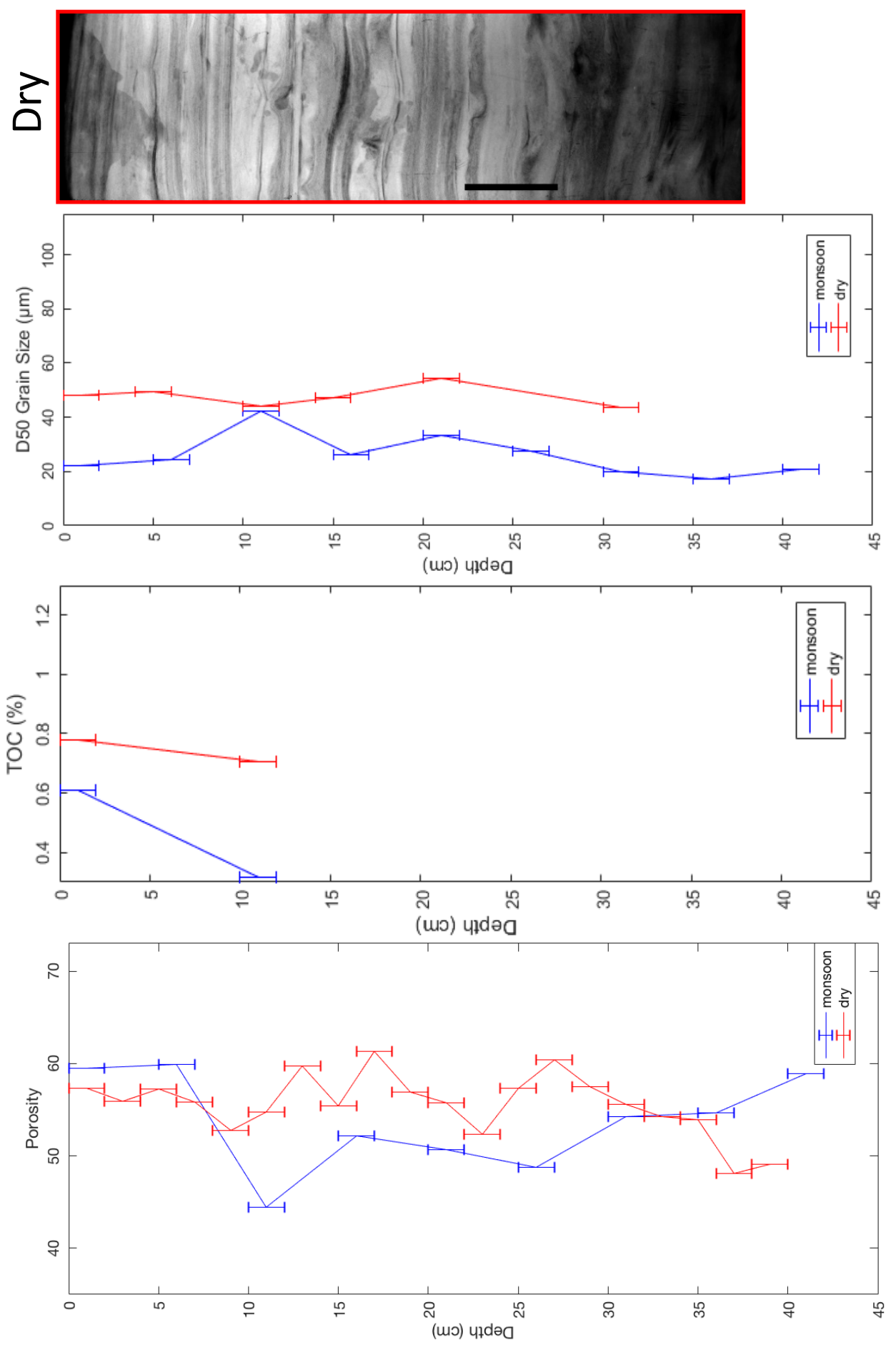

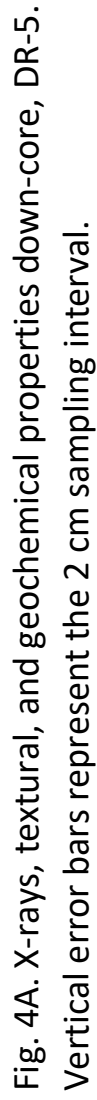

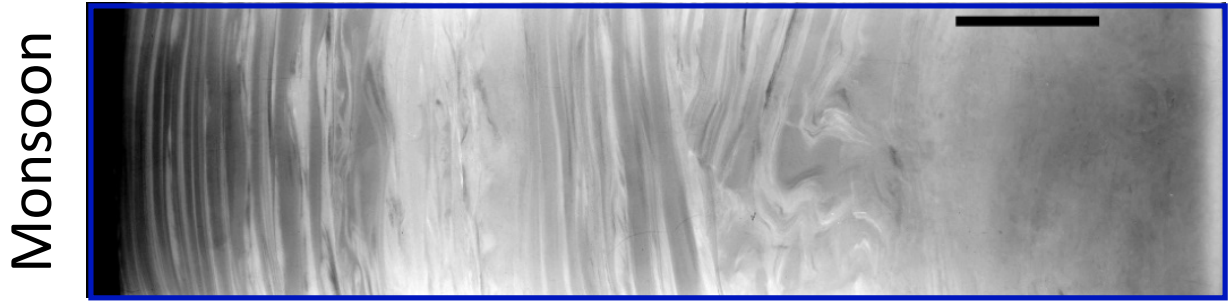



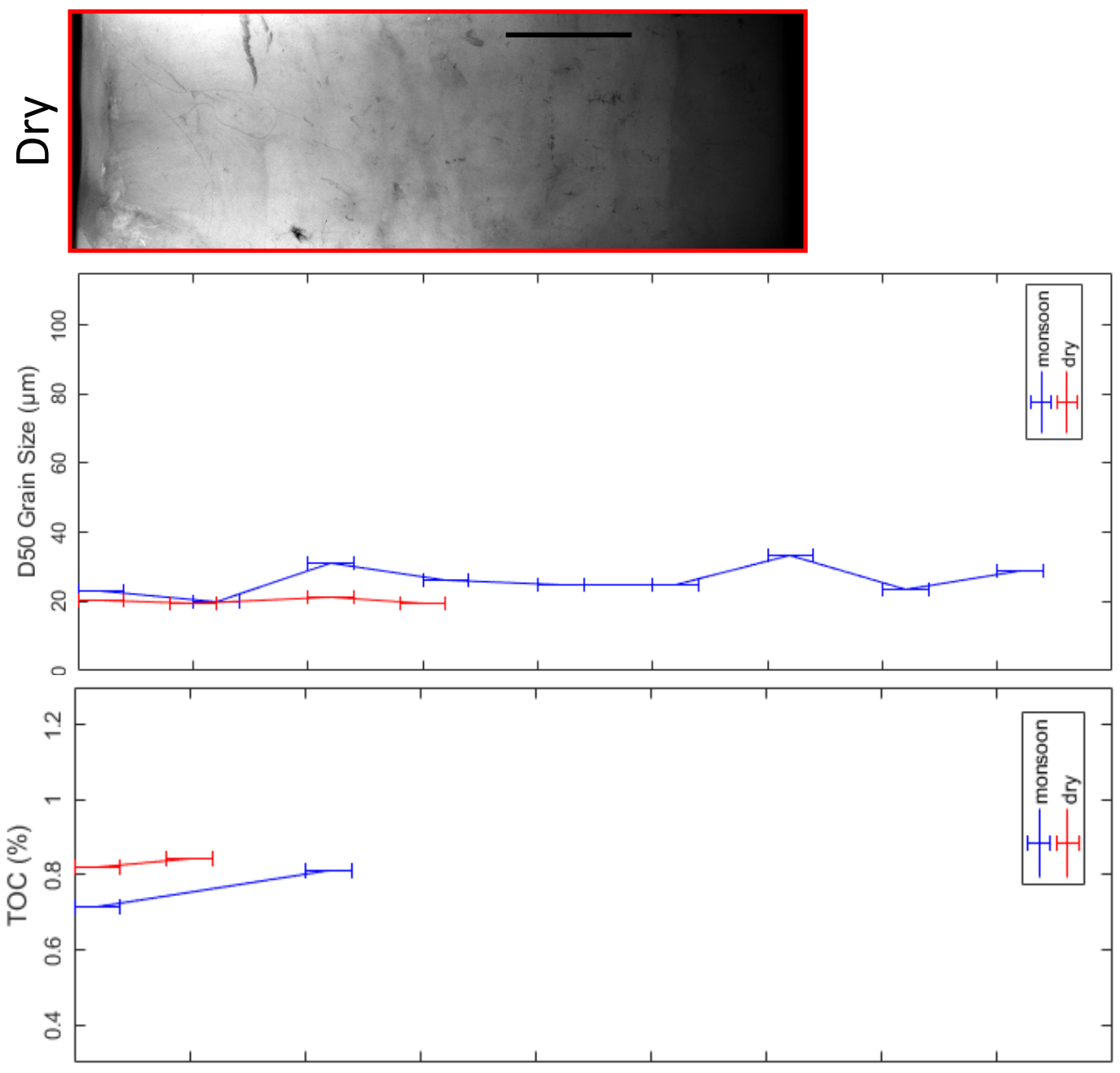

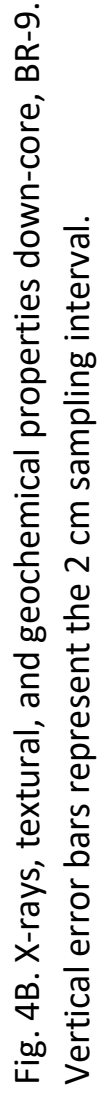


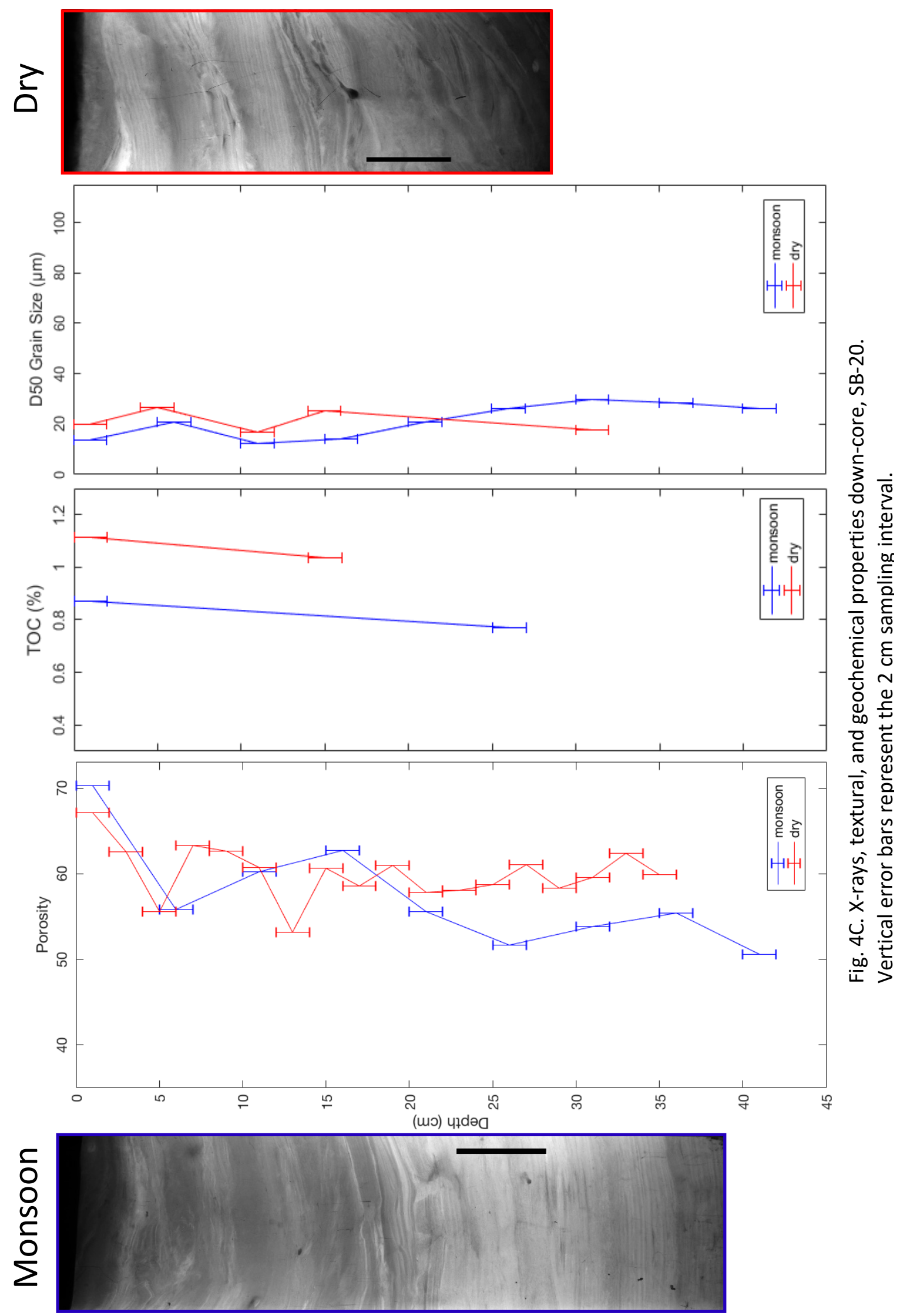

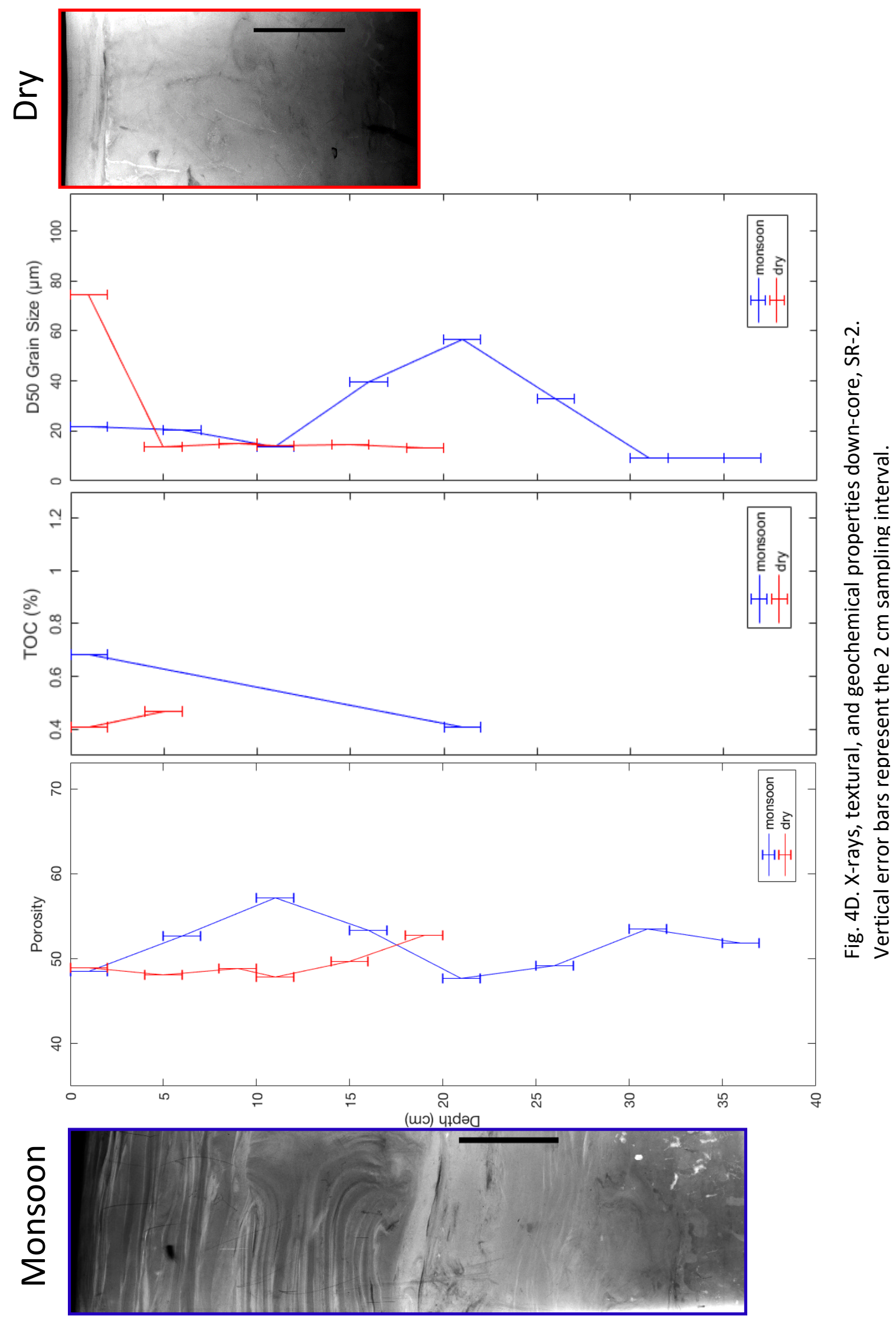

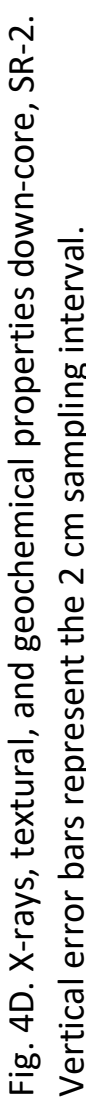


During the wet season, two cores collected showed no physical laminations, 12 contained coarse laminations, and 13 were finely laminated. Overall, finely laminated cores tended to be collected from the northeast Dhaki and Sutarkhali/Bhadra Rivers, while the coarsely laminated cores occurred more frequently in the southwest Dhaki and Shibsa Rivers (Fig. 5A). In the dry season, 8 cores showed no laminations, 12 showed coarse laminations, and 13 showed fine laminations. Finely laminated cores tend to appear more on the Bhadra/Sutarkhali Rivers (Fig. 5B). Out of the 26 locations examined for changes in the style of lamination from the wet to the dry season, 3 cores increased (lamination style got finer), 8 decreased (lamination style got coarser), and 15 showed no change between the wet and the dry season.

In both the wet and dry seasons, some cores collected showed no physical laminations ( 2 in the wet season and 8 in the dry season). During the wet season laminations in a single core extended to a depth $\geq 39 \mathrm{~cm}$, while in the dry season laminations are visible in a core $\geq 42 \mathrm{~cm}$ in depth. In the wet season, cores with the shallowest lamination depths tend to occur on the banks of the Shibsa and southwest Dhaki Rivers (the widest channels), while the cores with the deepest laminations were taken from the northeast Dhaki and Bhadra/Sutarkhali Rivers (Fig. 6A). In contrast, the depth of laminations in the dry season show no obvious spatial patterns (Fig. 6B). Assuming $5 \mathrm{~cm}$ is $\sim 10 \%$ of the average core length, a deepening or shallowing in the lamination of the core between the wet and dry season was only noted if it was greater than $5 \mathrm{~cm}$. Of the 26 locations examined in both the wet and dry seasons, 4 showed 

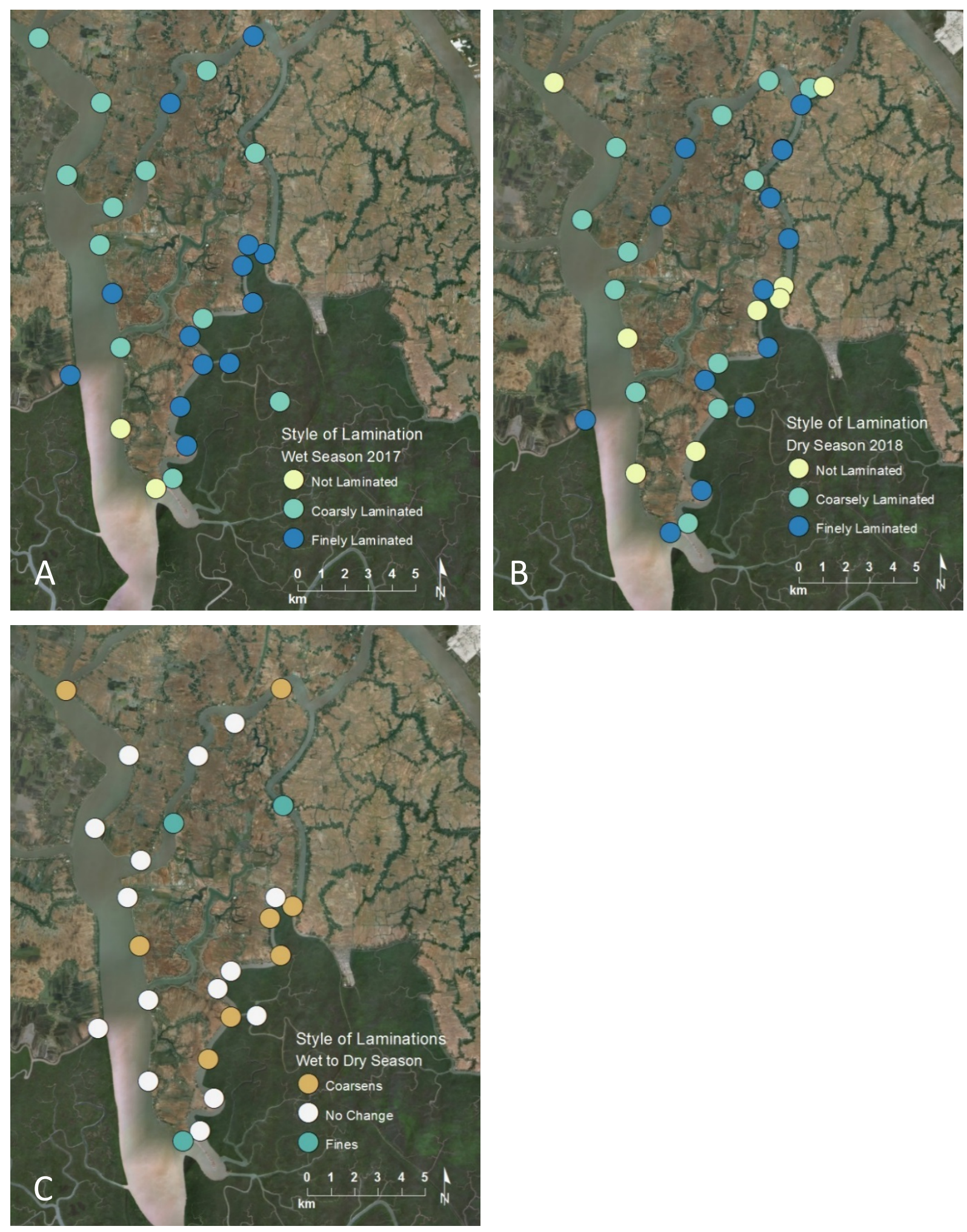

Fig. 5. Style of lamination in the wet (A) and dry (B) seasons. C) Changes in the style of laminations from the wet to the dry season. 

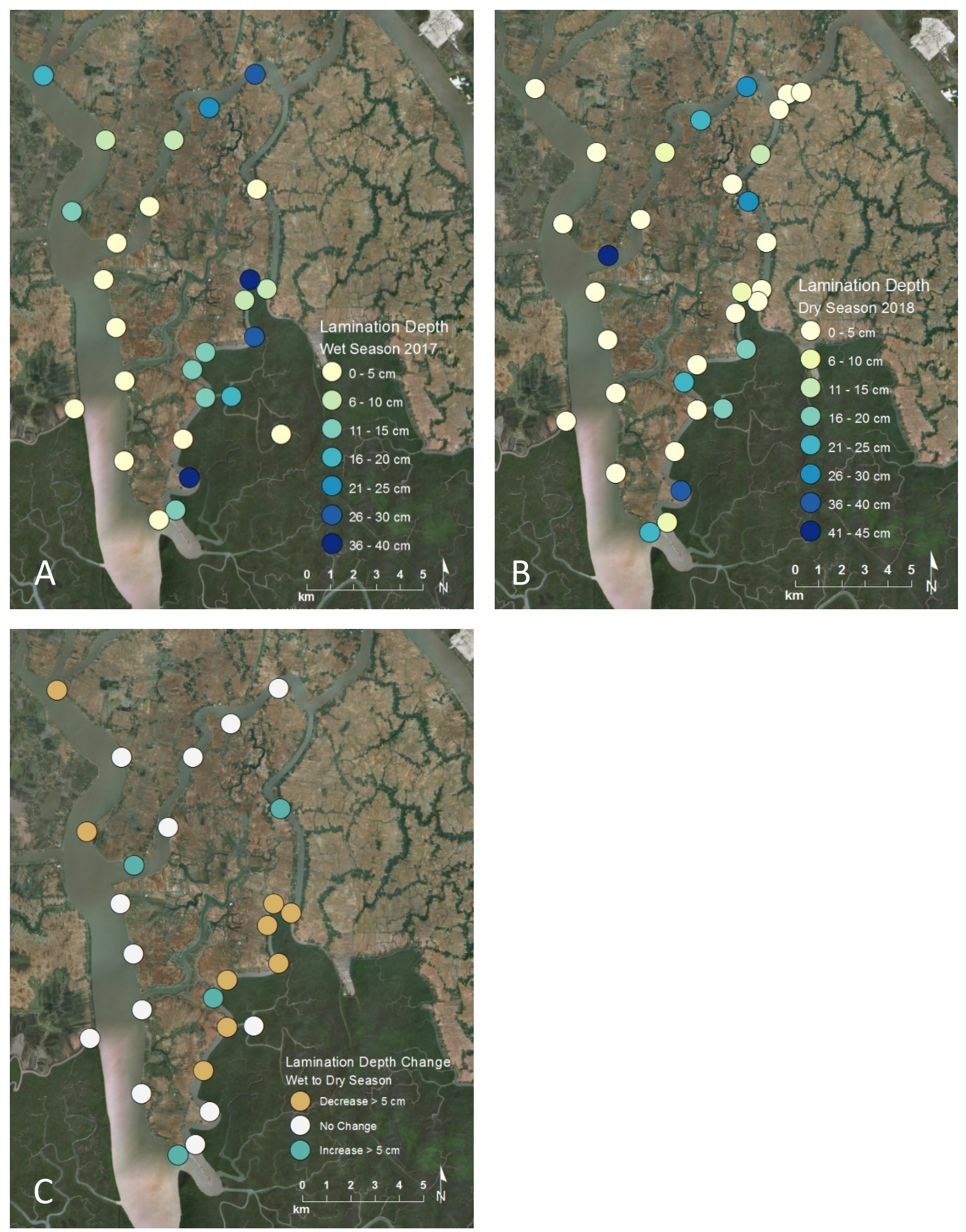

Fig. 6. Depth of lamination in the wet $(A)$ and dry $(B)$ seasons. C) Changes in the depth of lamination from the wet to the dry season. Cores with changes less than $5 \mathrm{~cm}$ in either direction are grouped into "No Change". 
laminations deepening, 9 showed laminations shallowing, and 13 showed no change in the depth of laminations. The cores with no change in lamination depths tend to occur on the Shibsa and Dhaki Rivers (Fig. 6C).

\subsection{Grain Size}

Surface grain size was examined in all cores, with the median particle size presented herein. In samples from cores collected during the wet season, the majority (24 cores) were composed of medium silt $(16-31 \mu \mathrm{m})$, six were composed of coarse silts (31-63 $\mu \mathrm{m})$, two were composed of sediments fine silts and clays $(<16 \mu \mathrm{m})$, and two were composed of sand sized sediments or larger (>63 $\mu \mathrm{m})$. During the wet season, the fine silts and clays are only seen inside the SNF, and sand size particles are seen on the Shibsa or on the Dhaki close to the Shibsa (Fig. 7A). Similar to the wet season, the majority (19) of the surface samples from cores collected in the dry season are composed of medium silts, eight were composed of coarse silts, two were composed of sands or coarser, and one was composed of fine silts and clays. In the dry season, the majority of medium silts occurred on the Bhadra/Sutarkhali Rivers and the sand only occurred on the Shibsa (Fig. 7B).

I compared the changes in median grain size between the wet and dry seasons, to assess a potential change in the depositional regime. Overall, 20 cores demonstrate coarsening in the top two centimeters from wet to dry season; however, 12 of those did not increase more than $10 \mu \mathrm{m}$, three increased between 10 and $20 \mu \mathrm{m}$, and five increased more than $20 \mu \mathrm{m}$. Furthermore, twelve cores decreased in grain size in the top two centimeters, with nine decreasing less than $10 \mu \mathrm{m}$, one decreasing between 10 

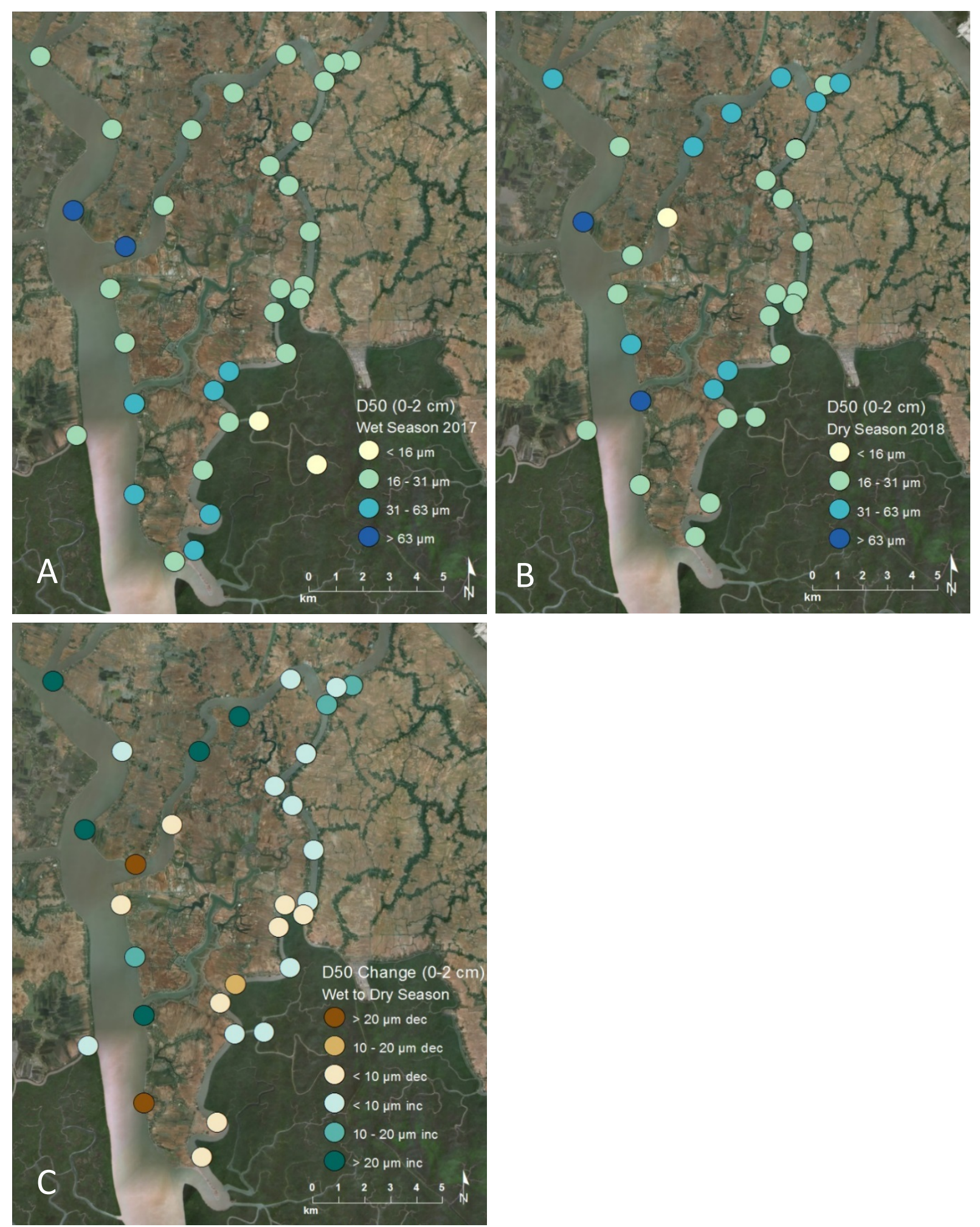

Fig. 7. Median surface grain size of the top two centimeters of the cores following the wet season $(A)$ and dry season $(B)$. C) Change in median grain size of the top two centimeters from the wet to the dry season. 
and $20 \mu \mathrm{m}$, and two decreasing more than $20 \mu \mathrm{m}$. The northern Bhadra and eastern Dhaki appear to coarsen, while the southern and western regions of the respective rivers fine. In general, there is a slight coarsening in the majority of surface sediments between the wet and dry season (Fig. 7C), though overall, grain size does not vary dramatically regardless of season, giving that $\sim 75 \%$ of the source material is in the silt fraction.

\subsection{Porosity}

As a complement to grain size (Fig. 8), the volume of pore space was examined in the top two centimeters of the cores. In the wet season (Fig. 8A), porosity of the top two centimeters was less than $50 \%$ in five cores, $50-55 \%$ in 13 cores, $55-60 \%$ in 11 cores, $60-65 \%$ in two cores, and greater than $65 \%$ in three cores. The three cores with the highest porosity values were collected from inside the SNF or on a main channel bank on the side of the SNF. In the dry season (Fig. 8B), four cores had a porosity value of less than $50 \%$ in the top two centimeters, 15 cores had a value $50-55 \%$, five had a value $55-60 \%$, five had a value $60-65 \%$, and two had a value greater than $65 \%$. All cores with porosity less than $50 \%$ were collected from the Shibsa River.

I compared how the porosity changed from the wet season to the dry season in the top two centimeters of the cores (Fig. 8C). In total, 19 cores increased in porosity in the top two centimeters. Of the 19, 14 increased less than 5\%, two increased 5-10\%, and three increased more than $10 \%$. Fourteen cores decreased in porosity, with 10 decreasing less than $5 \%$, four decreasing $5-10 \%$, and none decreasing more than $10 \%$. The majority of all cores show little change in porosity (increasing or decreasing) 

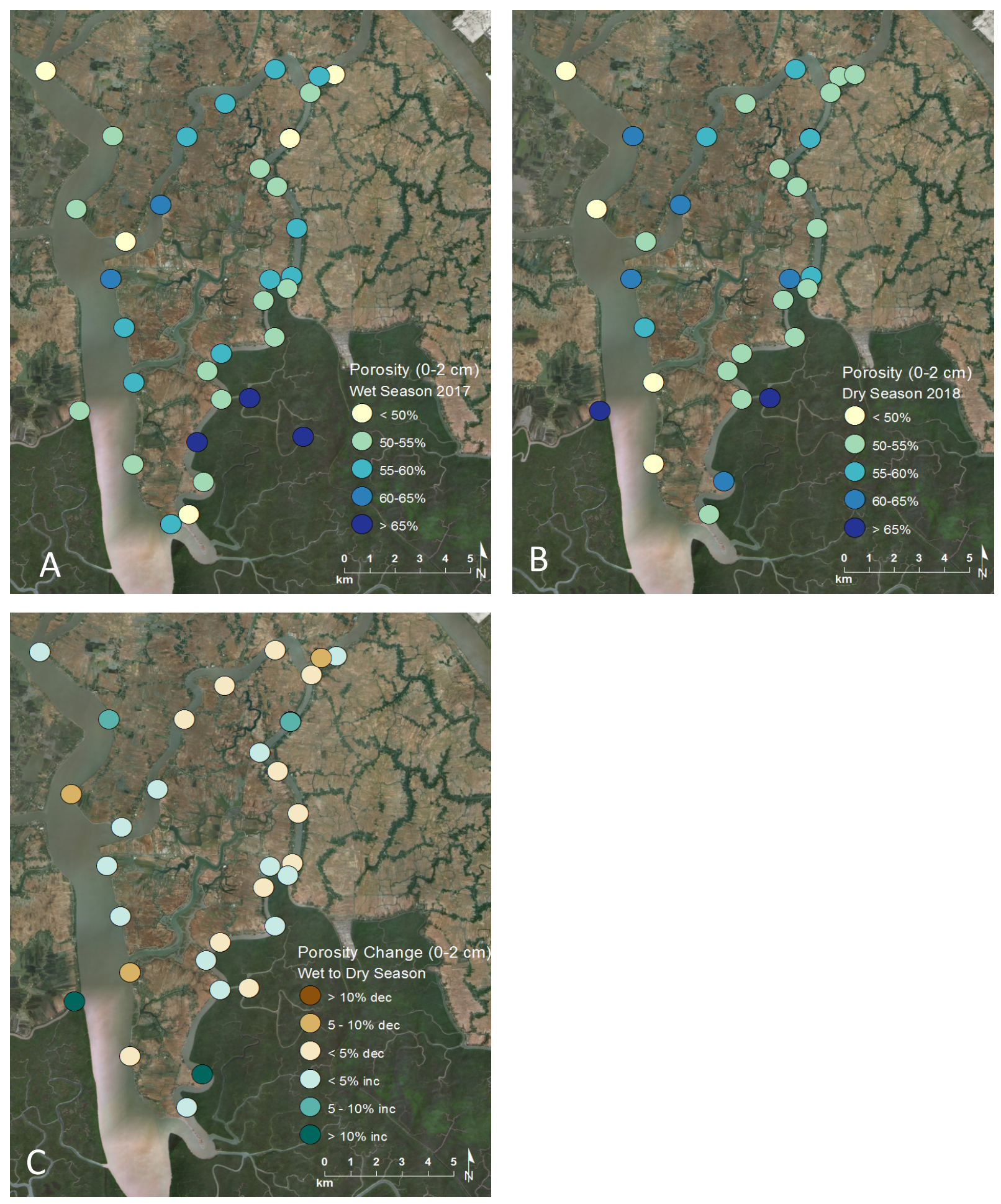

Fig. 8. Surface porosity of the top two centimeters of the cores following the wet season (A) and dry season (B). C) Change in porosity of the top two centimeters from the wet to the dry season. 
between the wet and dry season. In general, while porosity was not completely consistent across seasons, the observed variability was unpredictable in either space of extent.

\subsection{Total Organic Carbon}

In the top two centimeters of the core, wet season TOC content ranged from approximately $0.4-0.9 \%$ and dry season TOC content ranged from approximately 0.4 $-1.3 \%$. In total, eight cores increased in surface TOC and two cores decreased in surface TOC. TOC was also measured in samples from the bottom of the surface physically stratified layer. In five examples, TOC content increases down core, and four decrease, regardless of the season in which the core was collected. No spatial variations are present in TOC content.

\subsection{Radiochemistry}

Of the 35 cores analyzed for ${ }^{7} \mathrm{Be}$ activity, none showed a detectable peak above background concentrations. 


\section{CHAPTER 4 \\ DISCUSSION}

\subsection{Regional Patterns}

An important first step in understanding temporal variability in this system is establishing how the different proxies vary spatially. Because tidal current strength scales approximately (though not linearly) with channel width (sensu Hale et al., 2019; Bain et al., in press), we expect grain size distributions to follow accordingly. Indeed, we do see that the finest surface grains from both seasons are located in the SNF where the channels are, at most, half the width of the Bhadra/Sutarkhali (narrowest) channels (Fig. 7A,B). In addition, sand-sized particles from both seasons are only seen in the widest regions that likely experience the greatest current velocity (Fig. 7A,B), implying that regional hydrodynamics exert a control over grain size in the tidal channels. Furthermore, the shallowest lamination depths observed in the wet season are along the two larger rivers, where conditions are relatively less conducive to deposition (Fig. $6 A, B)$. In contrast, the narrower channels are lower-energy environments that could support deposition, as evidenced by the relatively thicker deposits of laminated sediment observed here (Fig. 6A,B). This suggests a hydrodynamic control on deposit thickness (e.g. Bartholdy et al., 2005). A similar pattern is observed in the style of lamination, where the greatest number of finely laminated cores from the wet season are from the Bhadra/Sutarkhali and northeastern Dhaki Rivers (Fig. 5A,B); narrower and shallower rivers exchanging less water and sediment than the larger Shibsa river. Conversely, the cores exhibiting coarser laminations were collected from the Shibsa 
and southwest Dhaki Rivers (Fig. 5A,B), on stretches that are greater in width, and likely tidal energy, than the locations of cores that displayed fine laminations.

\subsection{Seasonal Variability, Observed Seasonal Depositional Patterns, and Implications}

Overwhelmingly, the results from this study indicate continual reworking of sediments throughout the year. The strongest evidence for this comes from the $x$ radiographs, where most cores are dominated by physical laminations year-round (Fig. 5). Understanding the importance of physical reworking, we would like to be able to distinguish specific seasons using a set of diagnostics, to infer the depth to which sediment is being resuspended. Determining seasonal packages has proven exceptionally challenging, in large part due to the relatively coarse metrics we must rely on to tease out nuanced differences.

The style of lamination, which stays constant at 15 out of the 26 locations examined (Fig. 5C), shows a consistent dominance of physical processes year-round. This is particularly interesting, given the known reduction in the delivery of externally sourced sediment. When comparing the changes in the style and depth of laminations collectively, individual lamination coarsening is only found when the depth of laminations is shallowing (or not changing) in the core. Tidal energy (as inferred from tidal range or water discharge; Hale et al., 2019) does not differ greatly between the monsoon and the dry seasons, but reduced fluvial input during the dry season allows for sediment resuspension from channel banks, which results in constant reworking and a net loss of bank (sensu Wilson and Goodbred, 2015). In contrast, cores that demonstrate lamination fining between the seasons only occur when there is also 
deepening (or not changing) depth of lamination in the core, indicating that these locations experience conditions that promote the deposition of finer sediment packages, with the material likely sourced from elsewhere within this system.

Though the results of the TOC analysis were not diagnostic in determining the thickness of specific seasonal deposits, seven cores demonstrate an increase in TOC at both the surface and at depth from wet to dry season. Our assumption was that leaf litter should increase the surface TOC during the dry season. The increase presence of TOC at depth, in conjunction with the strong evidence for physical lamination and minimal bioturbation, indicate deep reworking of the sediment, with erosion and deposition working to advect TOC from the surface to deep into the core. This reworking also explains the absence of a detectable ${ }^{7}$ Be peak in any sample. Previous studies in this area have used ${ }^{7} \mathrm{Be}$ activity to indicate recent deposition on the mangrove platform following the monsoon season, so we know this to be an effective tool and understand that much of the sediment is of recent fluvial origin (Rogers et al., 2013). In the tidal channels, however, the admixture of ${ }^{7} \mathrm{Be}$-rich sediment with sediment in which ${ }^{7} \mathrm{Be}$ has decayed dilutes the concentrations of the radioisotope, resulting in peaks being indistinguishable from background concentrations. Those previous studies also had substantially more sediment with which to measure short-lived isotope activity than this study ( $\sim 50-150 \mathrm{~g}$ vs. $\sim 10 \mathrm{~g}$ ) owing to the different sapling techniques employed.

The eastern Dhaki and the northern Bhadra exhibit a general grain-size coarsening from the wet to dry season (Fig. 7C). During the dry season, the water discharge and suspended sediment load of the Gorai River are dramatically reduced (Mirza, 1998). While the overall sediment load of the Gorai is relatively small when 
compared to the indirect GBM river source, previous studies have demonstrated that it can play an important role in the hydrodynamics (and presumably sediment transport) in the vicinity of its confluence with the Dhaki River (Shaha and Cho, 2016; Bain et al., in press). The seasonal decrease in sediment supply of the Gorai is most evident in the eastern Dhaki and northern Bhadra, which demonstrate the most consistent grain-size coarsening observed in this study. With a reduced concentration of fluvially-sourced suspended sediment, the increased carrying capacity of the tidal currents in the channels preferentially erode the finer grains, leaving behind larger grains on the banks. This fine material, if transported onto the topset, can help to sustain delta elevation relative to SLR. As previously described, the presence of polders inhibits the widespread distribution of this material outside of the channel confines.

Having demonstrated that sediment reworking is perpetually widespread, we can begin to address the potential of these channels as a sediment source, following the model proposed by Nittrouer and Viparelli (2014). We observe that sediment on the banks of tidal channels in this portion of the GBM Delta is being reworked throughout the year. In their study of monsoon sedimentation, Rogers et al. (2013) found that just under $2 / 3$ of sediment on the platform is recently derived ( $<6$ mos.) from the GBM rivers, with the remaining fraction consisting of older, reworked material. It follows, then, that if resuspension is directly linked to sedimentation on the platform, we could expect to see a $2 / 3$ reduction in deposition during the dry season. In their study examining sedimentation rates in the SNF near Polder 32, Bomer et al. (submitted) observe an average monsoon deposition rate of $2.01 \pm 0.28 \mathrm{~cm}$, compared with $0.35 \pm 0.15 \mathrm{~cm}$ during the dry season; a reduction of $>80 \%$. Hale et al. (in review), also demonstrate 
that while the hydrodynamic conditions for sediment delivery to the platform are improved during the monsoon season, sediment delivery occurs year-round. Given our understanding of the regional hydrography and the near termination of GBM-derived sediment during the dry season, it seems only logical that the channel banks observed in this study area are supplying at least a portion of the sediment deposited in the SNF during the dry season. That we observe a reduction in the thickness of laminated sediments in cores collected adjacent to the SNF supports this notion (Fig. 7).

There are importance differences between the tide-dominated GBM system and the fluvial-dominated Mississippi River system from which this study draws inspiration. The Irrawaddy River Delta, another tide-dominated system associated with a major and muddy river, is currently prograding at an average rate of $3.6 \mathrm{~m} \mathrm{yr}^{-1}$ and sustaining topset elevation relative to sea level (Hedley et al., 2010). Those authors concluded that more than $95 \%$ of the sediment on the sub-aerial plain is sourced from the bedload and less than $5 \%$ is from the suspended load, which compliments the Nittrouer and Viparelli (2014) study in the Mississippi River. With this in mind, we expect that channel scour can play a significant role in sustaining the GBM Delta platform.

In order to understand the implications of channel scour and how much is necessary to sustain the GBM Delta, we performed a unit-scale analysis of channel erosion and platform deposition using observations from the Bhadra/Sutarkhali Rivers, and a $20 \mathrm{~km}^{2}$ sub-basin of the adjacent Sundarbans (outlined in Fig. 2). From Bomer et al. (submitted), we understand that $\sim 1 \mathrm{~cm}$ of sediment is deposited on the platform in the SNF during the dry season. Assuming a constant deposit thickness and bulk density (from Hale et al., in review) across the entire $20 \mathrm{~km}^{2}$ sub-basin described in their study, 
a total of $\sim 3 \times 10^{8} \mathrm{~kg}$ of sediment is deposited during the dry season. The assumption of constant deposit thickness is unlikely, as previous research has identified that relatively more sediment is deposited proximal to the sediment source (i.e., channel; Bomer et al, submitted; Hale et al, in review). The Bhadra/Sutarkhali Rivers (Fig. 1) have a combined intertidal and subaqueous planform area of $5.4 \mathrm{~km}^{2}$. In order in order to supply sufficient sediment for the Sundarbans to keep pace with RSLR $\left(1 \mathrm{~cm} \mathrm{yr}{ }^{-1}\right)$, the channel would need to experience $3-4 \mathrm{~cm} \mathrm{yr}^{-1}$ of erosion. Of course, this value was calculated assuming the only sediment delivered to this area of the Sundarbans is coming from the banks of the Bhadra/Sutarkhali Rivers and that there is a complete cut off of sediment supply coming from the GBM river system. As understood by Rogers et al. (2013) through ${ }^{7} \mathrm{Be}$ measurements, $\sim 40 \%$ of the sediment currently nourishing the platform is older, reworked material. While some of this material could be sourced locally, it is likely being supplemented by a combination of sediment on the continental shelf, and from the bed of the $\sim 100 \mathrm{~km}$ of channel bed along the Shibsa River between the field area and the Bay of Bengal.

We do observe some evidence for channel erosion, as evidenced by cores with a shallowing of lamination depth from the wet to dry season. Interestingly, with the exception of two cores on the energetic Shibsa, the only cores that exhibit such a shallowing in the depths of lamination are located directly on or adjacent to the Sundarbans (Fig. 6C). The implication is that whereas banks adjacent to the polders have no intertidal depositional sink for resuspended sediment, material eroded from the channels adjacent to the Sundarbans can be delivered to the platform during spring-tide flooding events. A curious complication is that more than half of the locations where we 
observe a shallowing of the physically laminated surface layer also demonstrate a modest fining of sediment from monsoon to dry season (Fig. 6C; Fig. 7C). This is not an expected result, as erosion is usually associated with a winnowing of the finest-grained sediment, and an overall bed coarsening. This fining may be a result of altered hydrodynamics due to the extreme seasonal difference in discharge of the Gorai. Bain et al., (in press) suggests that the channels connecting the Shibsa and Pussur Rivers (e.g. Bhadra/Sutarkhali Rivers) act as distributaries between the two main tidal channels. Their study also indicates that there is a greater tidal set up on the Pussur than on the Shibsa. As such, these factors might be responsible for moving the "depocenter" of fine-grain deposition further downstream, however, more research is definitely required. 


\section{CHAPTER 5 \\ CONCLUSIONS}

The data from the present study reflect two sampling periods, which provide snapshots of conditions occurring during the two dominant seasons in southern Asia. The absence of substantial or predictable changes in the numerous physical, radiochemical, and geochemical properties between seasons is likely the result of forcing conditions not changing dramatically throughout the year, indicative of constant sediment reworking. Overall, these data demonstrate a remarkable similarity of inferred sedimentary processes year-round, despite profound differences in freshwater and sediment supply. Most of the region demonstrates evidence for constant reworking of sediment in the system. Of particular interest is the observation that the thickness of the surface-laminated deposit decreases from wet to dry season in the vicinity of the SNF. Whereas sediment resuspended elsewhere in the study area remains confined to the channel, it appears that the SNF is serving as a sink for sediment in the adjacent channel. Future research should include additional sampling proximal to the SNF to see if this relationship holds. Based on the unit-scale analysis performed herein, the channel erosion rates necessary to sustain the $20 \mathrm{~km}^{2}$ sub-basin appear reasonable, especially if we consider the entire $100-\mathrm{km}$ reach of Shibsa River to the south as a potential sediment source. During the dry season, at least a portion of the sediment that is delivered to the platform is likely sourced from the banks of tidal channels in this system. 


\section{REFERENCES}

Allison, M. A., 1998, Historical changes in the Ganges-Brahmaputra delta front: Journal of Coastal Research, p. 1269-1275.

Allison, M., and Kepple, E., 2001, Modern sediment supply to the lower delta plain of the Ganges-Brahmaputra River in Bangladesh: Geo-Marine Letters, v. 21, no. 2, p. $66-74$.

Allison, M. A., Khan, S., Goodbred Jr, S., and Kuehl, S., 2003, Stratigraphic evolution of the late Holocene Ganges-Brahmaputra lower delta plain: Sedimentary Geology, v. 155 , no. $3-4$, p. $317-342$.

Anthony, E.J., Brunier, G., Besset, M., Giochot, M., Dussouillez, P., and Nguyen, V.L., 2015, Linking rapid erosion of the Mekong River delta to human activities: Nature Scientific Reports, v. 5, no. 14745.

Auerbach, L., Goodbred Jr, S., Mondal, D., Wilson, C., Ahmed, K., Roy, K., Steckler, M., Small, C., Gilligan, J., and Ackerly, B., 2015, Flood risk of natural and embanked landscapes on the Ganges-Brahmaputra tidal delta plain: Nature Climate Change, v. 5 , no. 2 , p. 153 .

Ayers, J.C., Goodbred, S., George, G., Fry, D., Benneyworth, L., Hornberger, G., Roy, K., Karim, M.R., Akter, F., 2016, Sources of salinity and arsenic in groundwater in southwest Bangladesh: Geochemical Transactions, v. 17, no. 4.

Bagla, P., 2014, India plans the grandest of canal networks: Science, v. 345, no. 6193, p. 128. 
Bain, R.L., Hale. R.P., and Goodbred, S.L., in press, Flow reorganization in an anthropogenically modified tidal channel network: An example from the southwestern Ganges-Brahmaputra-Meghna Delta: Journal of Geophysical Research: Earth Surface.

Bartholdy, J., Flemming, B.W., Bartholomä, A., and Ernstsen, V.B., 2005, Flow and grain size control of depth-independent simple subaqueous dunes: Journal of Geophysical Research, v. 110.

Barua, D. K., Kuehl, S. A., Miller, R. L., and Moore, W. S., 1994, Suspended sediment distribution and residual transport in the coastal ocean off the GangesBrahmaputra river mouth: Marine Geology, v. 120, no. 1-2, p. 41-61.

Boldt, K. V., Nittrouer, C. A., and Ogston, A. S., 2013, Seasonal transfer and net accumulation of fine sediment on a muddy tidal flat: Willapa Bay, Washington: Continental Shelf Research, v. 60, p. S157-S172.

Bomer, E.J., Wilson, C.A., Hale, R.P., Hossain, A.N.M., and Rahman, R.M.A, submitted, Surface elevation and sedimentation dynamics in the Ganges-Brahmaputra tidal delta plain, Bangladesh: implications for the sustainability of natural and humanimpacted coastal systems.

Brammer, H., 2014, Bangladesh's dynamic coastal regions and sea-level rise: Climate Risk Management, v. 1, p. 51-62.

Britsch, L. D., and Dunbar, J. B., 1993, Land loss rates: Louisiana coastal plain: Journal of coastal research, p. 324-338. 
Chamberlain, E.L., Wallinga, J., Reimann, T., Goodbred, S.L., Steckler, M.S., Shen, Z., and Sincavage, R., 2017, Luminescence dating of delta sediments: Novel approaches explored for the Ganges-Brahmaputra-Meghna Delta: Quaternary Geochronology, v. 41, p. 97-111.

Coleman, J. M., 1969, Brahmaputra River: channel processes and sedimentation: Sedimentary Geology, v. 3, no. 2-3, p. 129-239.

Flood, R.P., Barr, I.D., Weltje, G.J., Roberson, S., Russell, M.I., Meneely, J., Orford, J.D., 2018, Provenance and depositional variability of the Thin Mud Facies in the lower Ganges-Brahmaputra delta, West Bengal Sundarbans, India: Marine Geology, v. 395, p. 198-218.

Fricke, A.T., Nittrouer, C.A., Ogston, A.S., and Vo-Luong, H.P., 2017, Asymmetric progradation of a coastal mangrove forest controlled by combined fluvial and marine influence, Cu Lao Dung, Vietnam: Continental Shelf Research, v. 147, p. 78-90.

Galloway, W.E., 1975, Process framework for describing the morphologic and stratigraphic evolution of deltaic depositional systems: Deltas: Models for Exploration, p. 87-98.

Goodbred Jr, S. L., and Kuehl, S. A., 1998, Floodplain processes in the Bengal Basin and the storage of Ganges-Brahmaputra river sediment: an accretion study using 137Cs and 210Pb geochronology: Sedimentary Geology, v. 121, no. 3-4, p. 239258. 
Goodbred, S. L., and Kuehl, S. A., 1999, Holocene and modern sediment budgets for the Ganges-Brahmaputra river system: Evidence for highstand dispersal to floodplain, shelf, and deep-sea depocenters: Geology, v. 27, no. 6, p. 559-562.

Hale, R.P., Bain, R.L., Goodbred, S., and Best, J., 2019, Observations and scaling of tidal mass transport across the lower Ganges-Brahmaputra delta plain: implications for delta management and sustainability: Earth Surface Dynamics, v. 7 , no. 1 , p. 231-245.

Hale, R.P., Wilson, C.A., Bomer, E.J., in review, Seasonal variability of forces controlling sedimentation in the Sundarbans National Forest, Bangladesh.

Hedley, P.J., Bird, M.I., and Robinson, R.A., 2010, Evolution of the Irrawaddy delta region since 1850: The Geographical Journal, v. 176, no. 2, p. 138-149.

Higgins, S., Overeem, I., Rogers, K., and Kalina, E., 2018, River linking in India:

Downstream impacts on water discharge and suspended sediment transport to deltas: Elem Sci Anth, v. 6, no. 1.

Joshi, N. M., 2013, National River Linking Project of India: Hydro Nepal: Journal of Water, Energy and Environment, v. 12, p. 13-19.

Malvern Panalytical, 2018, Laser Diffraction (LD): https://www.malvernpanalytical.com/en/products/technology/light-scattering/laserdiffraction (Accessed August, 2018).

Milliman, J. D., and Syvitski, J. P., 1992, Geomorphic/tectonic control of sediment discharge to the ocean: the importance of small mountainous rivers: The Journal of Geology, v. 100 , no. 5, p. 525-544. 
Mirza, M.M.Q., 1998, Diversion of the Ganges water at Farakka and its effects on salinity in Bangladesh: Environmental Management, v. 22, iss. 5, p. 711-722. Nittrouer, J.A. and Viparelli, E., 2014, Sand as a stable and sustainable resource for nourishing the Mississippi River delta: Nature Geoscience, v. 7, p. 350-354.

Pethick, J., and Orford, J. D., 2013, Rapid rise in effective sea-level in southwest Bangladesh: its causes and contemporary rates: Global and Planetary Change, v. 111 , p. $237-245$.

Rahman, R., and Salehin, M., 2013, Flood risks and reduction approaches in Bangladesh, Disaster risk reduction approaches in Bangladesh, Springer, p. 65-90. Roberts, H.H., Coleman, J.M., Bentley, S.J., and Walker, N., 2003, An embryonic major delta lobe: A new generation of delta studies in the Atchafalaya-Wax Lake Delta System: Gulf Coast Association of Geological Societies, v. 53, p. 690-703.

Rogers, K. G., Goodbred Jr, S. L., and Mondal, D. R., 2013, Monsoon sedimentation on the 'abandoned' tide-influenced Ganges-Brahmaputra delta plain: Estuarine, Coastal and Shelf Science, v. 131, p. 297-309.

Rogers, K. G., and Overeem, I., 2017, Doomed to drown? Sediment dynamics in the human-controlled floodplains of the active Bengal Delta: Elem Sci Anth, v. 5.

Schumacher, B.A., 2002, Methods for the determination of total organic carbon (TOC) in soils and sediments: Ecological Risk Assessment Support Center, U.S. Environmental Protection Agency.

Seidensticker, J., and Hai, M. A., 1983, The Sundarbans wildlife management plan: conservation in the Bangladesh coastal zone. 
Shaha, D.C., and Cho, Y.K., 2016, Salt plug formation caused by decreased river discharge in multi-channel estuary: Nature Scientific Reports, v. 6, no. 27176.

Syvitski, J. P., Kettner, A. J., Overeem, I., Hutton, E. W., Hannon, M. T., Brakenridge, G. R., Day, J., Vörösmarty, C., Saito, Y., and Giosan, L., 2009, Sinking deltas due to human activities: Nature Geoscience, v. 2, no. 10, p. 681.

Ta, T.K.O., Nguyen, V.L., Tateishi, M., Kobayashi, I., Tanabe, S., and Saito, Y., 2002, Holocene delta evolution and sediment discharge of the Mekong River, southern Vietnam: Quaternary Science Reviews, v. 21, no. 16-17, p. 1807-1819.

Tessler, Z., Vörösmarty, C. J., Grossberg, M., Gladkova, I., Aizenman, H., Syvitski, J., and Foufoula-Georgiou, E., 2015, Profiling risk and sustainability in coastal deltas of the world: Science, v. 349, no. 6248, p. $638-643$.

Wilson, C., Goodbred, S., Small, C., Gilligan, J., Sams, S., Mallick, B., and Hale, R., 2017, Widespread infilling of tidal channels and navigable waterways in the human-modified tidal deltaplain of southwest Bangladesh: Elem Sci Anth, v. 5, no. 78.

Wilson, C. A., and Goodbred Jr, S. L., 2015, Construction and maintenance of the Ganges-Brahmaputra-Meghna delta: linking process, morphology, and stratigraphy: Annual review of marine science, v. 7, p. 67-88. 


\section{APPENDIX 1: CORE LOCATIONS WITH LABELS}

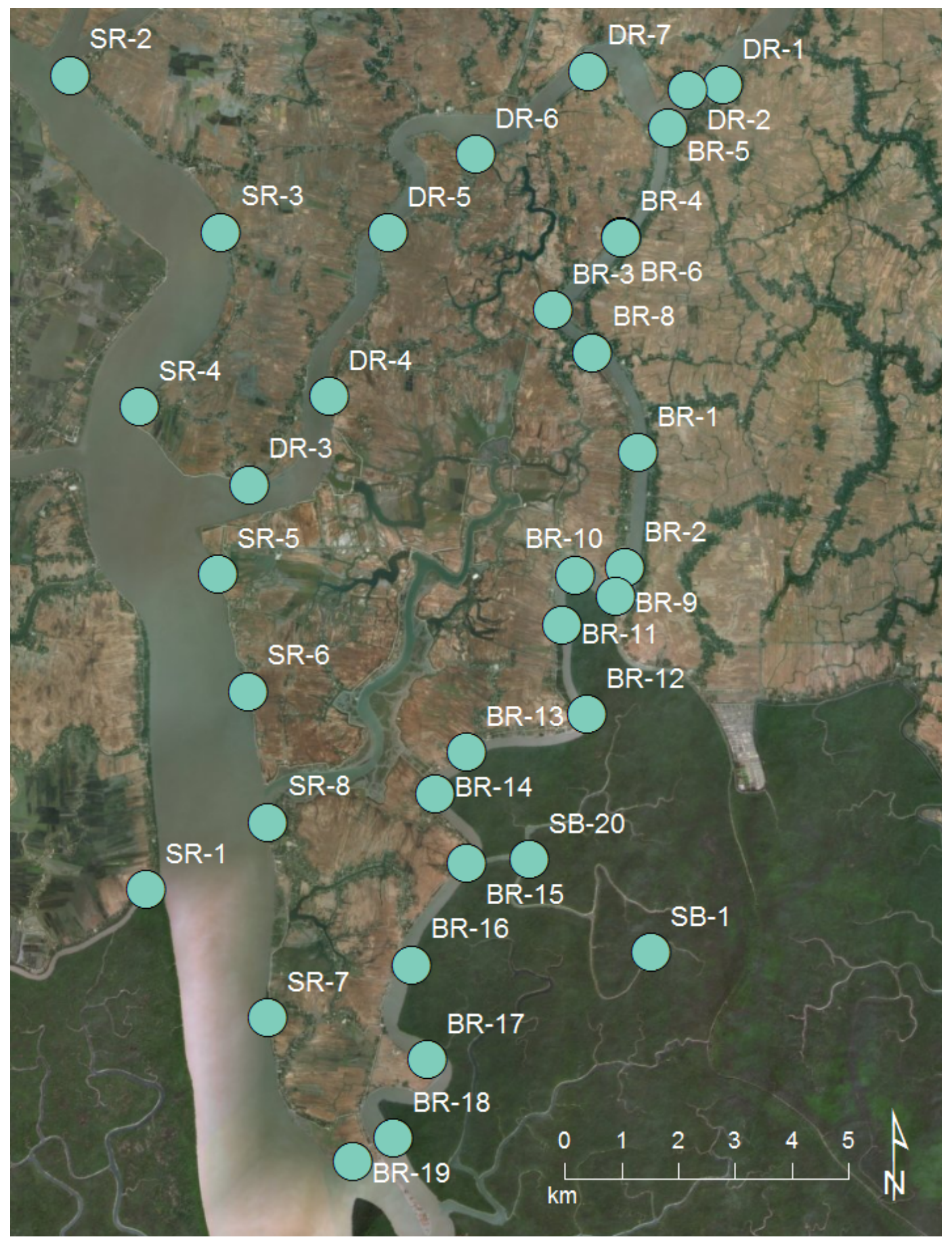

Basemap source: ESRI. 


\section{APPENDIX 2: DATA PROFILES WITH X-RAYS}
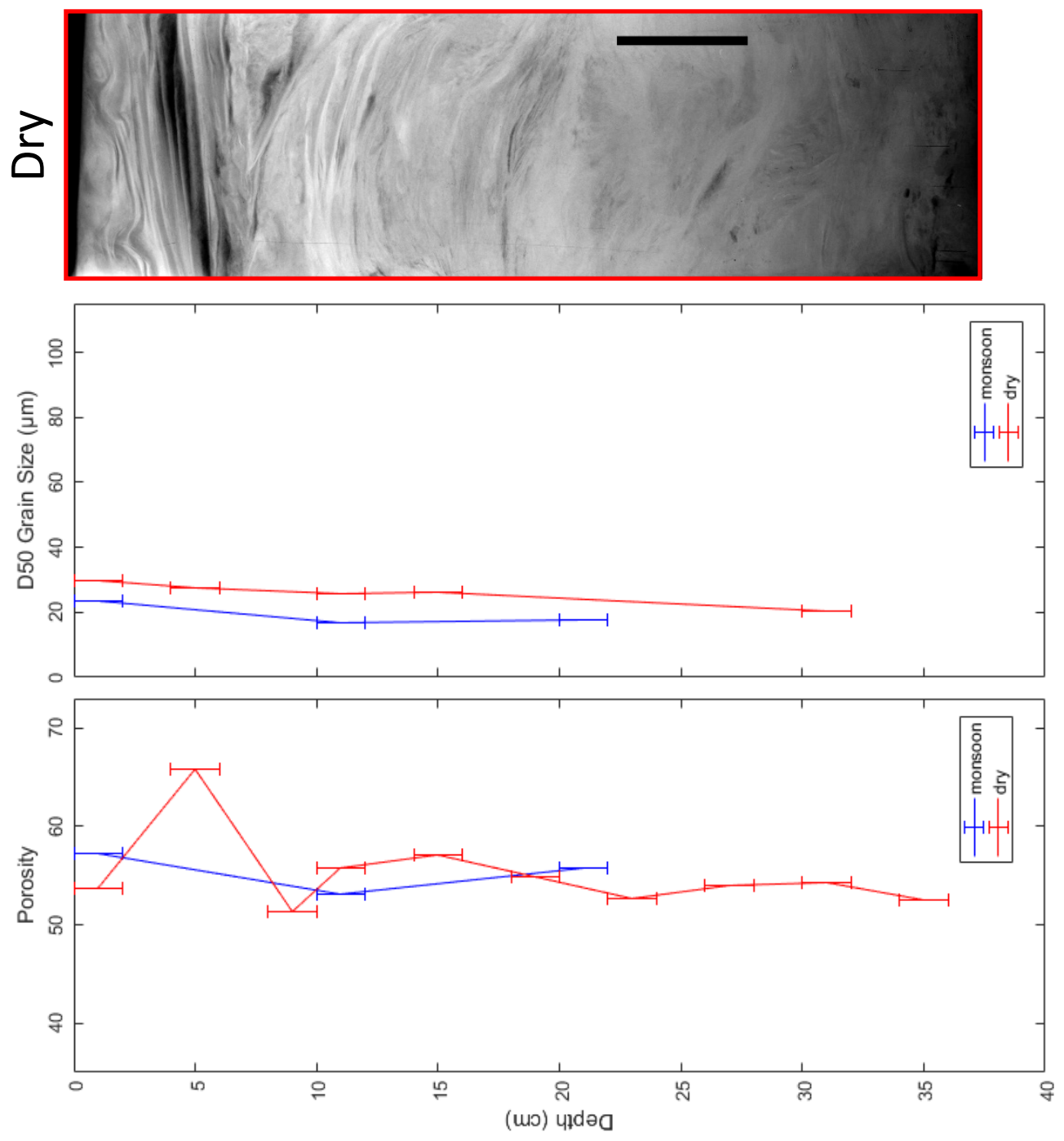

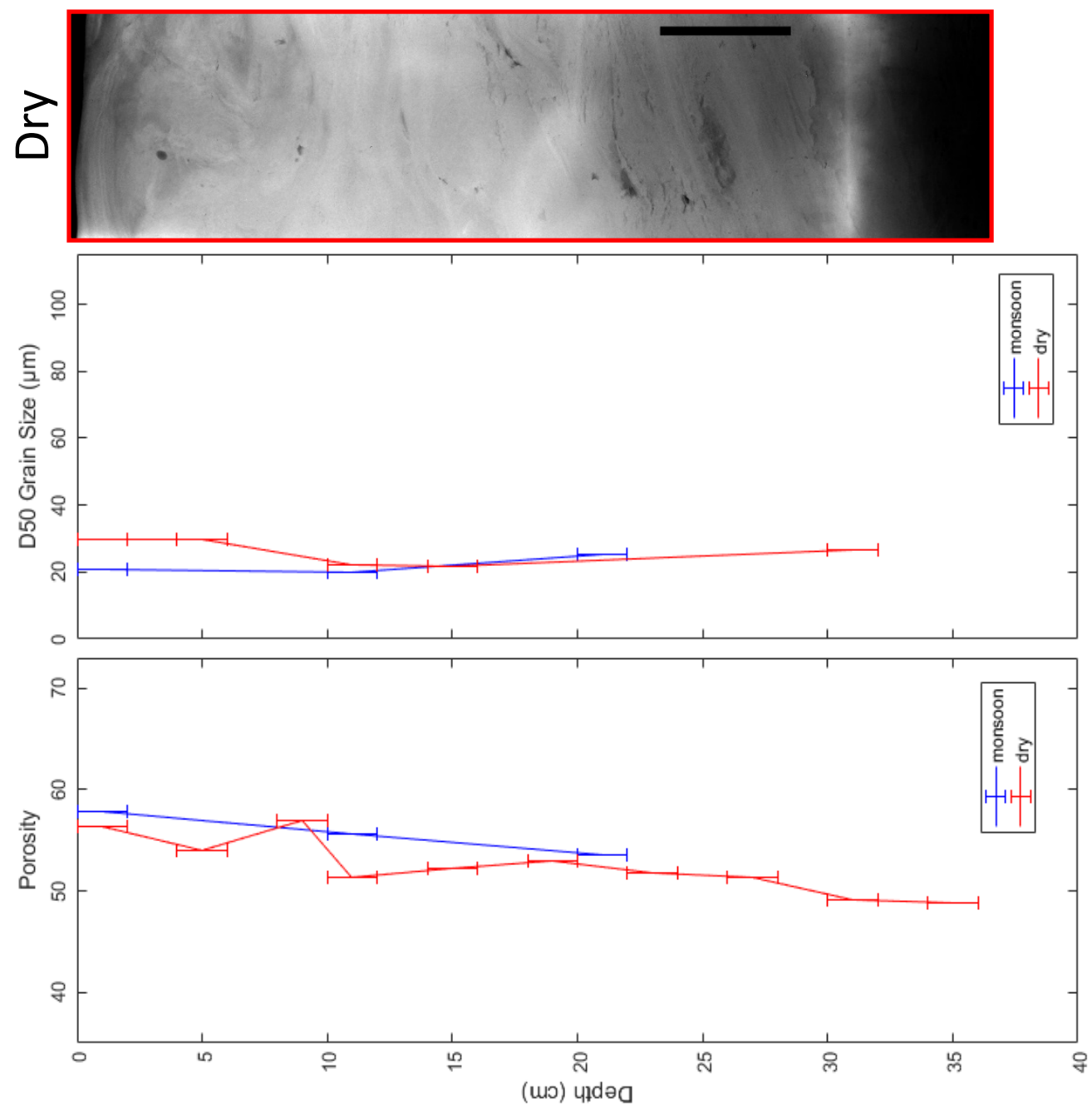

$\frac{N}{\frac{1}{0}}$ 

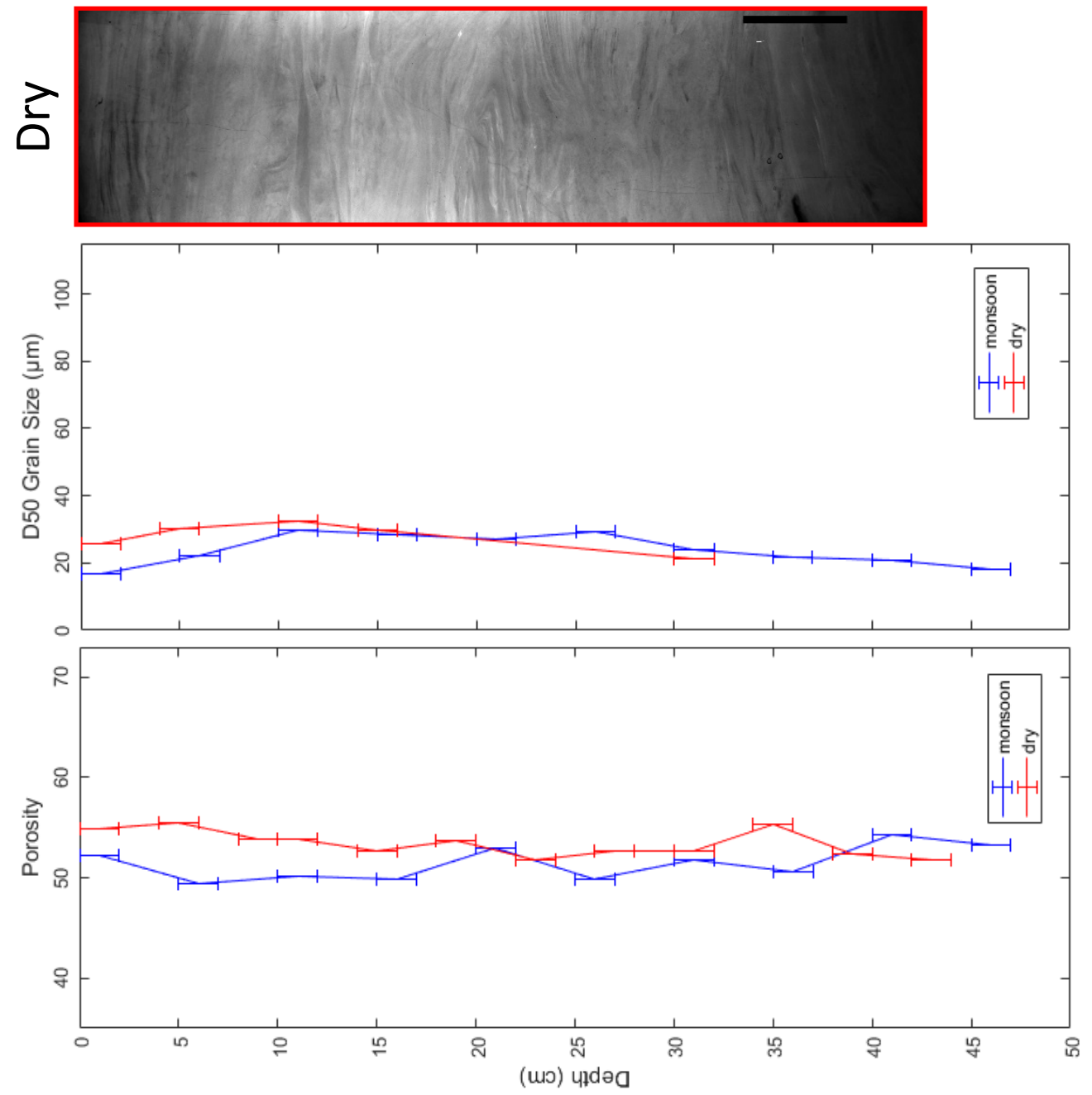

$\frac{m}{\frac{1}{n}}$ 

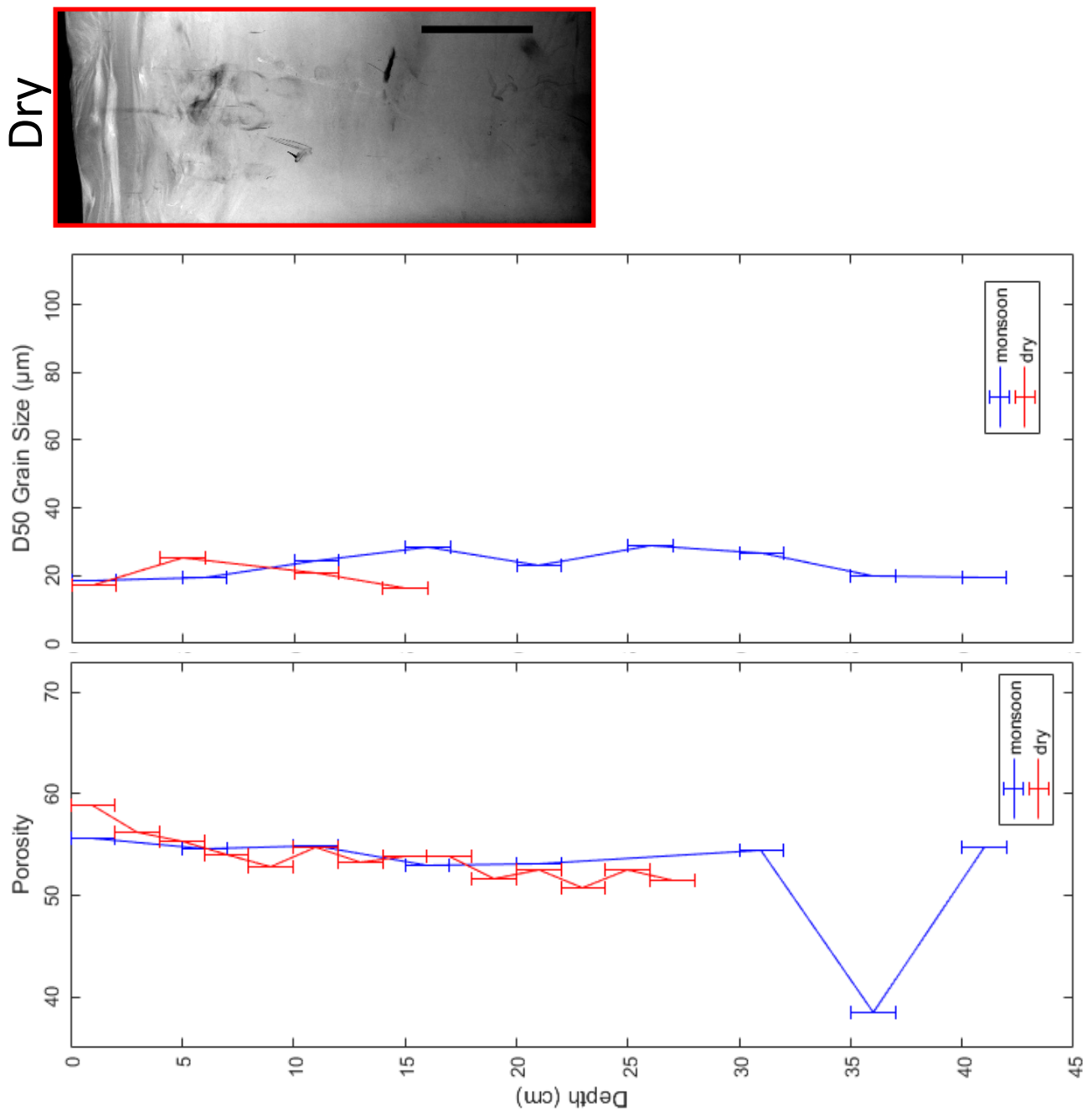


\section{ำ}
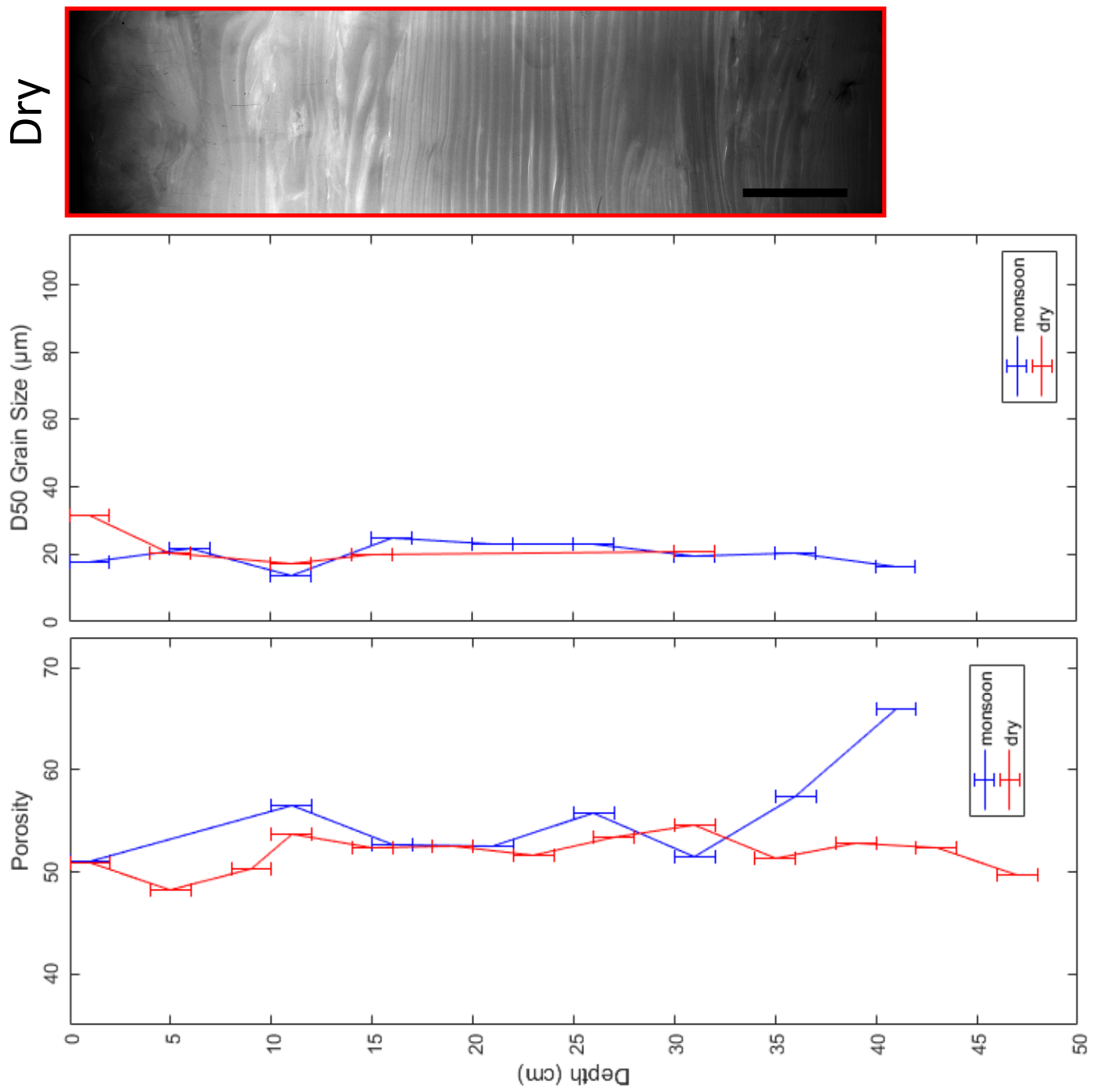

누 

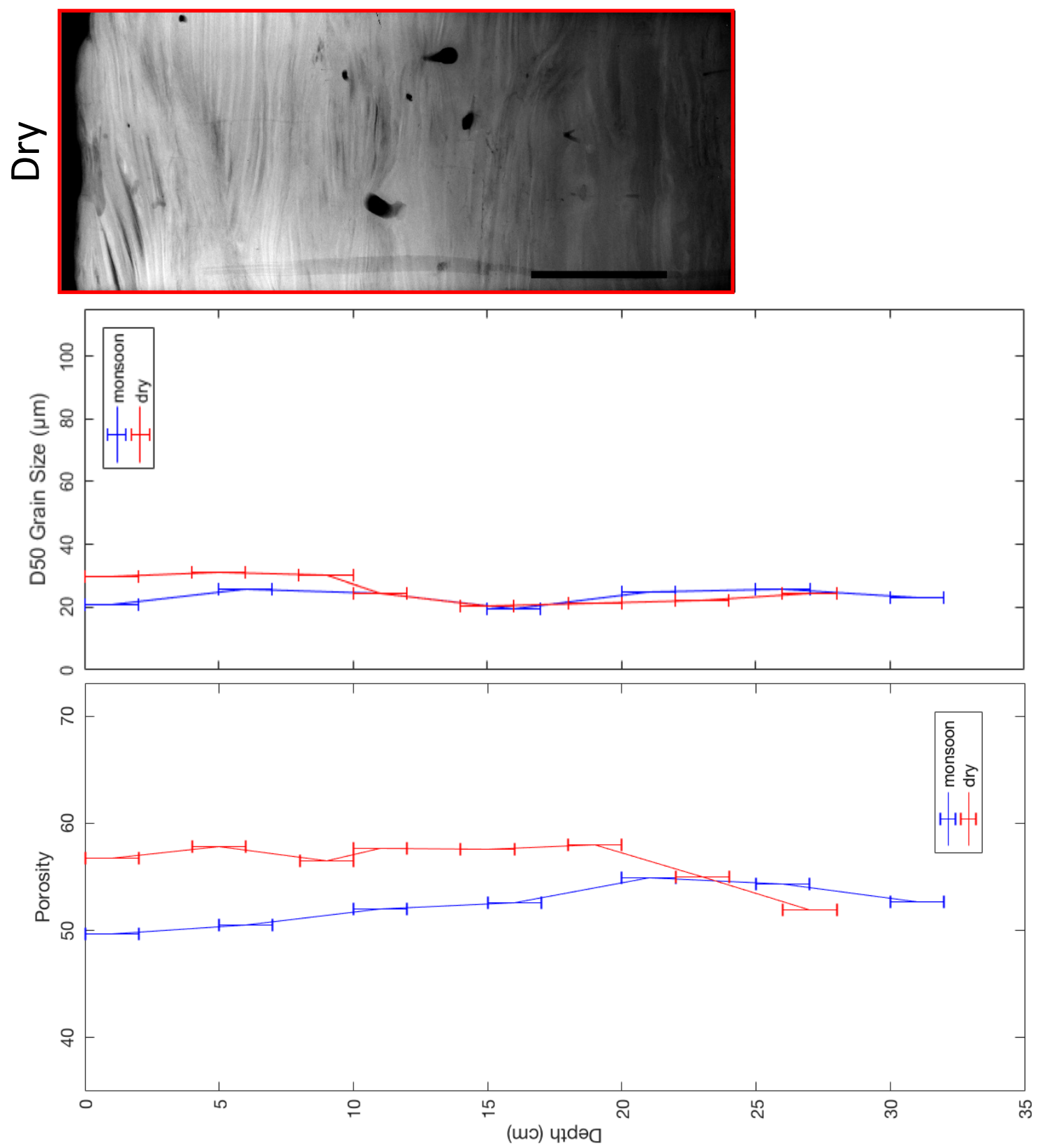

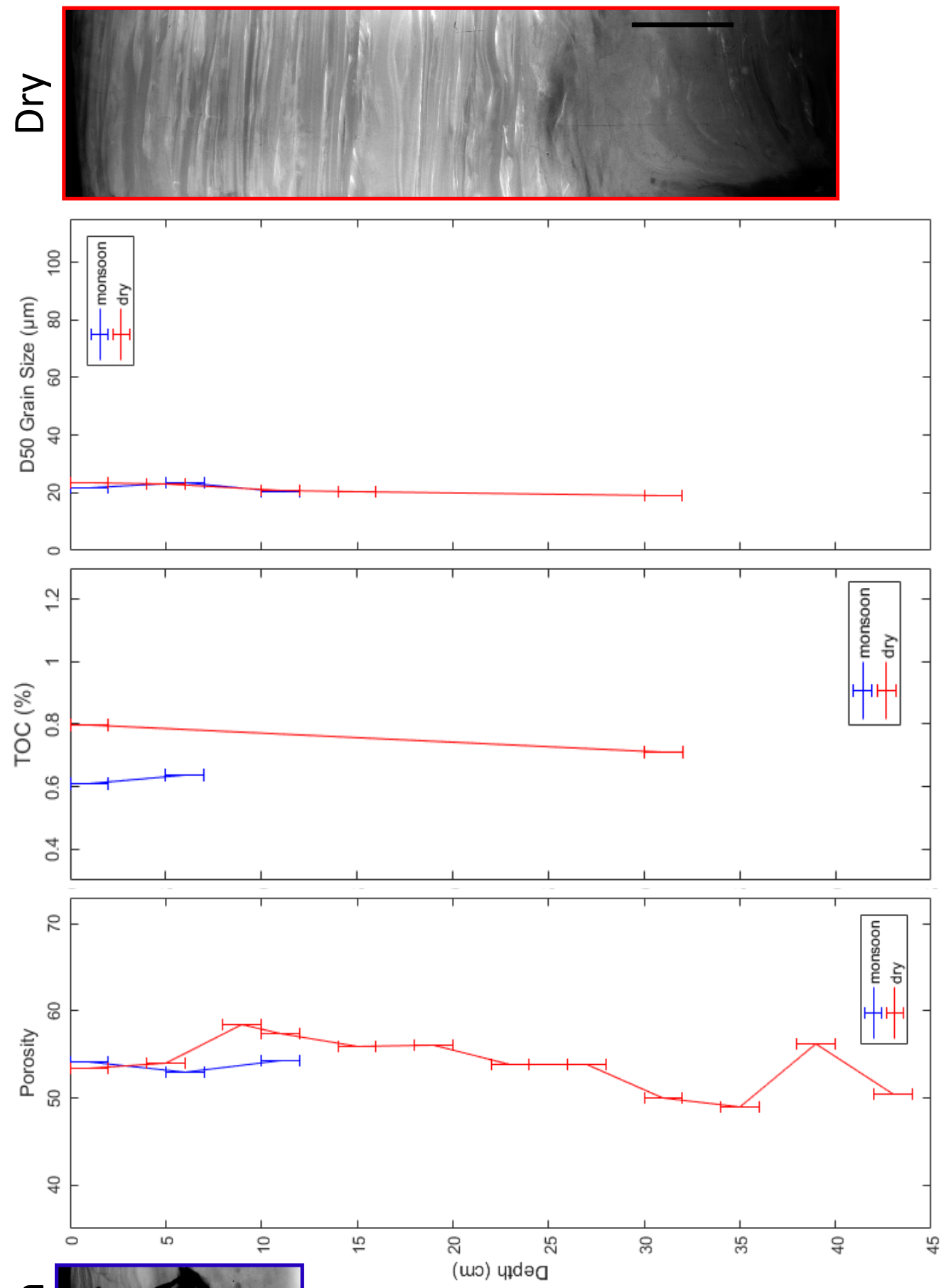

$\infty$
$\dot{1}$
$\frac{1}{\infty}$

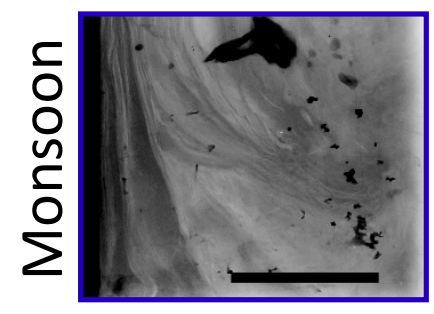



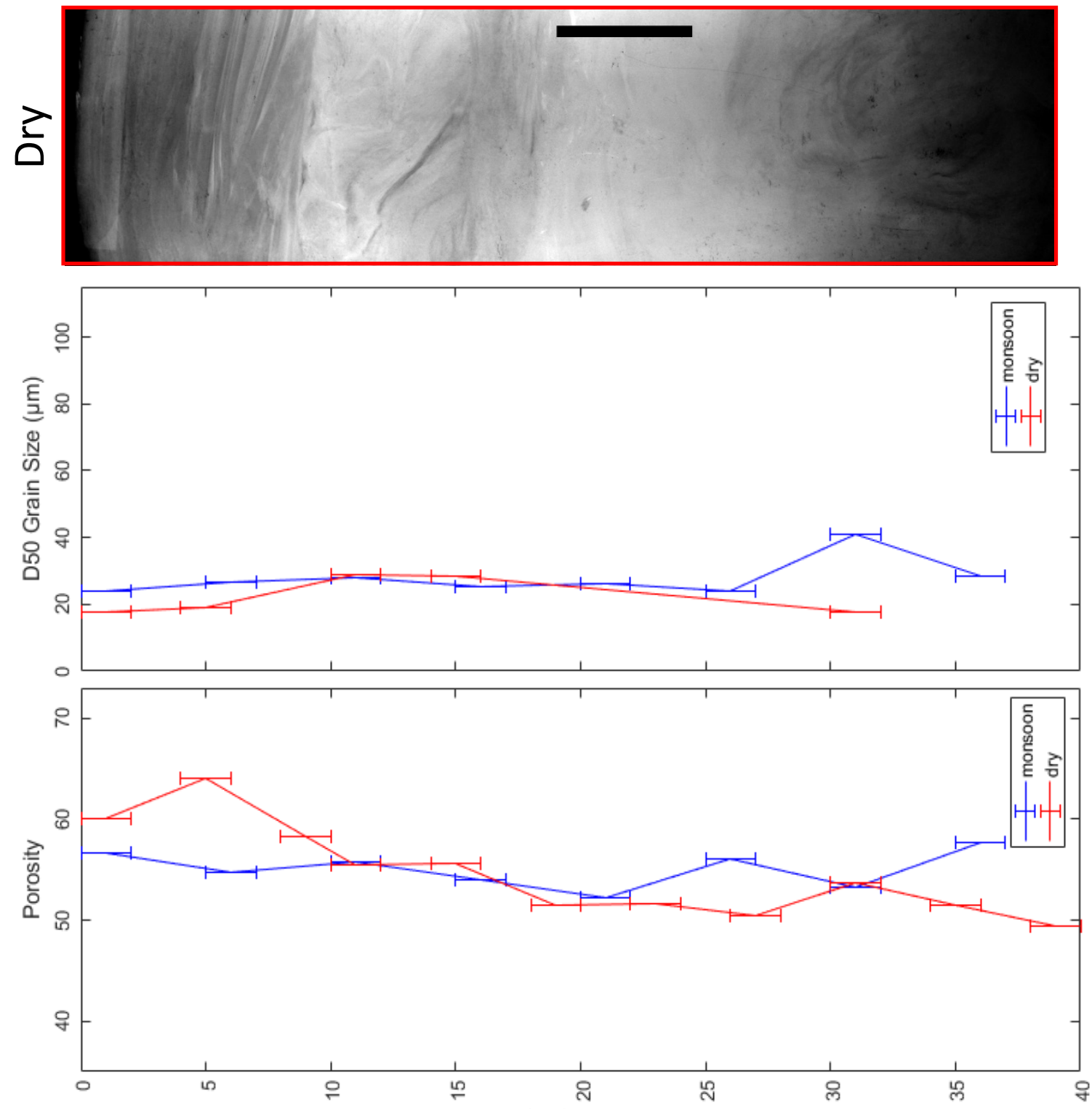

움

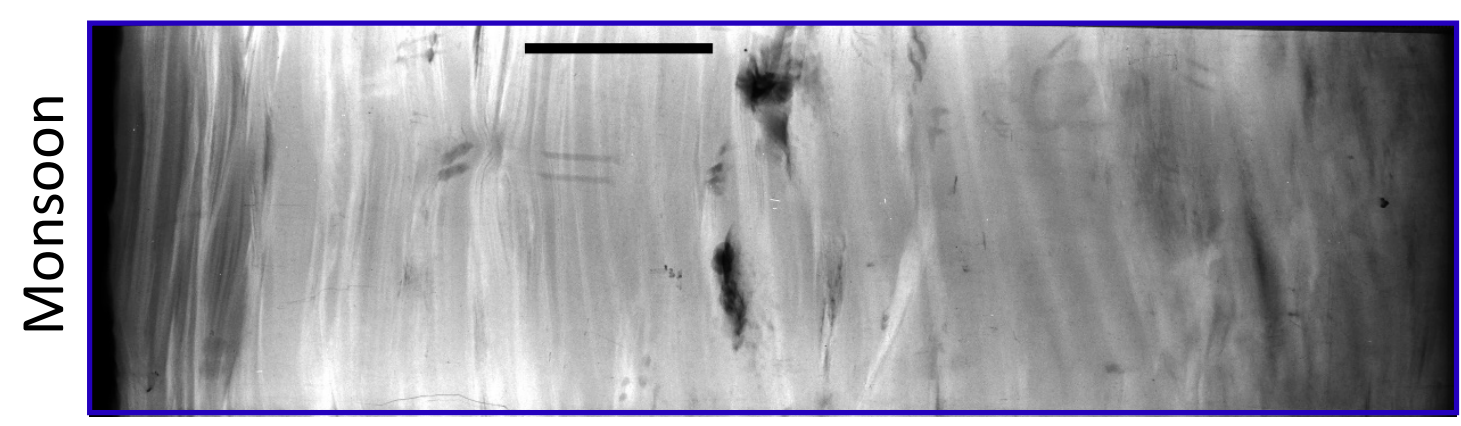



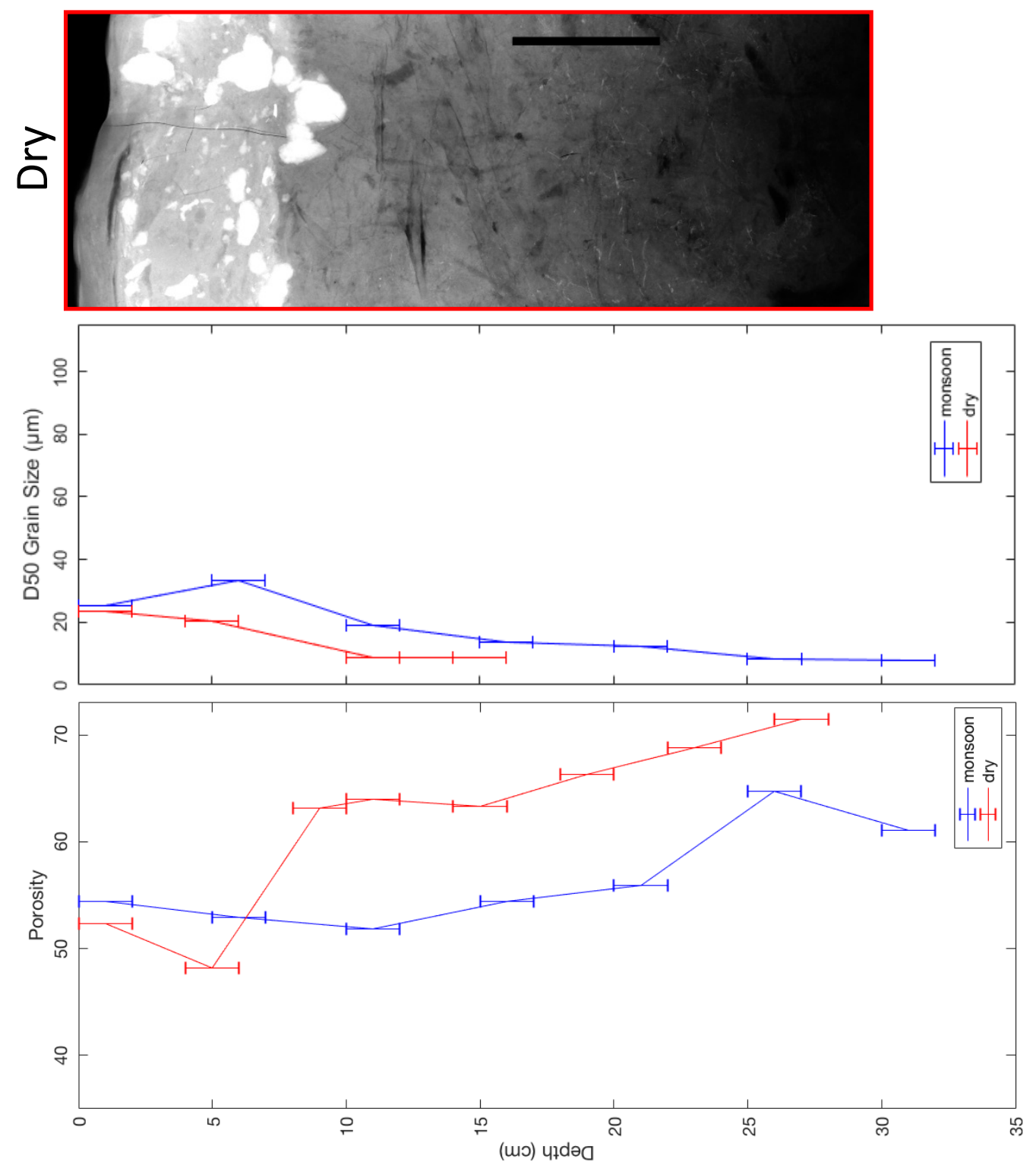

नr
$\frac{1}{\infty}$

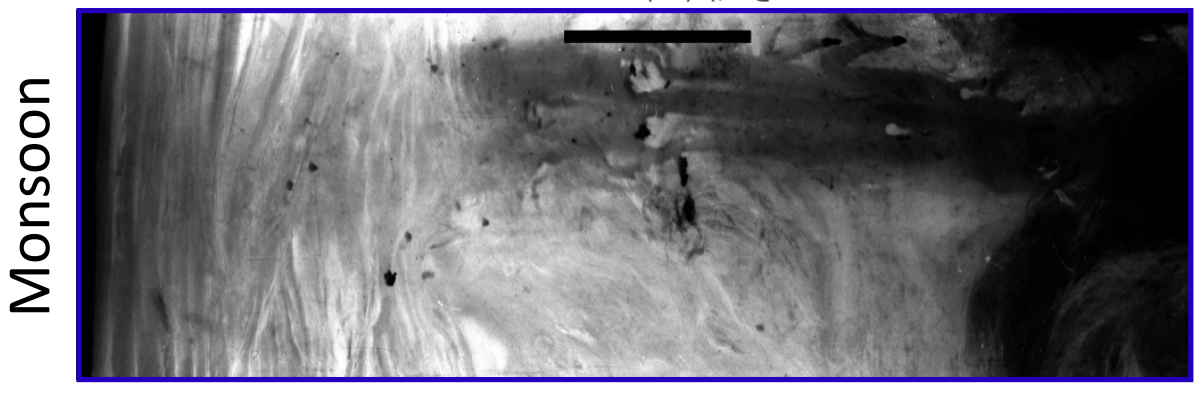



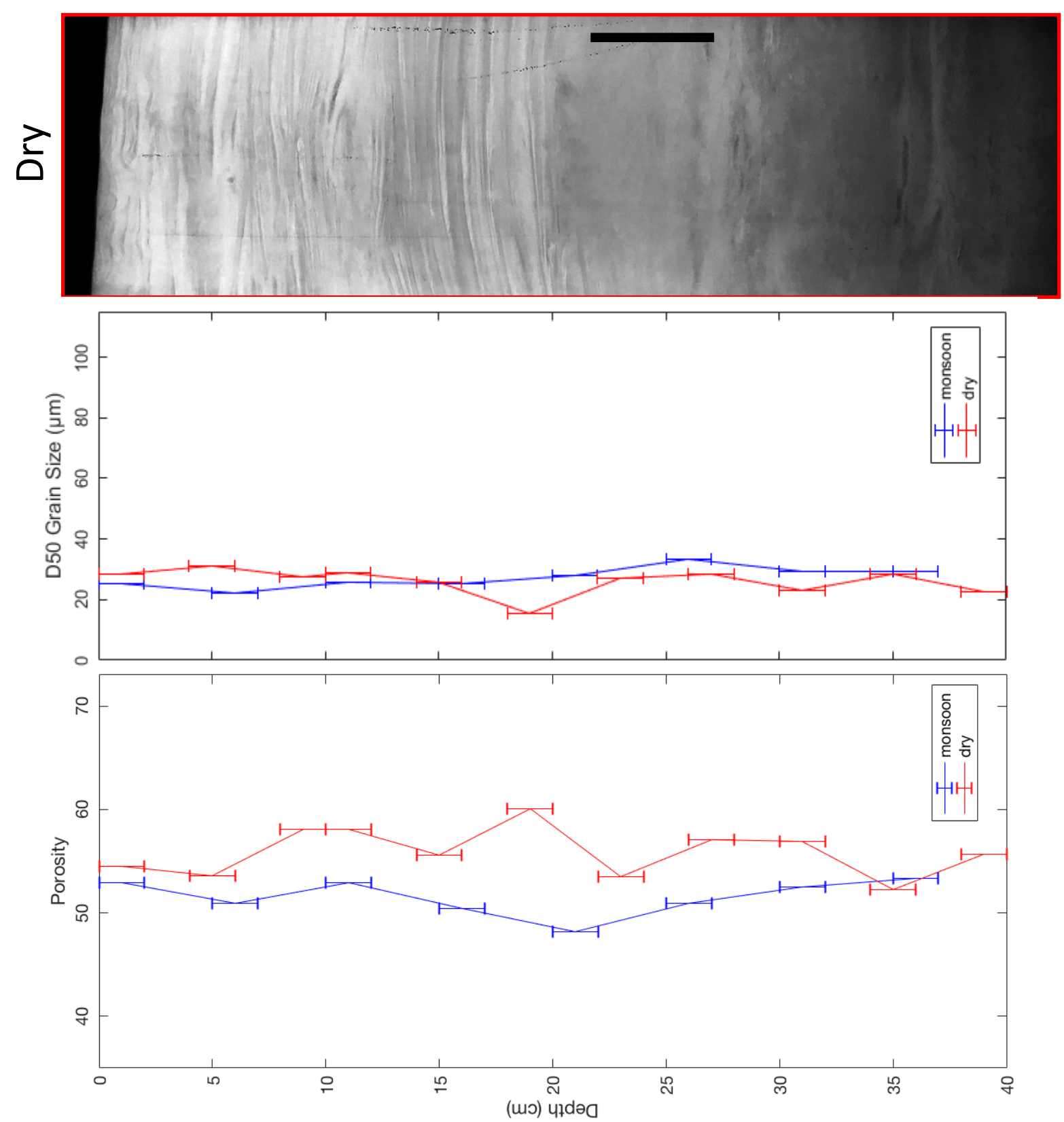

궁

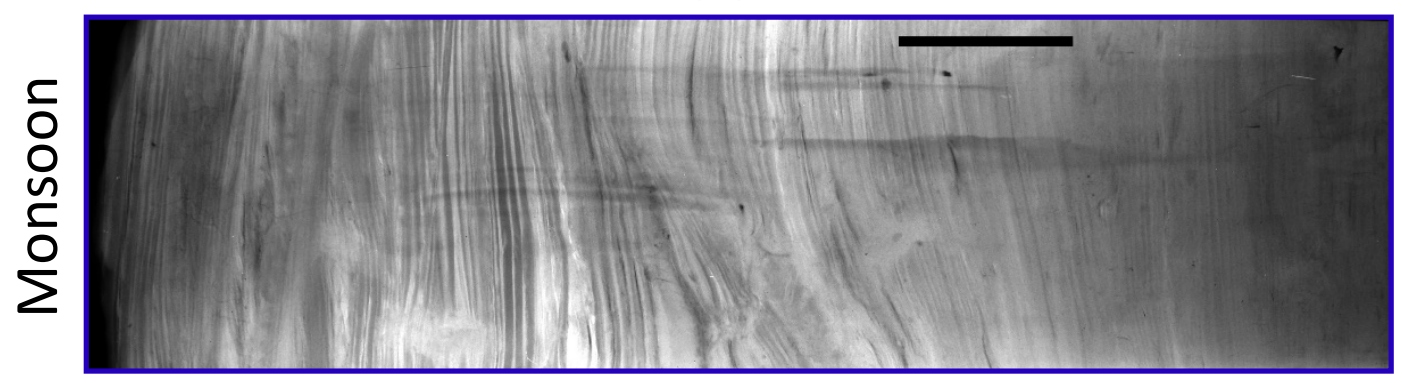



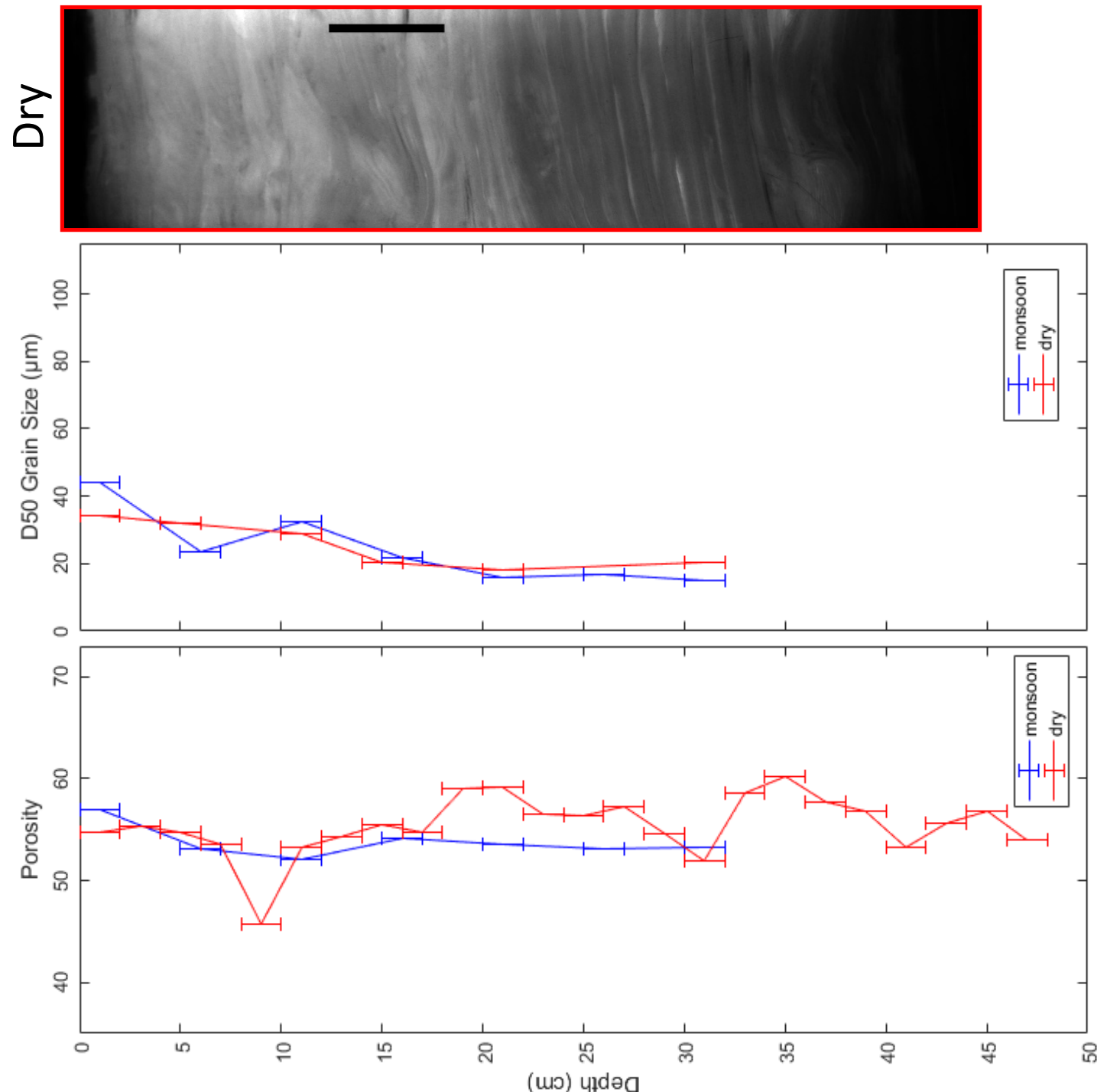

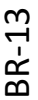

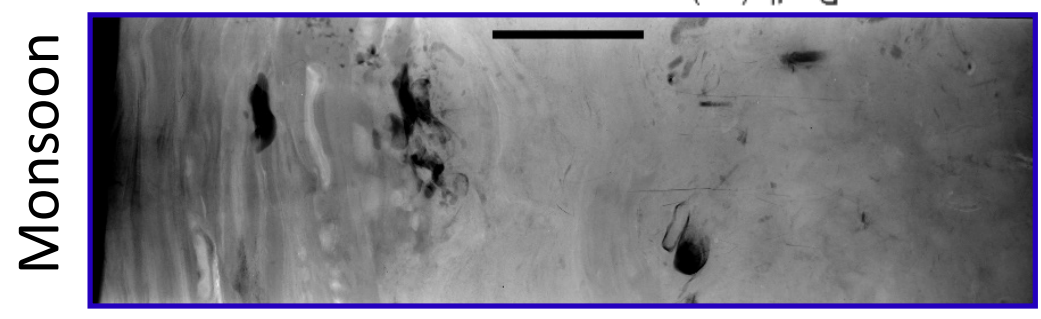



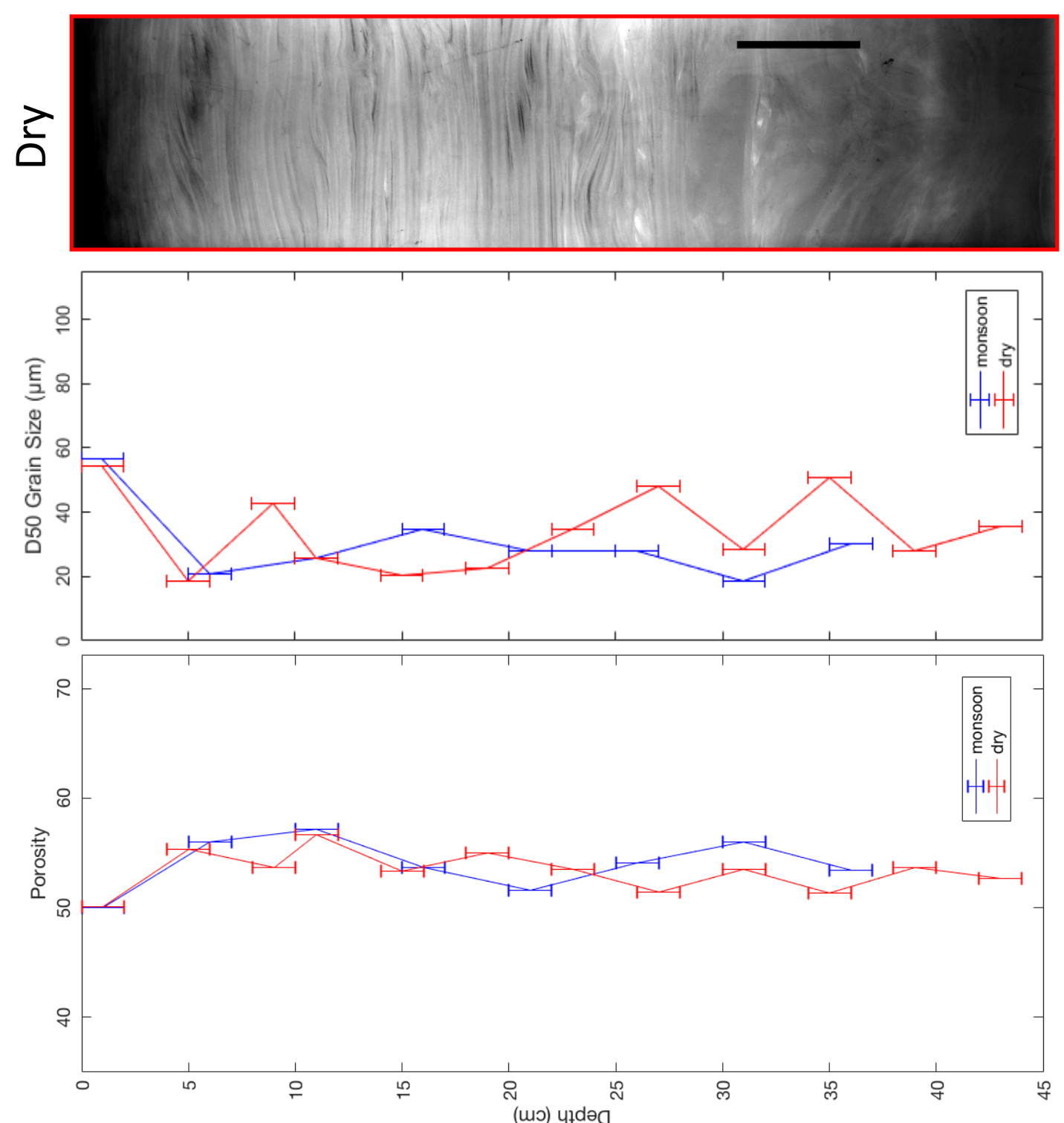

$\underset{\frac{1}{\infty}}{\stackrel{7}{0}}$

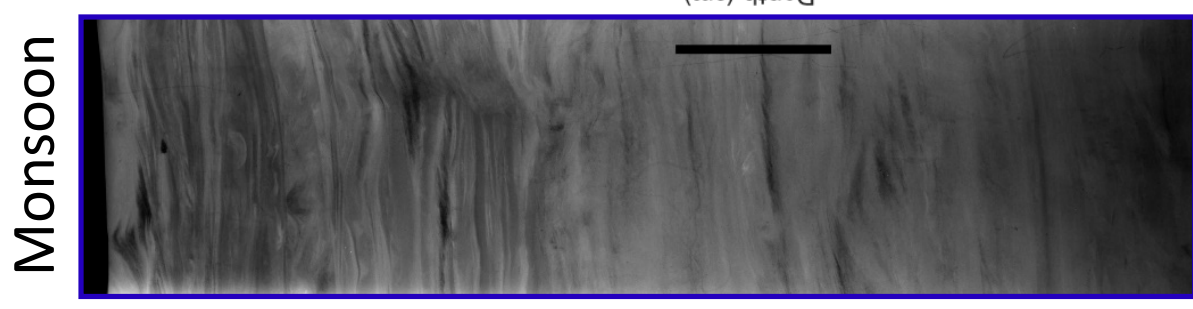



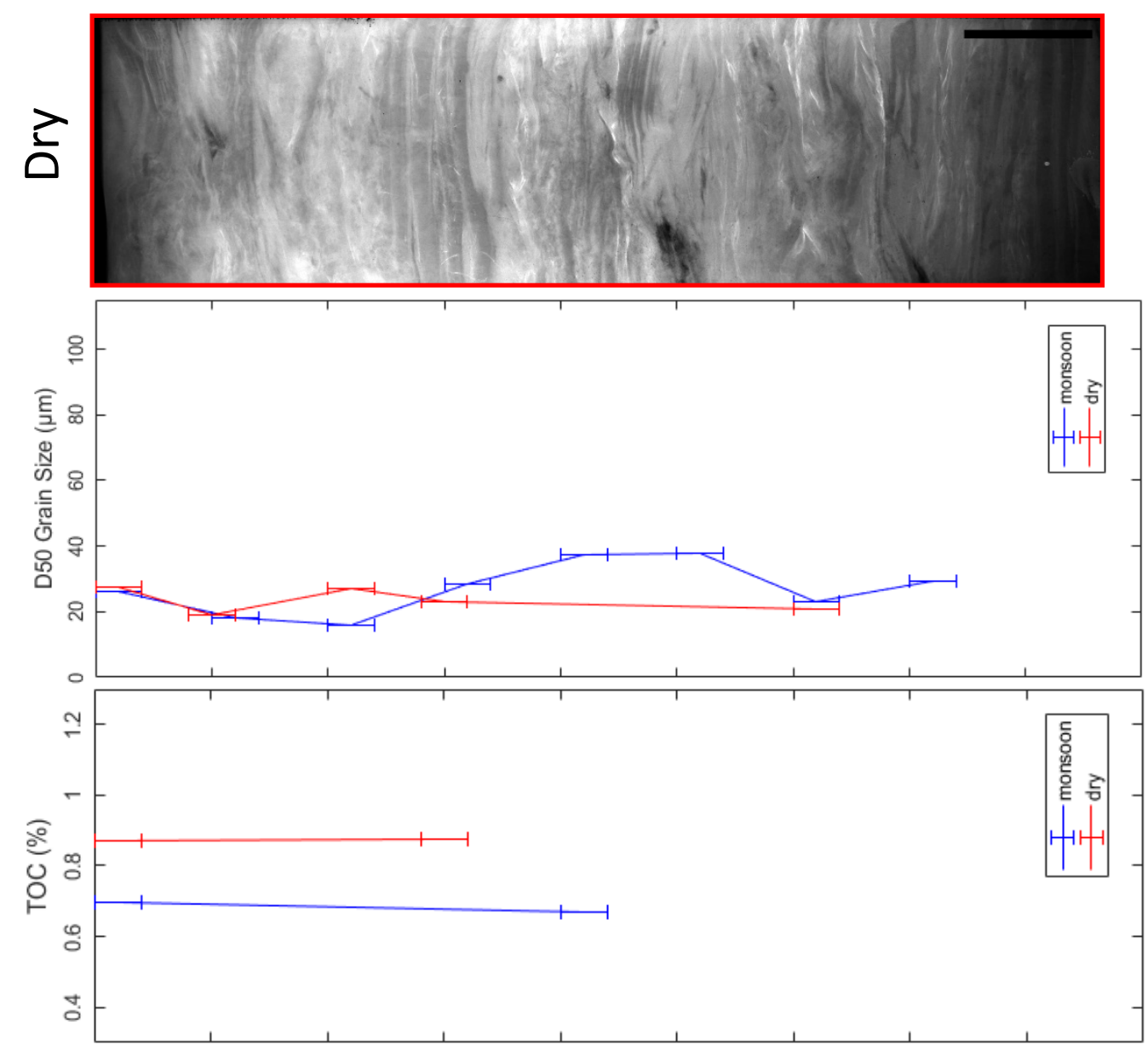

$\underset{\substack{n \\ \frac{1}{0}}}{\frac{n}{0}}$
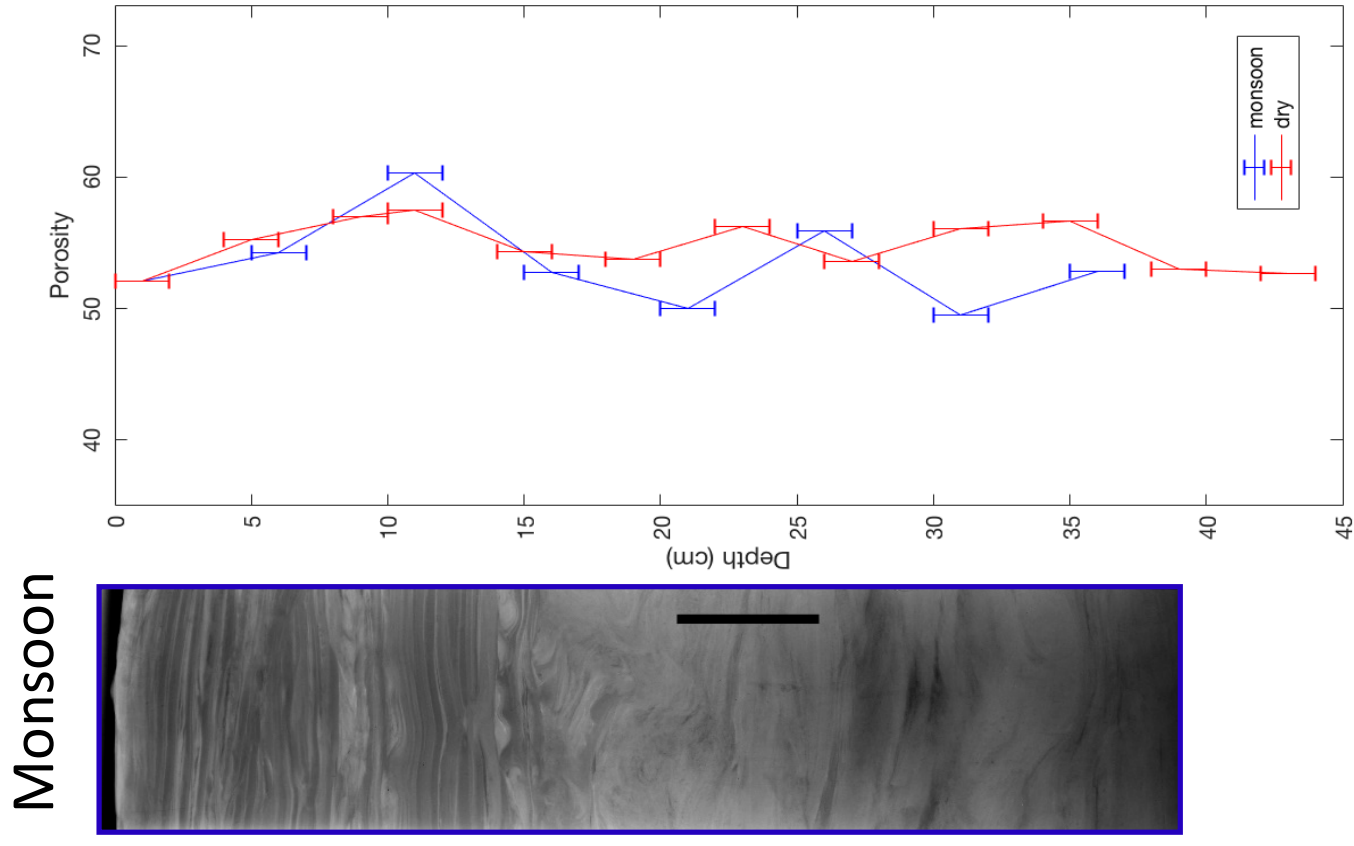

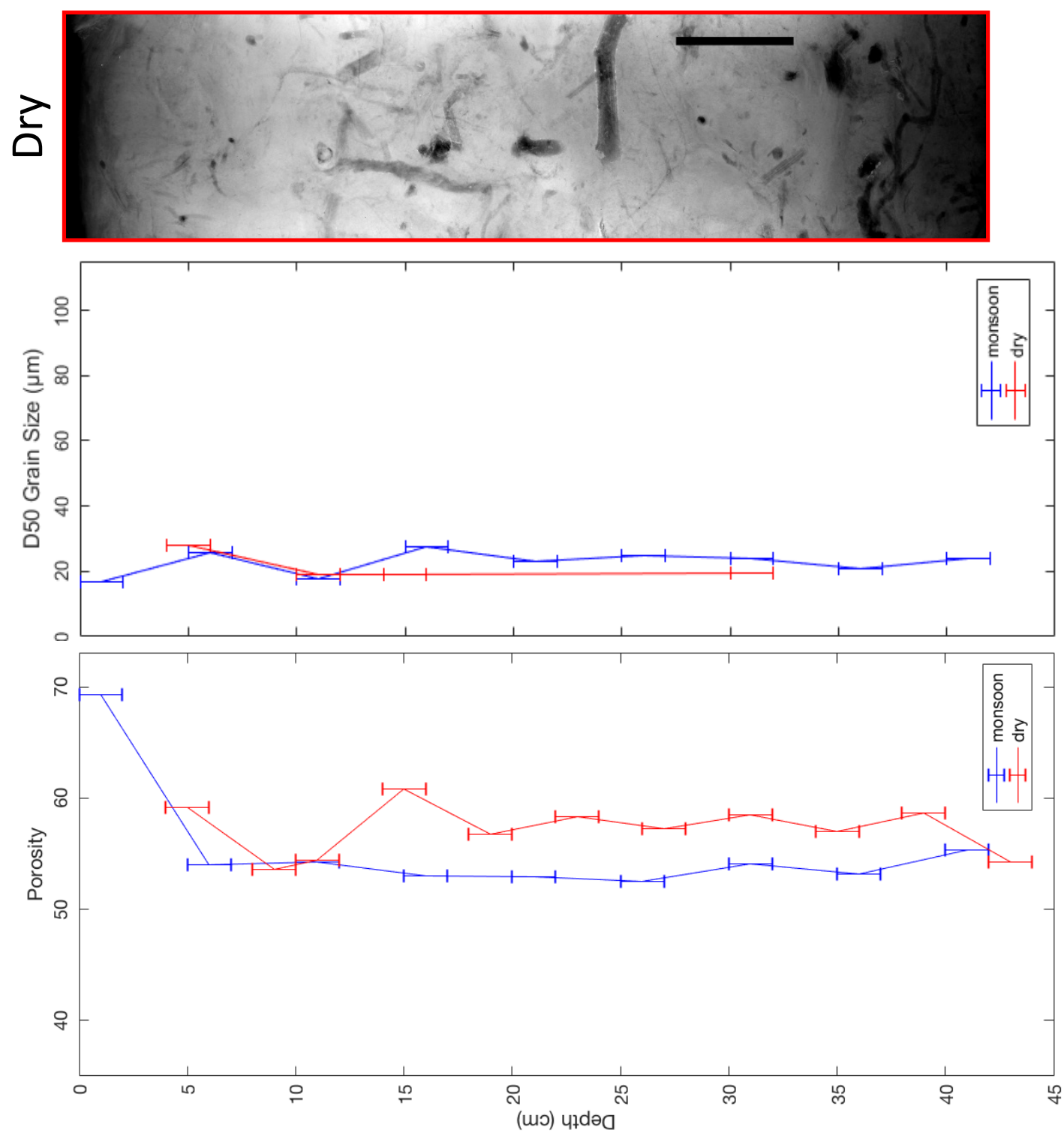

$\frac{0}{1}$
$\frac{1}{0}$

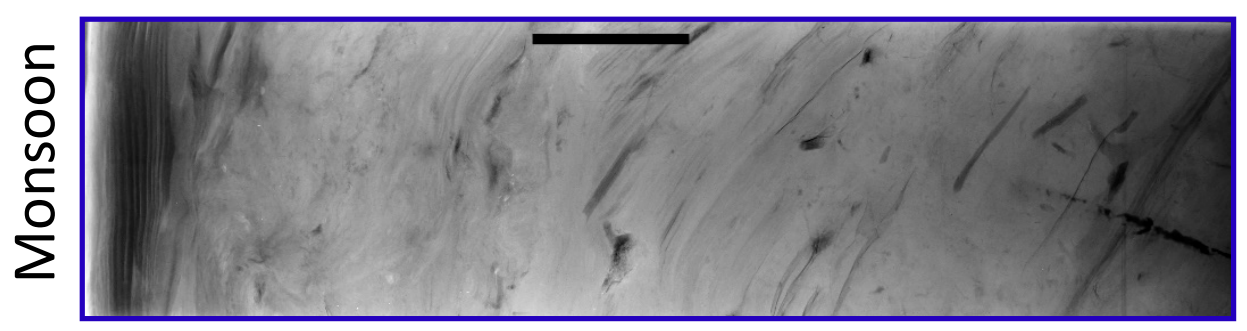



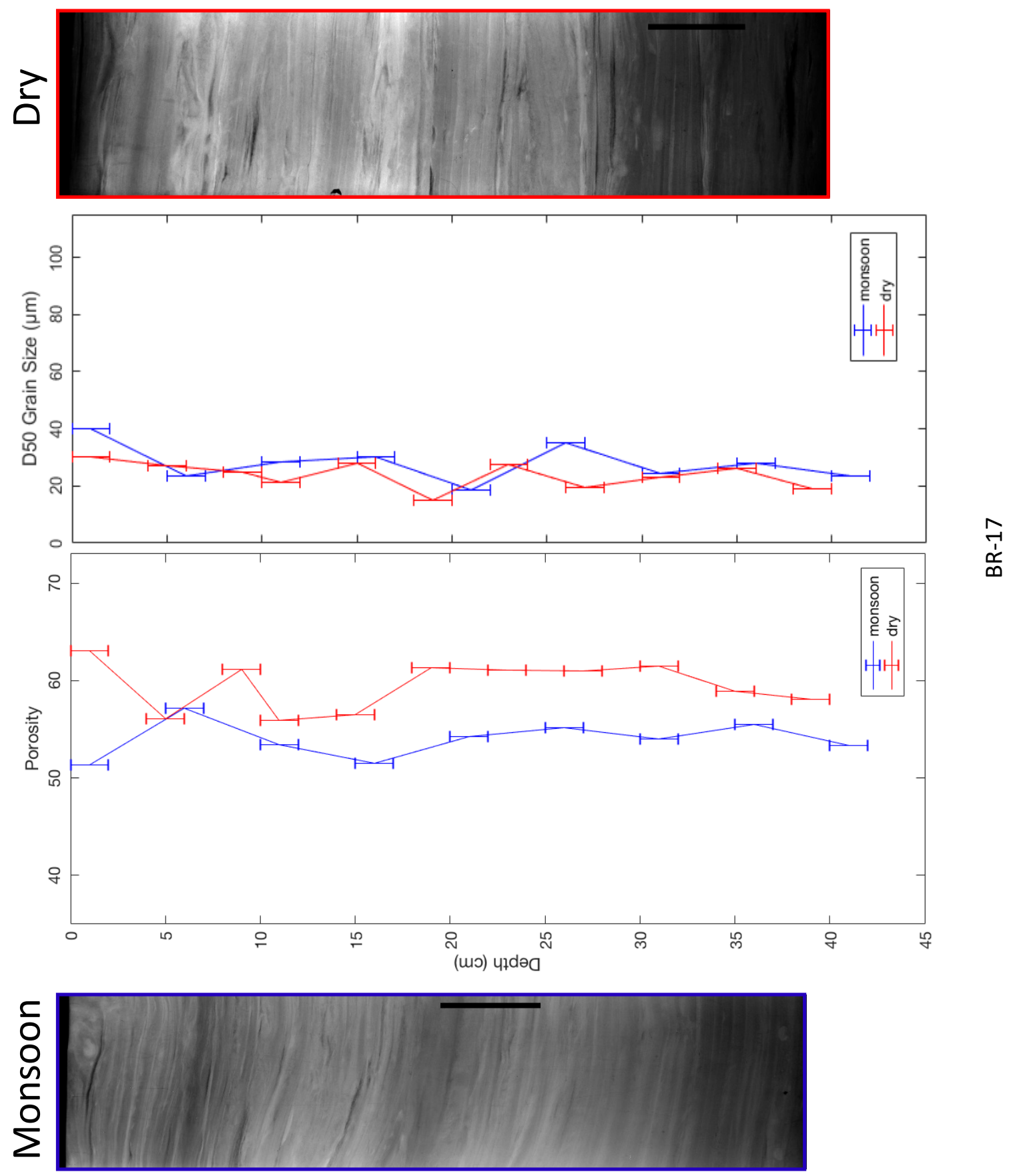

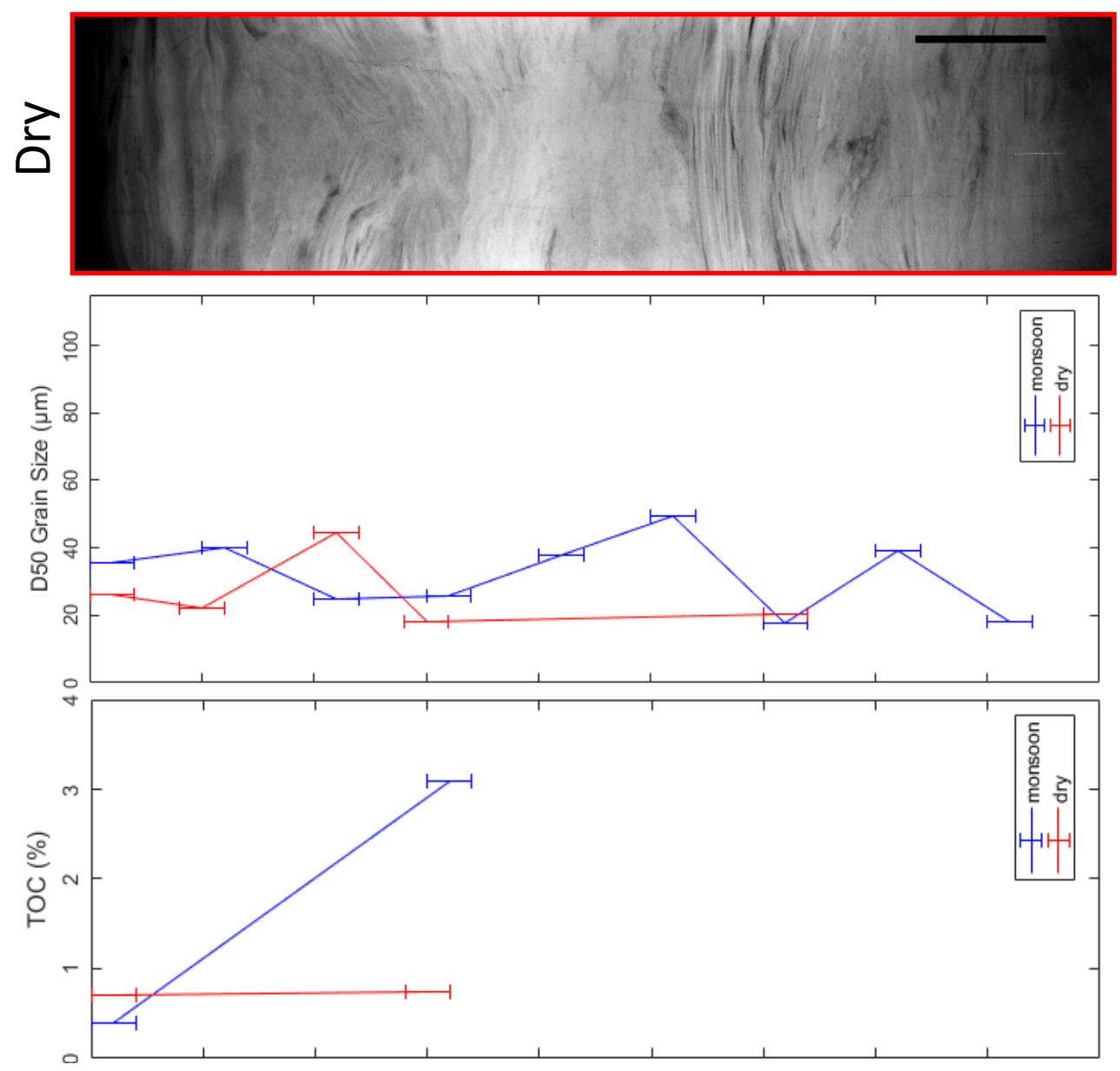

$\frac{\infty}{1}$
$\frac{1}{0}$
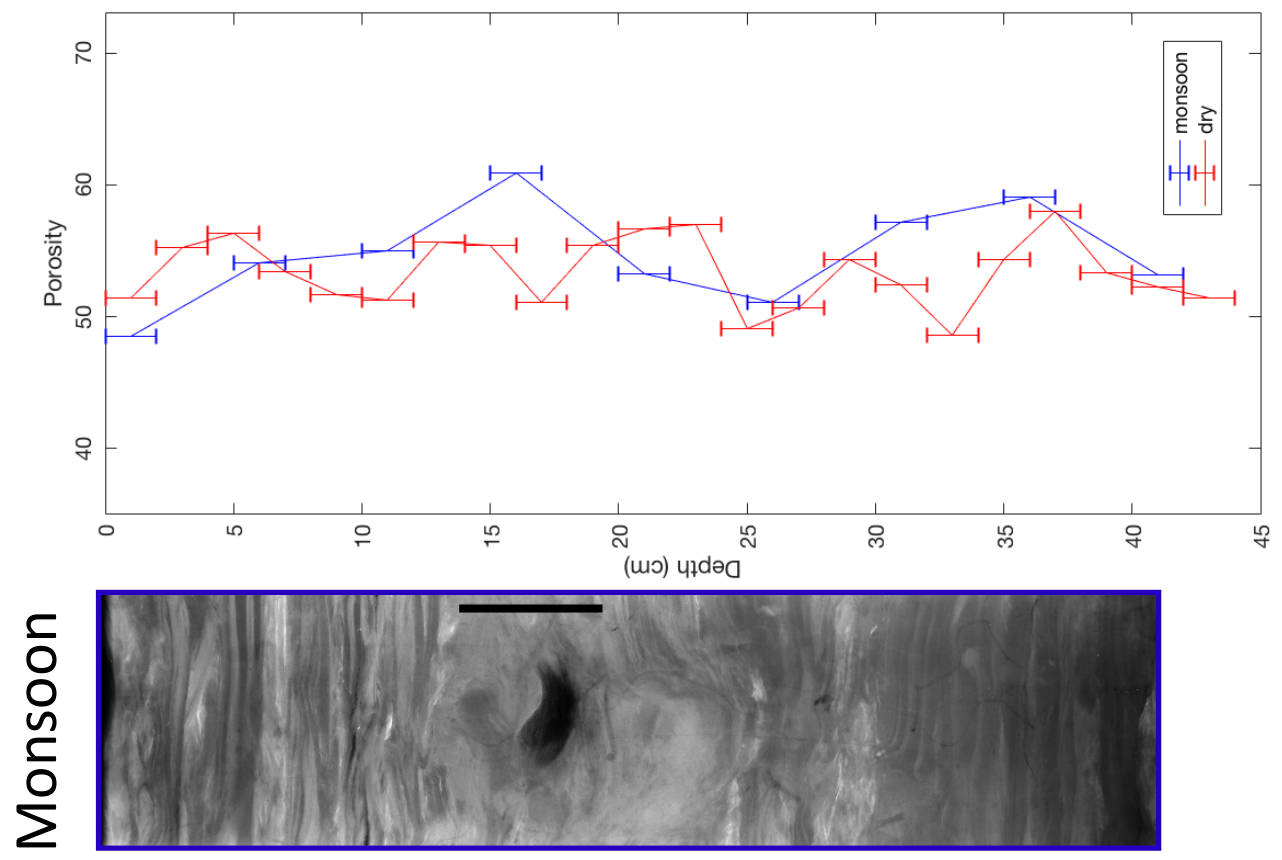

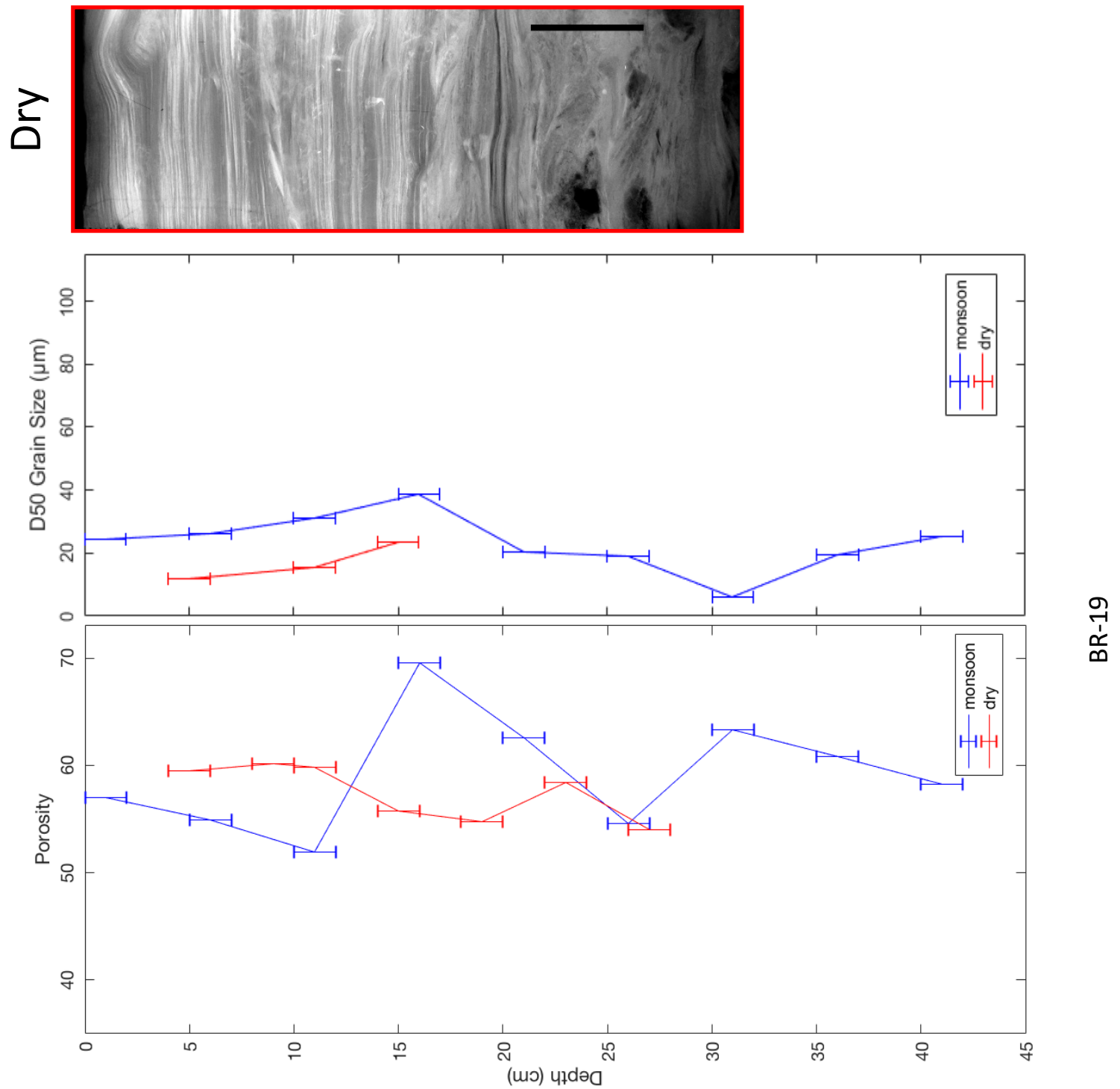

宛





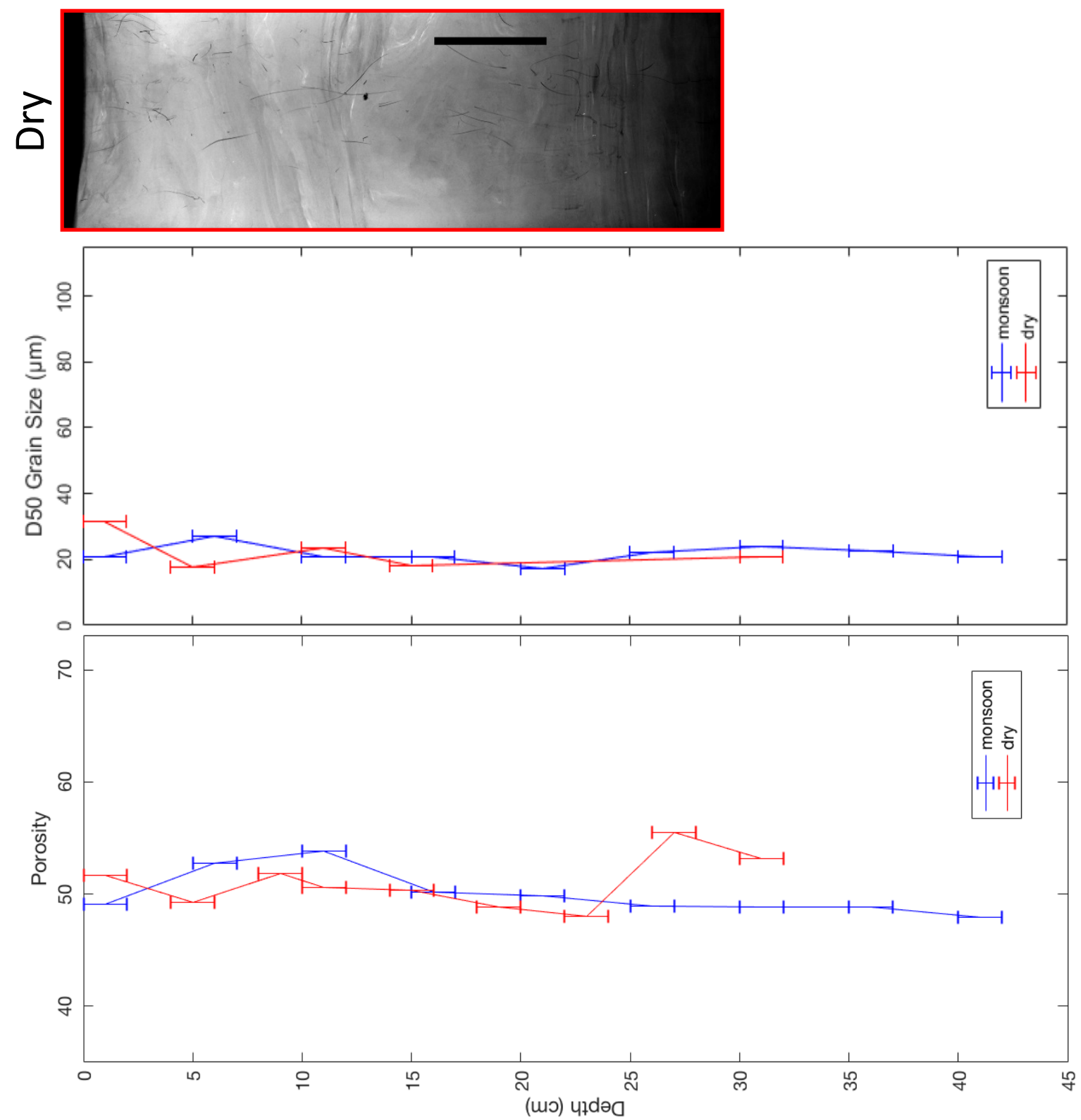

官 

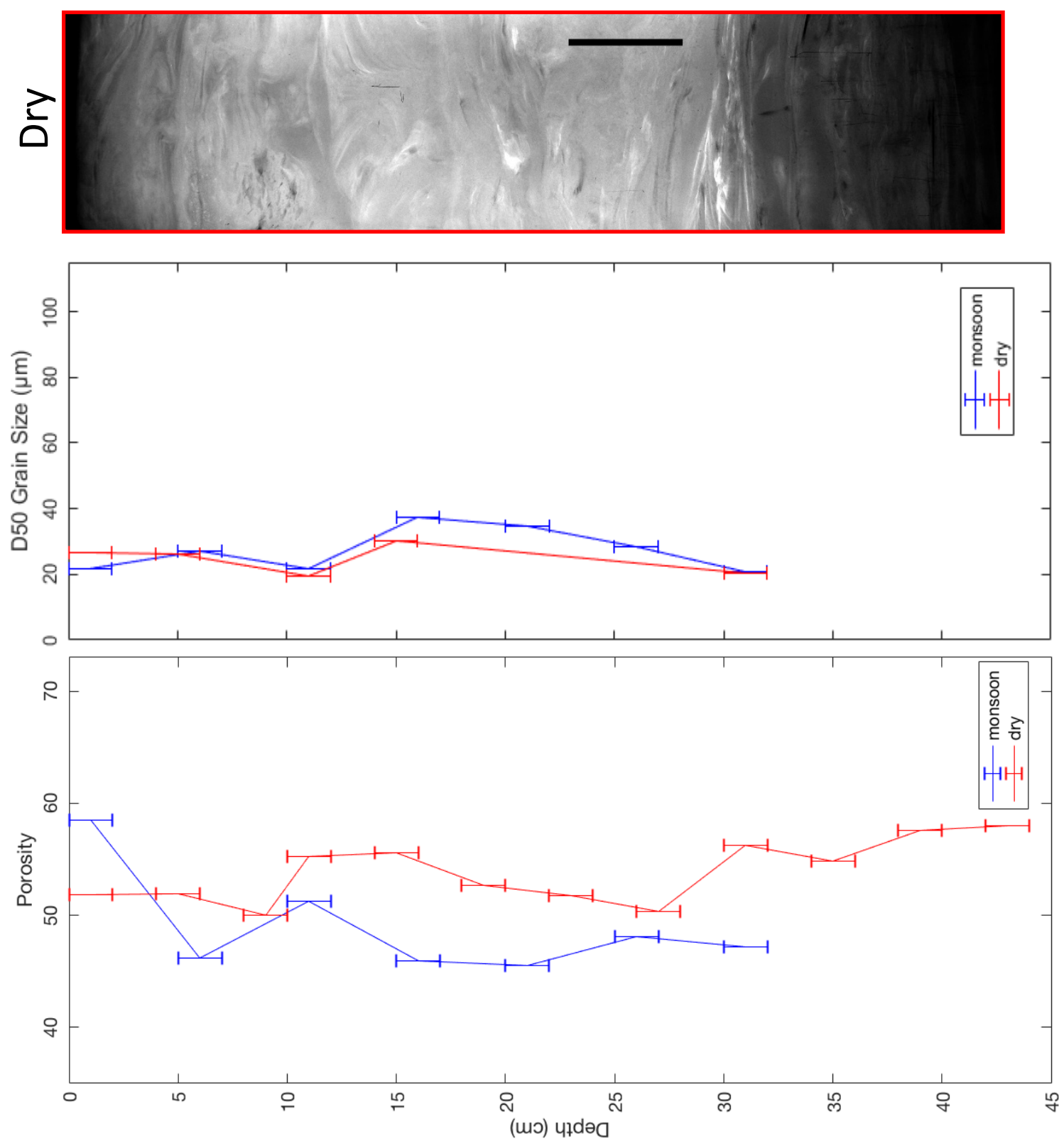

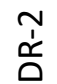



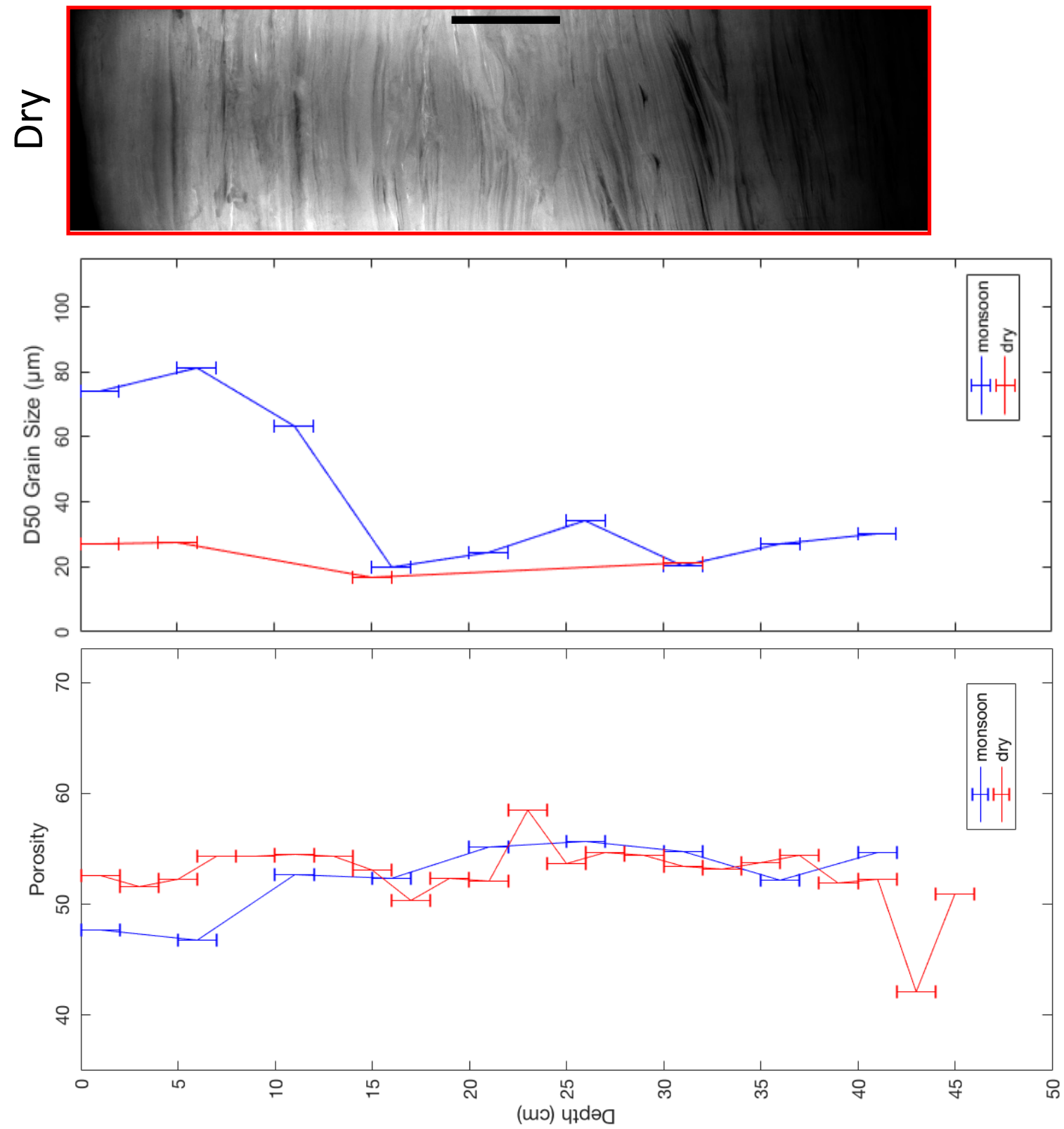

$m$
$\stackrel{1}{0}$

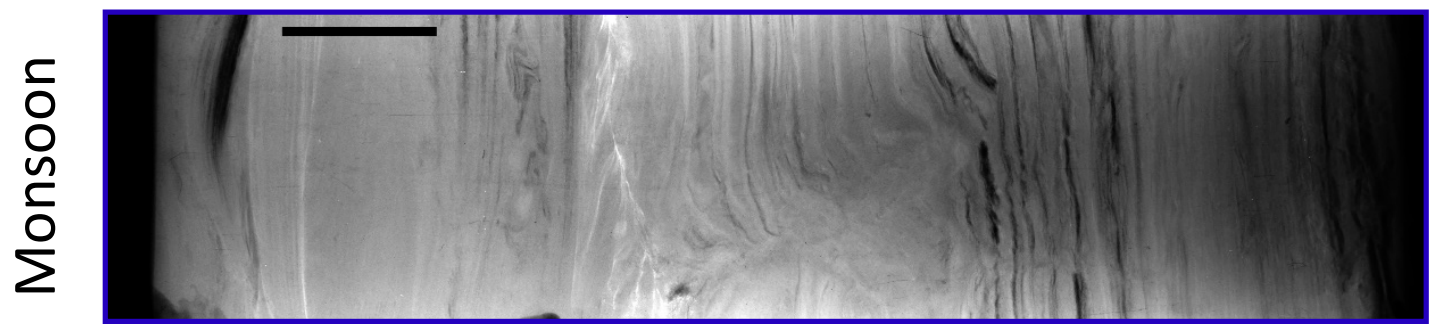



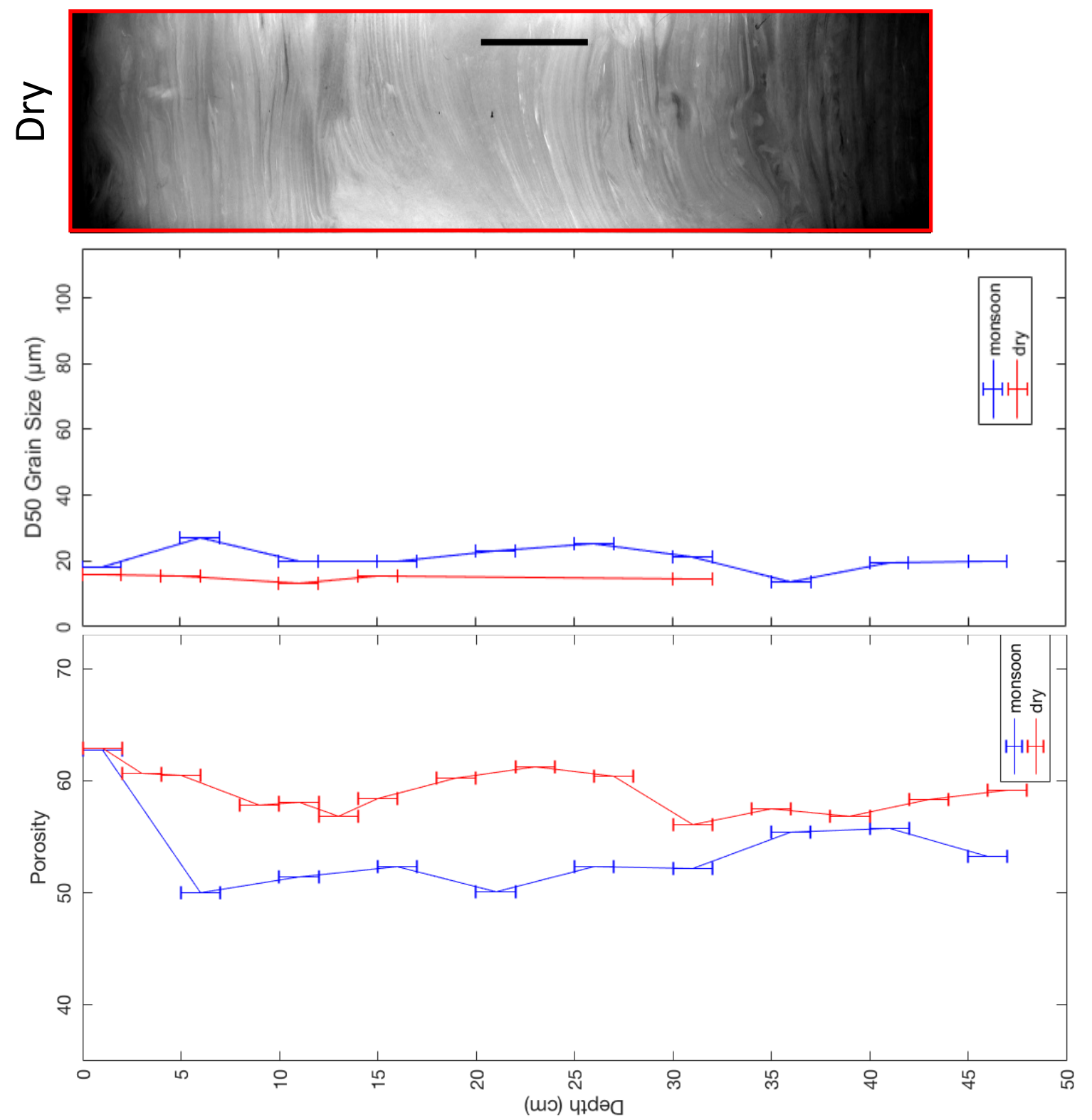

宊

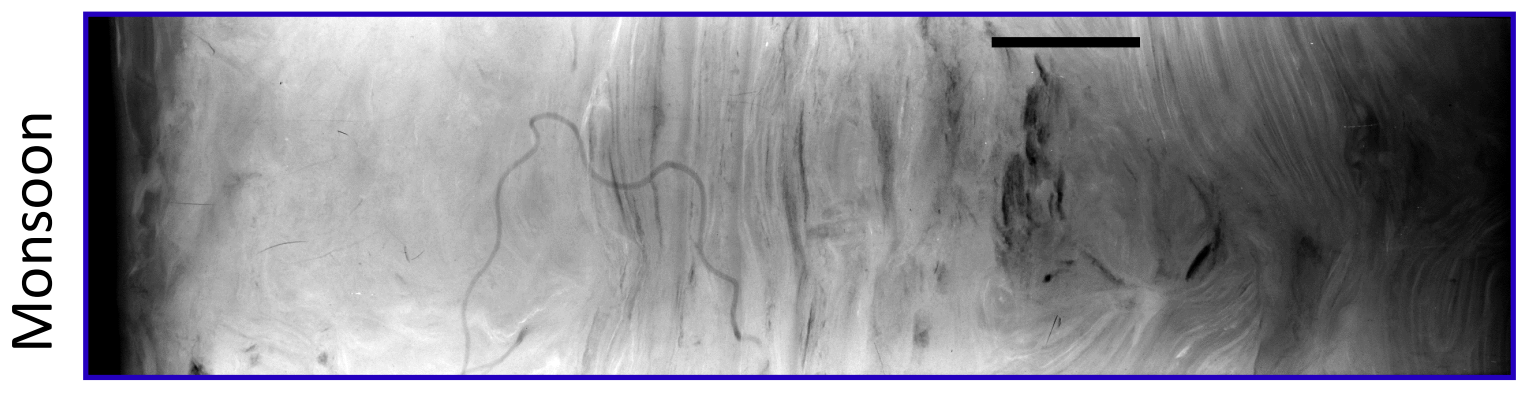





i
of

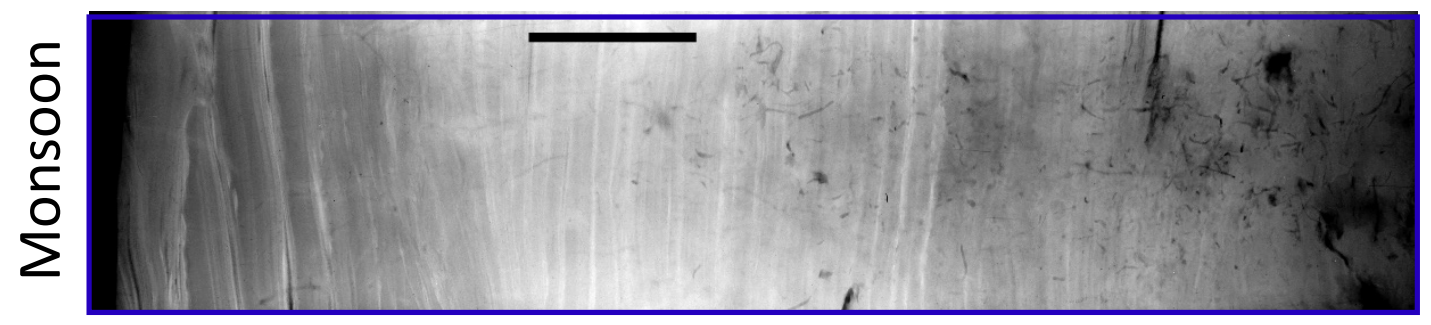



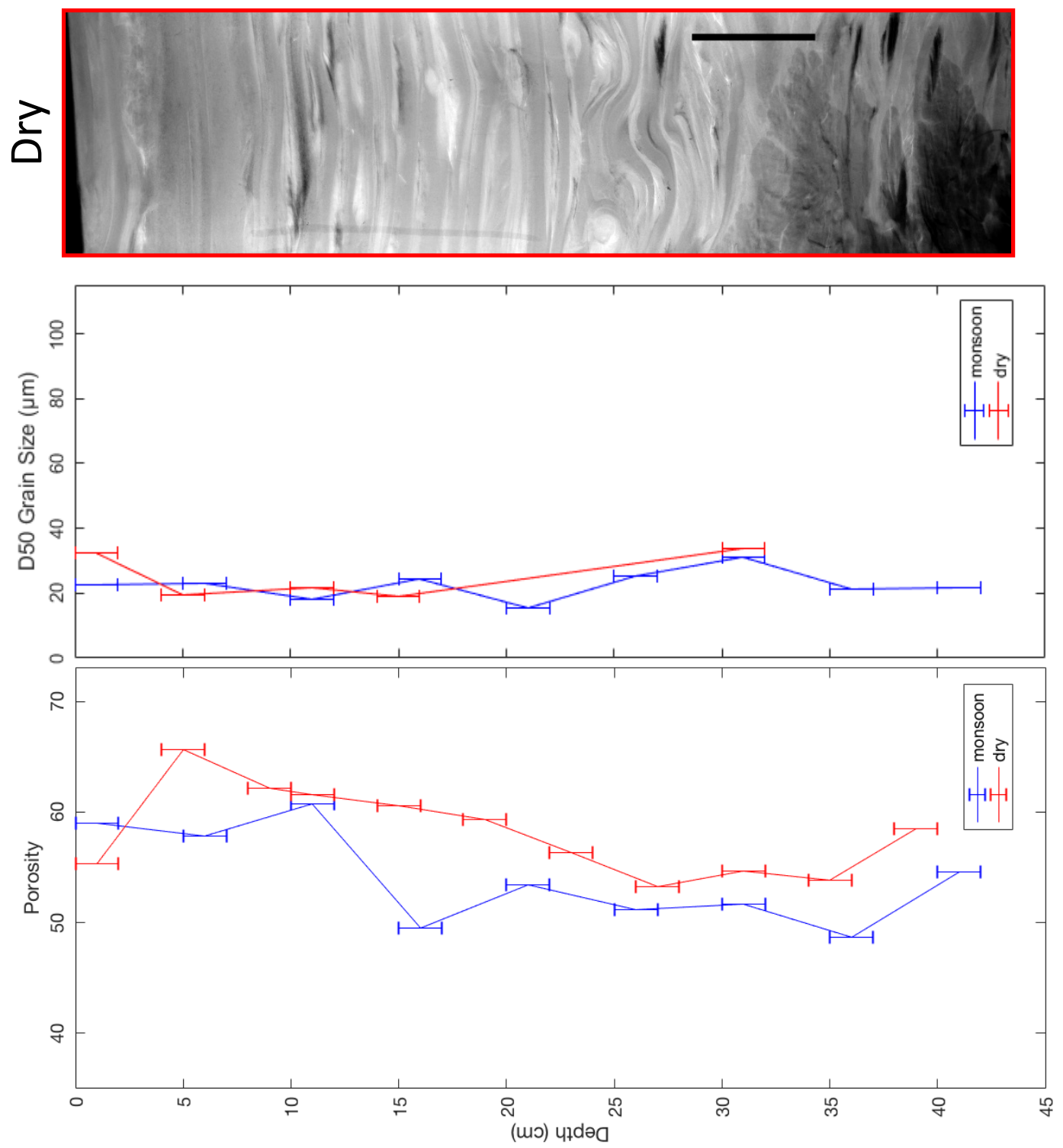

容

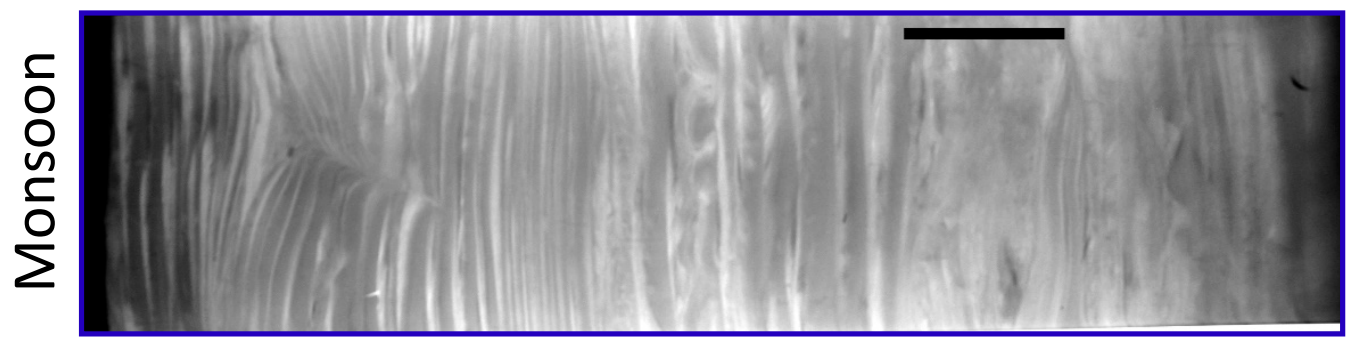



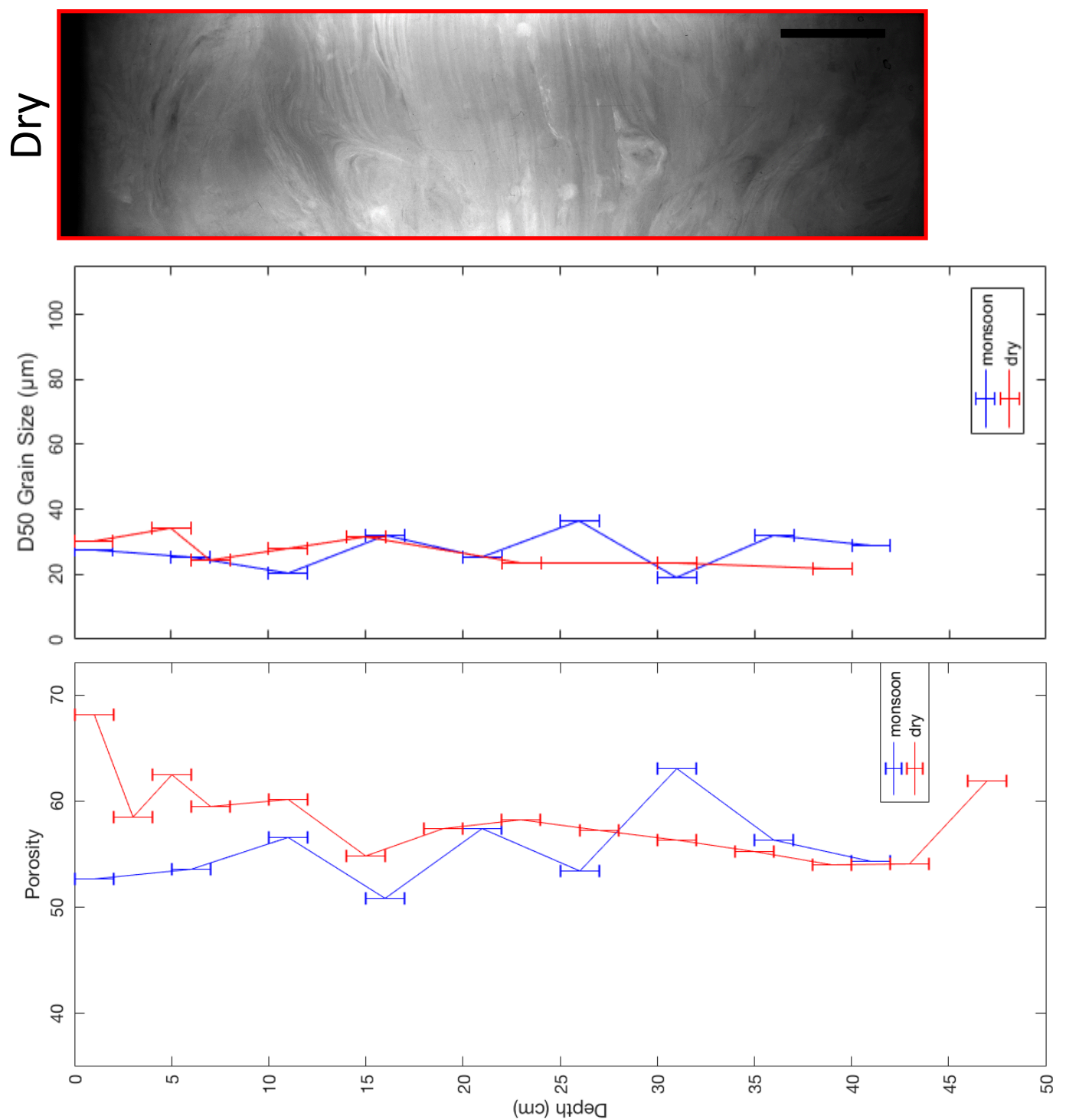

立

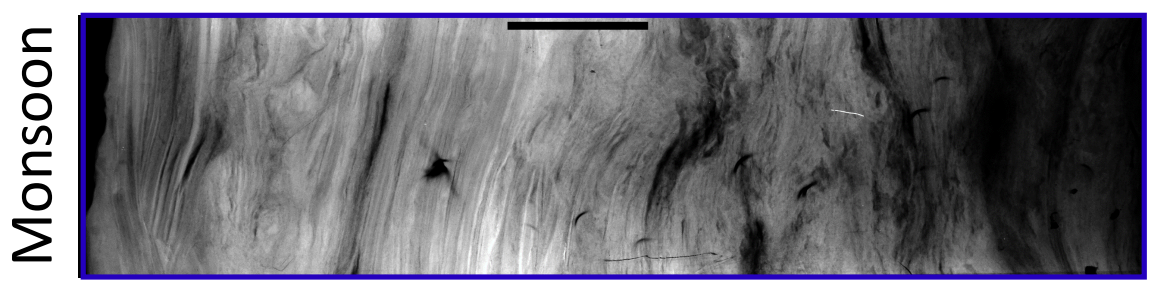



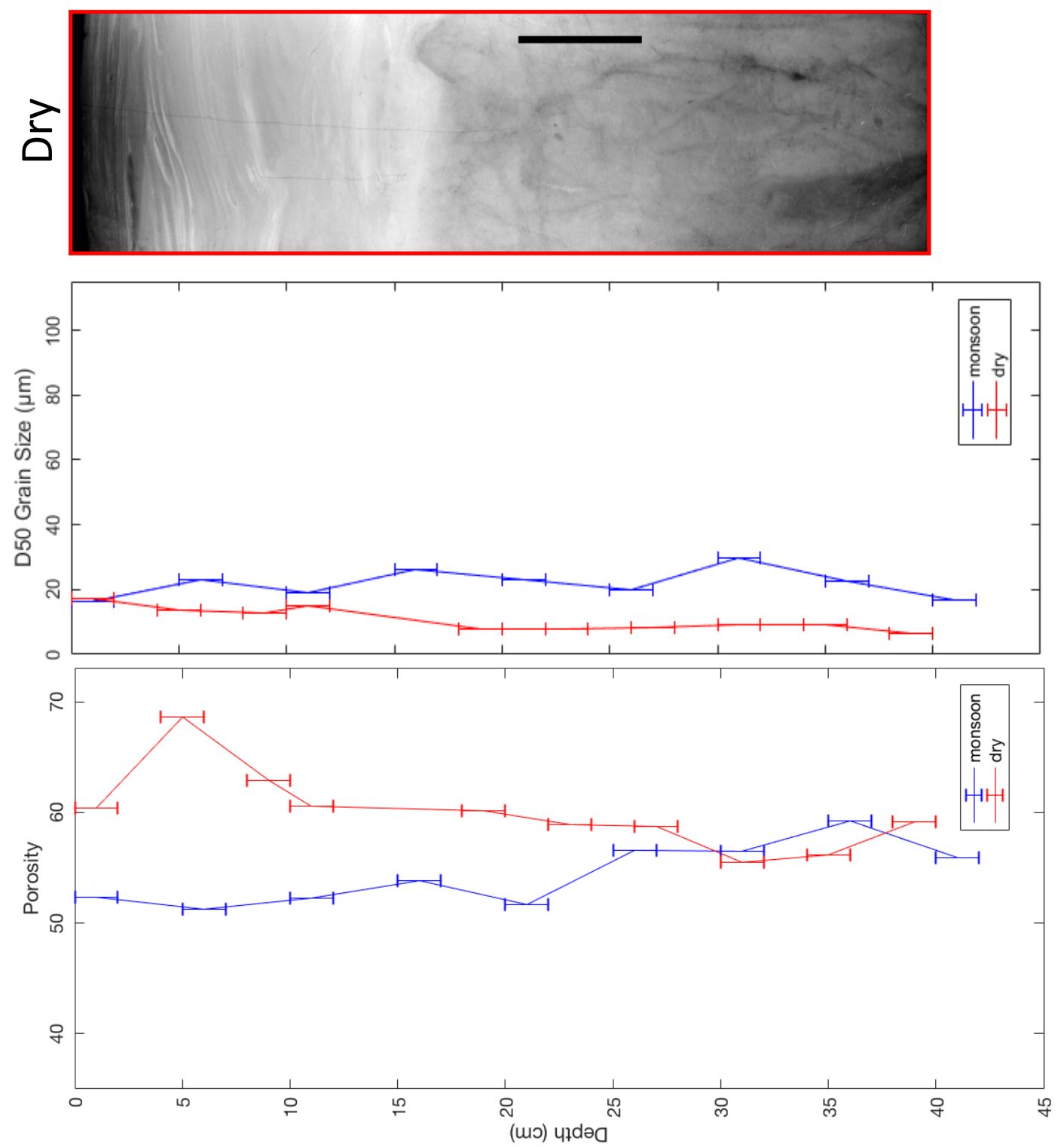

$\underset{n}{\mathfrak{1}}$

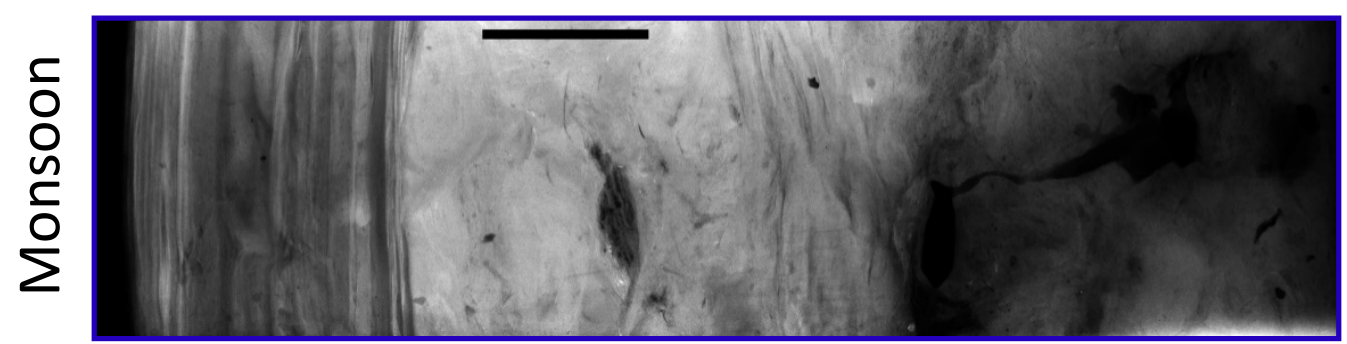



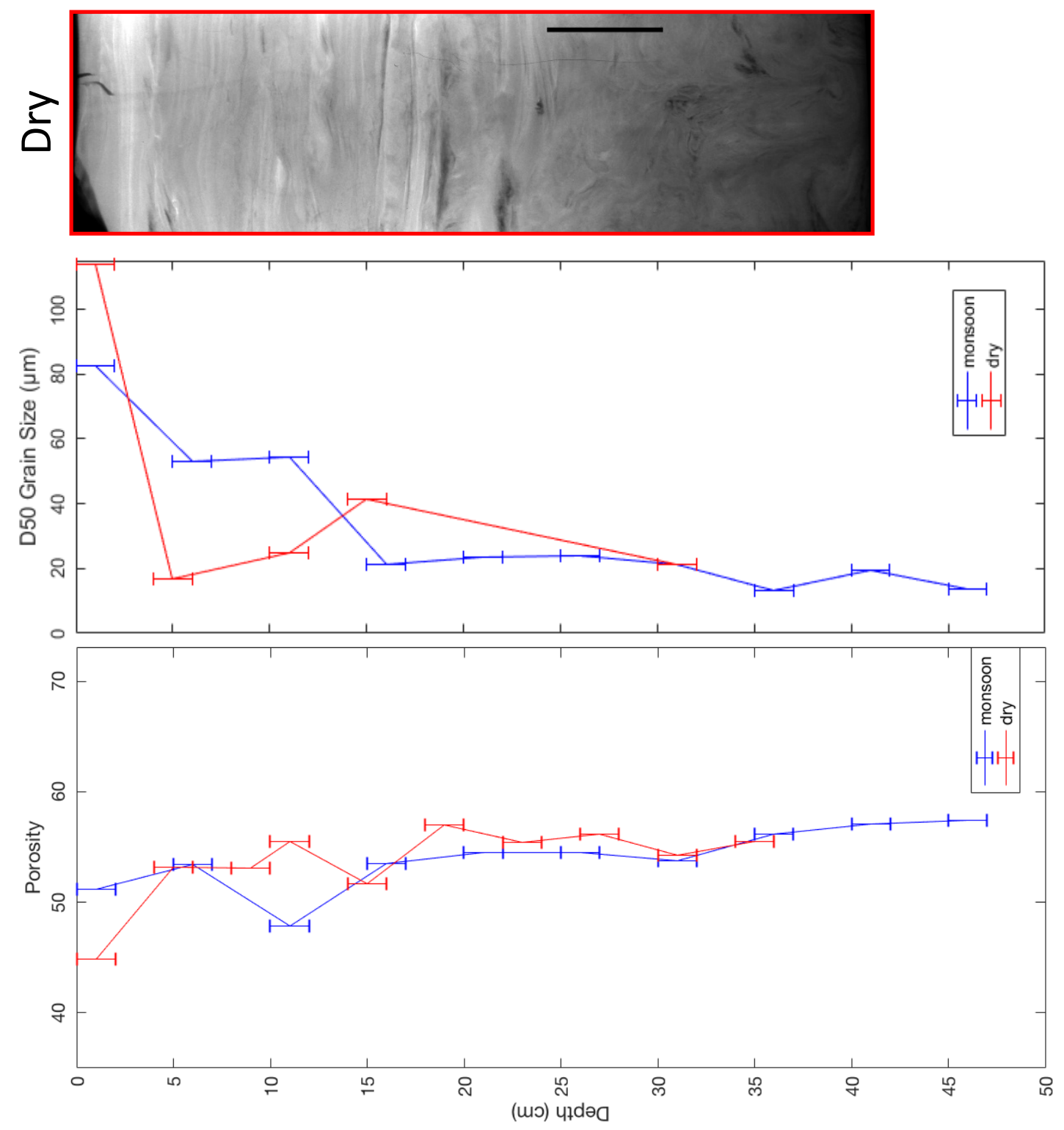

竞





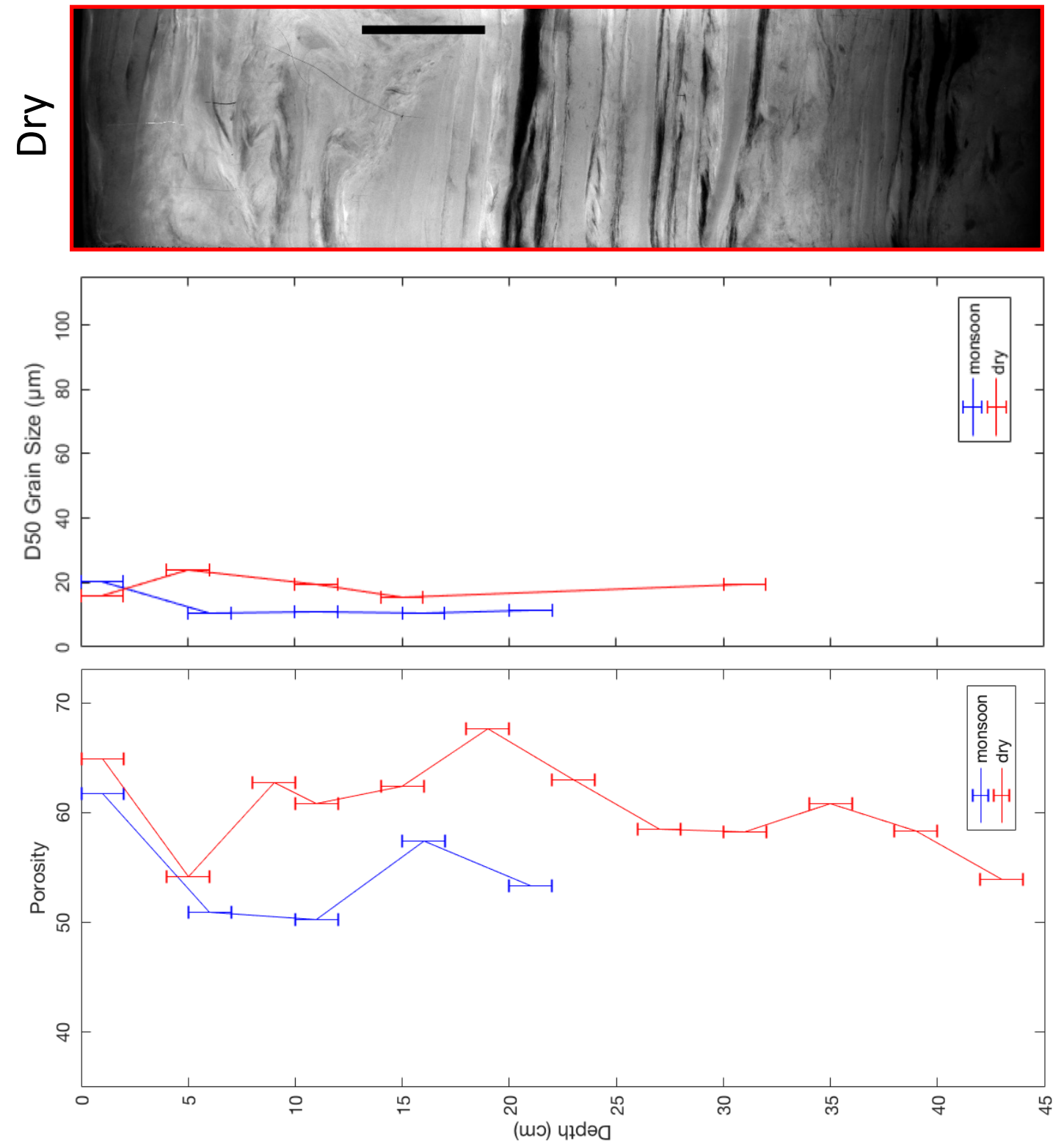



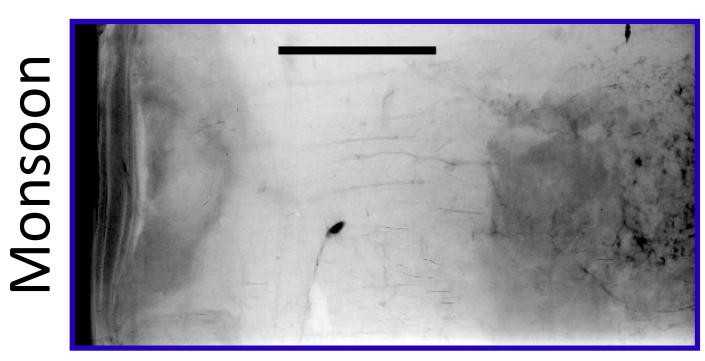



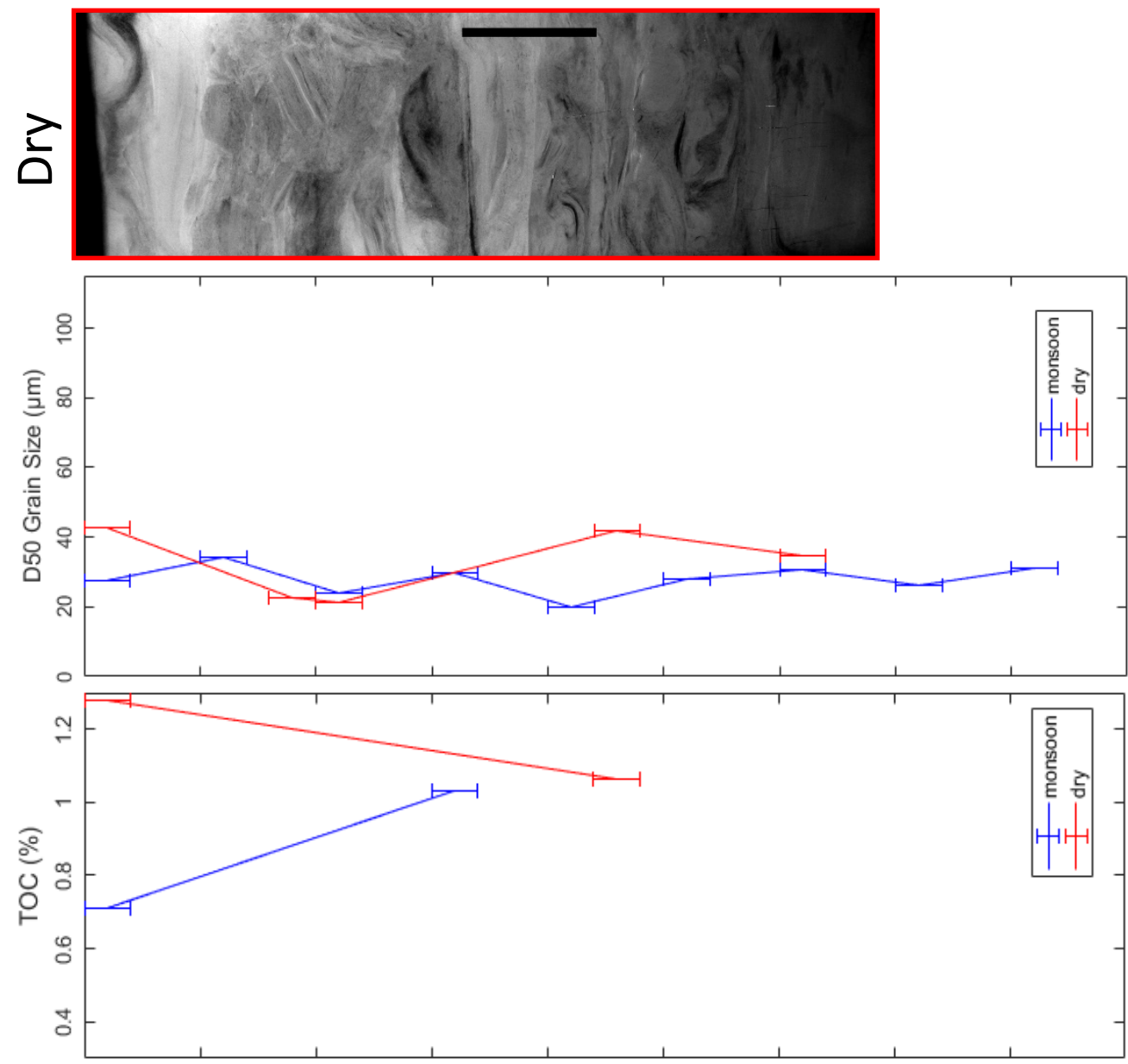

0
of
v
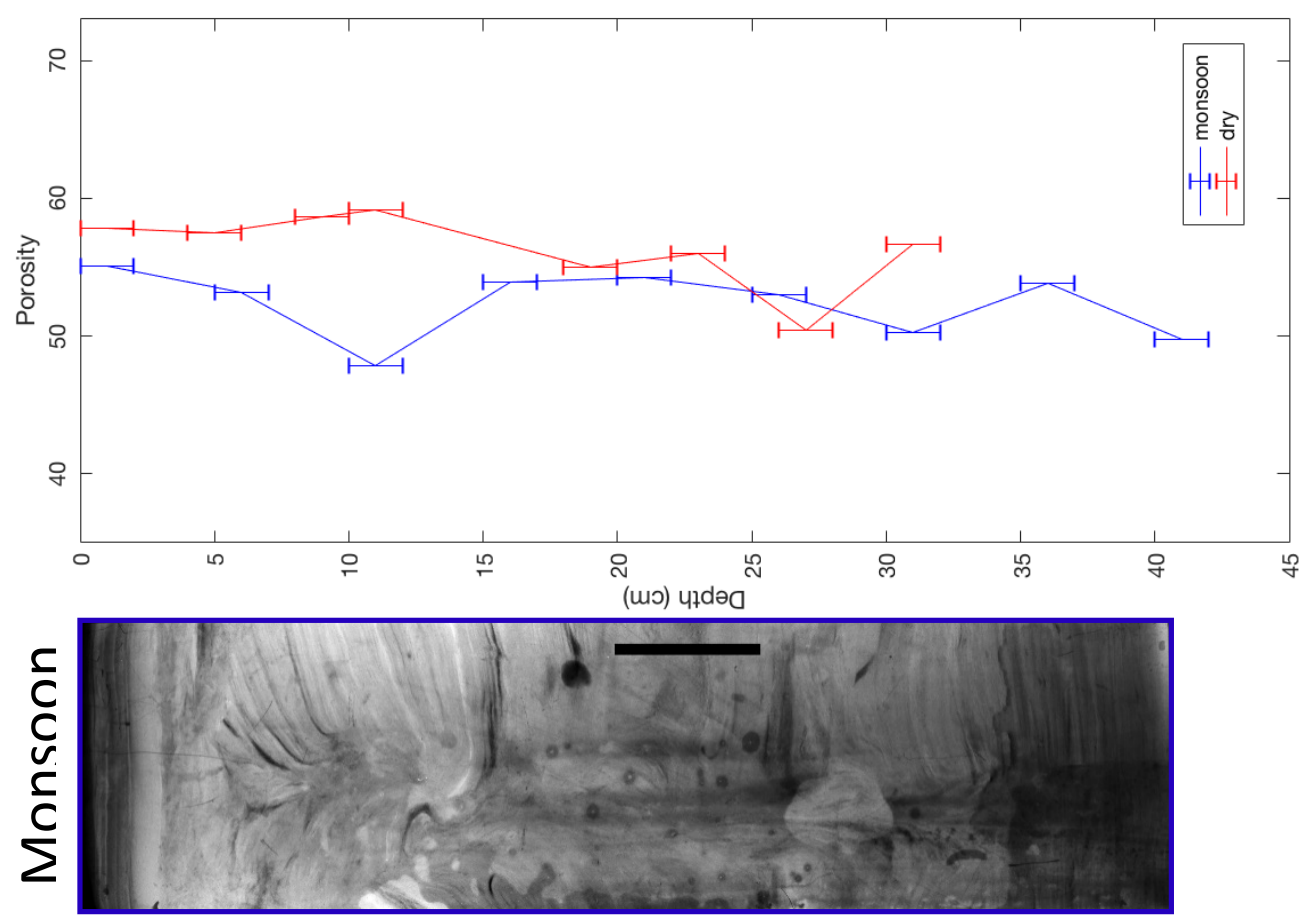

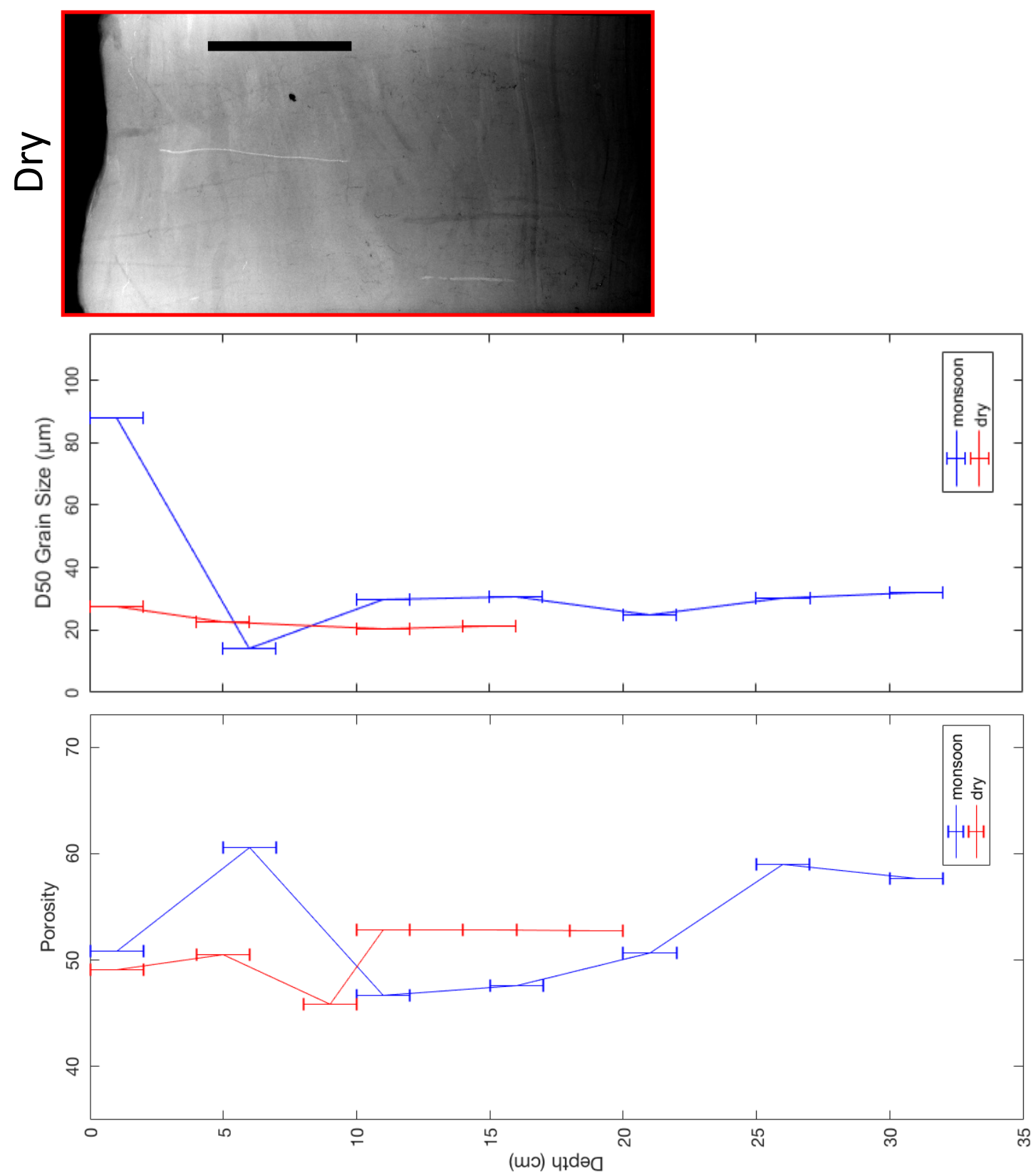

沜

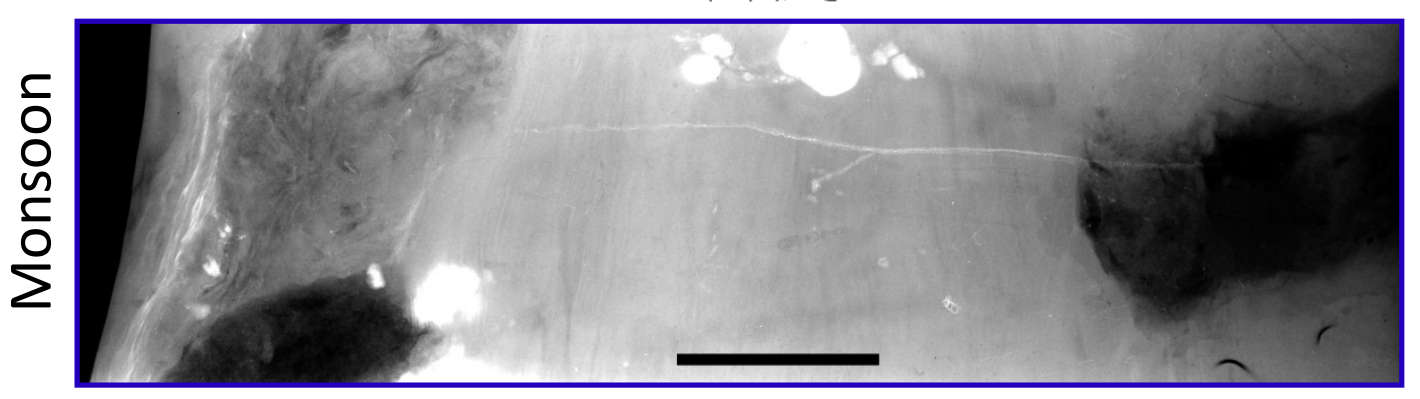



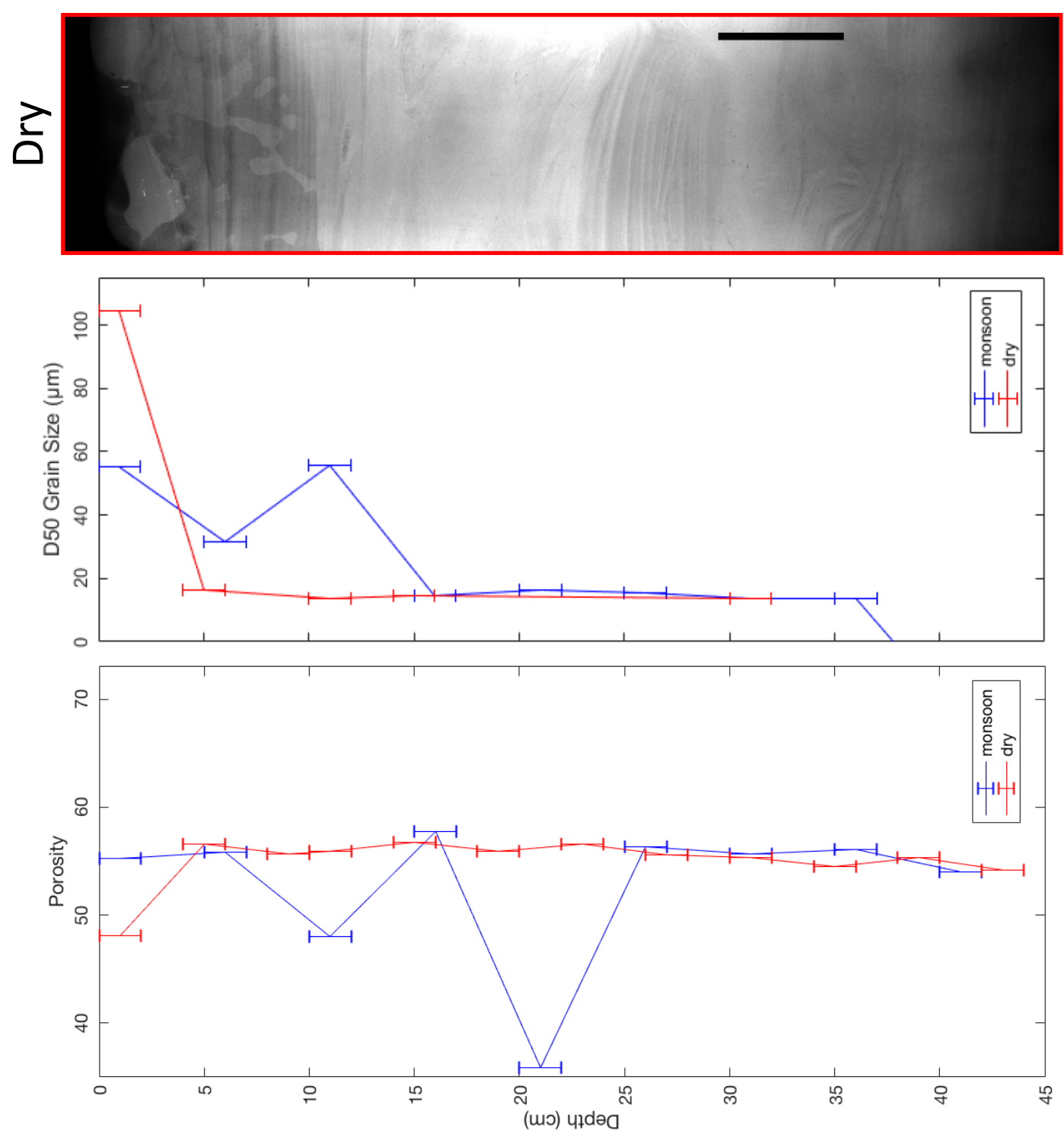

$\infty$
1
$n$
$w$

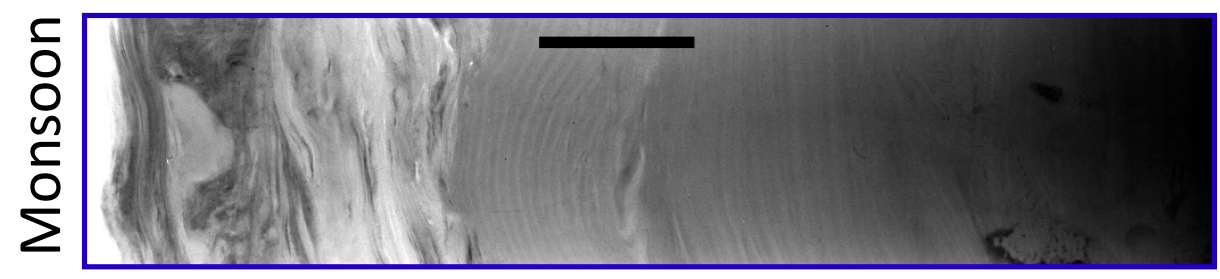




\section{VITA}

Kallie Flaxington Brown

Old Dominion University

Department of Ocean, Earth, \& Atmospheric Sciences

4600 Elkhorn Avenue, Room 406

Norfolk, VA 23529

\section{Education}

M.S., Ocean and Earth Science

2017-2019

Old Dominion University, Advisor: Richard Hale

Vice President, Graduate Student Organization (2018-2019)

B.S., Geology

Norfolk, VA

The College of William \& Mary, Advisors: R. Lockwood and J. Kaste

2014-2016

Williamsburg, VA

\section{Grants and Awards}

Neil and Susan Kelley Endowed Scholarship $(\$ 4,900) \quad 2018$

Paul W. Kirk Jr Wetland Research Award $(\$ 3,250)$

Lee Entsminger Scholarship for Coastal Geology $(\$ 1,500)$

\section{Publications and Conference Proceedings}

Brown, K.F., and Hale, R.P., 2019, Seasonal impacts on sediment characteristics in the GangesBrahmaputra-Meghna Delta. Geological Society of America Southeastern Section Meeting, Charleston, SC, 28-29 March.

Brown, K.F., Hale, R.P., Datta, D.K., and Datta, S., 2018, Persistence of Depositional Features in a Strongly Seasonal, Tide-Dominated Delta. American Geophysical Union Fall Meeting, Washington, D.C., 10-14 December.

Hale, R.P., Lucio, J., and Brown, K.F., 2018, Determining bathymetric changes in a tidal inlet using satellite-based synthetic aperture radar. American Geophysical Union Fall Meeting, Washington, D.C., 10-14 December.

Hale, R.P., Wilson, C.A., Goodbred, S.L, Brown, K.F., and Bomer, J., 2018. Mangrove forest tidal channel sediment dynamics on a mesotidal mega delta. Ocean Sciences Meeting, Portland OR, 11-16 February. 